\title{
Contract Farming in Vietnam: Empirical Research on Marketing Determinants, Farm Performance and Technical Efficiency of the Export-oriented Rice Sector in the Mekong River Delta
}

\author{
Dissertation \\ to obtain the Ph.D. degree \\ (IPAG) \\ at the Faculty of Agricultural Sciences, \\ University of Goettingen, Germany

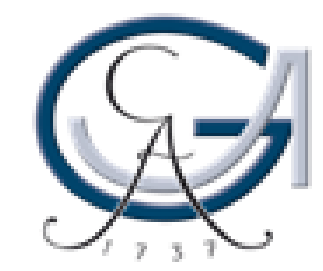 \\ presented by \\ Ngoc Huong, Le \\ born in Ha Tinh, Vietnam
}

In the International Ph.D. Program for Agricultural Sciences in Goettingen

Göttingen, September 2018 
1. Name of supervisor: Prof. Dr. Ludwig Theuvsen

2. Name of co-supervisor: Prof. Dr Achim Spiller

3. Name of further member of the examination committee: Prof. Dr. Xiaohua Yu

4. Date of dissertation: 29.10 .2018 


\section{Summary}

Better market linkages and higher farm benefits for smallholder farmers in emerging and developing economies have received remarkable attention worldwide (Minot and Roy, 2007; Kumar et al., 2011). In this regard, contract farming (CF) is proposed as a better solution to the fact that smallholders are otherwise potentially dropped out of the modern marketing channels because of small-scale production and farmers from emerging and developing countries are to earn more farm benefit by getting closely linked to modern, in many cases global food value chains markets (Bacon, 2005; Mangala and Chengappa, 2008; Minten et al., 2009; Rao et al., 2012; Jia and Bijman, 2013). Furthermore it is expected that the challenges of a sharply increasing world population, the overuse of natural resources, and the reduction of overall agricultural land size can be met by contracting smallholder farmers (Sartorius, 2013). However, the circumstances of farmers' decision in contracting and its influences on farm performances have remained uncertain so far for many specific countries and products (Rao et al., 2012).

Among the major rice farming countries in Southeast Asia, i.e. Cambodia, Laos, the Philippines, and Thailand, Vietnam is characterized by very favorable natural and social conditions for irrigated rice production in bulk. Irrigated rice production in the country is based on high soil quality, tropical monsoon weather, numerous water-flows and a large share of the population working in the agricultural sector (more than 66\%) (Ya'kub et al., 2012). However, low quality and a lack of professionalism are dramatic problems of the Vietnamese rice export sector (Reardon et al., 2014). Vietnam is still known as a low-quality rice supplier; as a result the Vietnamese rice price is $20 \%$ to $30 \%$ lower than the Thai rice price (Kubo, 2013). The Vietnamese rice has also lately entered the world export market while the prices were already steadily declining (Nielsen, 2003; Dechachete, 2011; Ramberg, 2011). Currently, the Vietnamese rice sector is characterized by a lack of information with short technical assistances, and low input qualities. It is assumed that there is still a large potential to increase the ability of smallholders to improve production and increase rice yields, overcome existing market barriers, access export markets and increase farm benefits and improve the livelihood of farmers' families. By further promoting the $\mathrm{CF}$ scheme in 2002, the Vietnamese government proposed a better frame for the agricultural sector, especially, for the rice sector in the country (Kompas, 2002; Hoang and Yabe, 2012; Vu, 2012). 
By farmers' participation in the CF scheme, the production of high-quality products due to improved farmer training and better quality of input factors is a possible solution for Vietnamese rice to more successfully compete on the world market (Dawe, 2004). Furthermore, farmers can expect a price differential due to improved quality and competitiveness. Thus, this scheme is assumed to support smallholders to increase farm benefits. In addition, the CF scheme has been implemented to improve farmers' bargaining power and to create an official ground for smallholders to directly deal with private sectors in the Vietnamese economy. In terms of firm benefits, these decisions also clarify the government's efforts to support the private sector in supplying agricultural inputs to farmers such as seeds, fertilizers, pesticides, credit, and extension services (Ya'kub et al., 2012). Furthermore, this step is also an important procedure to secure national food demand, improve international competitiveness, and upgrade the position of export-oriented rice farmers (Goletti et al., 1997; ADB, 2005). However, in terms of empirical research, up to this date, there are only very few studies that explore the benefits of CF for exporters of rice farmers in Vietnam, especially with regard to the Mekong River Delta (MRD) where about $90 \%$ of the national export rice quantity is produced (Loc and Son, 2011). Therefore, there is a lack of in-depth quantitative studies analyzing the effects of CF participation with regard to farmers' marketing decisions, farm performance and technical efficiency, especially, in the export-oriented rice production segment. Against this background it is the objective of this dissertation to close this research gap by providing a better understanding of farmers' decision making with regard to the $\mathrm{CF}$ scheme and providing more in-depth insights into the effects of contract farming on efficiency and farm performance.

The conceptual framework of this study is based on the New Institutional Economics perspective proposed by Coase (1937) and Williamson (1975). The underlying ideas about the contract concept explained in the following basically refer back to the three major substrands, i.e. agency theory (Ross, 1973), transaction cost theory (Benjamin et al., 1978; Williamson, 1979), and property rights theory (Alchian and Demsetz, 1973; Grossman and Hart, 1986). Thereof, the transaction cost theory is particularly suitable for this study since it describes "uncertainty" as a main dimension (together with "asset specificity" and "frequency") influencing the appropriateness of governance mechanisms in (food) supply chains (Williamson, 1979). The market imperfections due to a lack of information, a limited accessibility of inputs, and a shortage of technical assistance all contribute to "uncertainty" and are related to the research topic and objective of this study. In spite of increasing 
pressure to deliver high quality export products at competitive prices to enter the up-market domestic and global value chains, the $\mathrm{CF}$ scheme still faces some constraints in emerging and developing economies. This can be explained by reference to the poor coordination among parties, unfavorable contracts, and specified socio-demographic characteristics (Da Silva, 2005; Simmons et al., 2005; Hongdong, 2007; Wang et al., 2014). Nonetheless, these aspects have only been poorly analyzed so far and are not well understood, both from a theoretical and an empirical perspective. This dissertation seeks to overcome this weakness by building up the conceptual framework and empirical methodology to capture these aspects of the export-oriented rice sector in the Mekong River Delta of Vietnam.

We address these research objectives by using primary data collected in early 2016 in the Mekong River Delta (MRD) of Vietnam, where nearly $90 \%$ of the country's export rice is produced. The target population of 250.000 households lives in the three main exportoriented rice production regions namely Kien Giang, Can Tho, and An Giang provinces, in the MRD (USDA, 2015). Using a structured questionnaire, 250 households were randomly chosen from the aforementioned provinces. To thereby ensure the comparability of contract and non-contract farmers, we randomly selected 134 contract farmers from contractor lists and 116 non-contract farmers from village official lists of 12 villages. The surveyed households had to meet two criteria: Firstly, they had to be located in the same area as the contract participants, and secondly, they also had to produce export-oriented rice. These selected farmers cumulate rice under written contracts. The contracting company is in charge of specifying the production practices, including input supply (seeds, fertilizer, pesticides), extension services, and the commitment of buying the products (Simmons et al., 2005; Bijman, 2008). In this study, the export-oriented rice farmers were interviewed regarding the information about three types of export-oriented rice producing seasons between November 2014 and October 2015.

In the first paper, we explore the factors that determine smallholder farmers' probability in developing and emerging economies to participate in CF scheme. We particularly focus on the accessibility of market information. A binary probit model is applied to examine the probability to participate in the CF scheme. We follow Heckman's (1979) method to compare the probit results with the maximum-likelihood estimation (MLE) in order to control any sample selection bias (Wynand and Bernard, 1981). Results reveal that farmers' contracting decisions are strongly affected by farm characteristics, market information access, and household characteristics. Remarkably, the accessibility of world market price 
information significantly increases smallholders' likelihood to participate in CF. Moreover, the extension service offered by the contractors is considered to be an important motivator for rice smallholders to participate in $\mathrm{CF}$. The availability of price information should be taken into account by the government to motivate the active participation of smallholders in contractual arrangements.

The second paper provides the evidence about how the CF scheme influences household income and rice profit within the export-oriented rice sector in Vietnam. We employ the Ordinary Least Squared (OLS) estimation in combination with propensity score matching (PSM) procedure to control any sampling bias. The result confirms a positive effect of contract participation status on farming households' performance. Particularly, together with "farming size" and "the accessibility of extension services", "the accessibility of world price information" is found as a positive determinant. Moreover, CF participation is considered to be an important influencer for rice smallholders to increase their income and rice profit. In addition, it becomes evident that not only larger-scale farmers but also small-scale farmers can benefit from contract participation. In this connection, the OLS regression in combination with PSM gives noticeable evidence for the role of CF in improving household income of smallholders by $20.87 \%$ and rice profit by $30.54 \%$ in Vietnam.

In the third paper, we investigate how $\mathrm{CF}$ improves the technical efficiency of farming and the technical inefficiency determinants of export-oriented rice production in the country. The Stochastic Frontier Analysis (SFA) is applied to measure the production frontier and the farming technical inefficiency determinants, and PSM is again applied to control for selfselection bias. The results show that the average technical efficiency is of $87.33 \%$ with a range between $56.48 \%$ and $96.47 \%$. The results suggest convincible opportunities for farmers to increase the productivity of export-oriented rice production in the country by nearly $13 \%$ without raising the current resource levels. Land, seed, fertilizer, machine, and labor are identified as the major inputs of the production frontier. Moreover, the sociodemographic characteristics of the sample also slightly influence the TE of rice farming, however their influence is non-significant. Based on the findings, "educational level", "rice farming experience" and "off-farm income" are found as determinants positively influencing rice farming TE. In contrast, there is a low negative effect of credit accessibility. In addition, CF participation is considered to have an influence (even though not a significant one) for rice smallholders to increase their farm TE. In this connection, contract participation could 
support not only larger-scale farmers but also small-scale farmers from developing and emerging economies in improving their production patterns. 


\section{Acknowledgements}

First of all, I would like to thank my supervisors, Prof. Dr. Ludwig Theuvsen and Dr. Verena Otter, for the opportunity to work on this exciting project; thanks for all your kind support and helpful guidance on the topic and my doctoral program. I would also want to express my thankfulness to all members of the chair of "Management in Agribusiness" at University of Goettingen for their nice treat and motivation during my time at the chair. I am also indebted to my thesis committee members, Prof. Dr. Ludwig Theuvsen, Prof. Dr Achim Spiller and Prof. Dr. Xiaohua Yu for their inputs in the review process.

I would like to acknowledge the financial support from the Vietnamese Ministry of Education and Training (Steering Committee of Program 911) for the doctoral program in Germany. Special thanks go to the Fiat Panis Foundation, Germany for the financial support for conducting the field works in the Mekong River Delta of Vietnam in early 2016. I would like to address my appreciation to the Goettingen Graduate School of Social Sciences (GGG), the University of Goettingen for offering me the family-oriented finishing grant. I once again would like to thank the Fiat Panis Foundation for providing a conference grant for participating in the International Food and Agribusiness Management Association (IFAMA) World Conference 2017 in Miami, USA, and the International Association of Agricultural Economists (IAAE) conference grant for participating in the International Conference of Agricultural Economist (ICAE) 2018 in Vancouver, Canada. Without receiving these supports, I could not have pursued my doctoral program and participated in these highly ranked international conferences.

I am also thankful for the professional interactions I had with Prof. Dr Siegfried Bauer, University of Gießen. Thank you for your support during the initial days of my doctoral study in Gießen by offering German courses, block seminars, pre-Ph.D courses, and the opportunity to interact with pleasant colleagues and friends.

My data collection at field in the Mekong River Delta has been successfully conducted with the information assistance from the LocTroi Group, enumerator members at the Can Tho University, An Giang University, and Nha Trang University. Special appreciation also goes to Bang, Le, My, Phuong, Hang, Tuan and team "3 cung" at the LocTroi Group who supported me to conduct household interviews and data entry.

I am most grateful to my family members who understood and supported me with the path I have chosen. Special thanks go to my mother Thi Be Phan, my husband Hieu Tran, my 
parents in law Hung Trang and Quang Le, my son Nam Khanh Tran, and my daughter Ngoc Minh Trang Tran, for your ceaseless motivation during the long period of my study in Germany. Specially, thanks for sharing your love and supporting me along the journey.

I also would like to extend my gratefulness to Martina, the secretary of the chair of Management in Agribusiness, my international and Vietnamese friends in Goettingen, especially, Caetano, Sabrina, Luis, Thuy and Anna, who are a part of my fantastic life in Germany.

Last but not least, I would like to express my gratitude to all the survey respondents in the Mekong River Delta for your time, information, cooperation, and warmly greeting us to your humble homes. The inspiration and information during our talks have always been the driving force for me to go further in academic works and other agricultural business activities. 


\section{List of abbreviations}

$\begin{array}{ll}\text { CF } & \text { Contract Farming } \\ \text { FAO } & \text { Food and Agriculture Organization of the United Nations } \\ \text { GDP } & \text { Gross Domestic Product } \\ \text { GSO } & \text { General Statistics Office (Viet Nam) } \\ \text { ha } & \text { Hectare } \\ \text { IRRI } & \text { The International Rice Research Institute } \\ \text { kg } & \text { Kilogram } \\ \text { km } & \text { Kilometer } \\ \text { m } & \text { Square meter } \\ \text { MRD } & \text { Mekong River Delta } \\ \text { RRD } & \text { Red River Delta } \\ \text { SFA } & \text { Stochastic Frontier Analysis } \\ \text { PSM } & \text { Propensity Score Matching } \\ \text { TE } & \text { Technical Efficiency } \\ \text { USD } & \text { United States Dollars } \\ \text { USDA } & \text { United States Department of Agriculture } \\ \text { VND } & \text { Vietnamese Dong (the currency of Vietnam) } \\ \text { WB } & \text { World Bank }\end{array}$




\section{List of tables}

Table 2.1 Descriptive statistics for the variables included in the estimations $\quad 24$

Table 2.2 Distribution of contract-types in the sample 25

Table 2.3 The terms of outputs price listed in the contract 25

Table 2.4 Farmers perception of the benefits of contract farming 25

Table 2.5 Probit model estimations on the contract farming participation 26

Table 3.1 Descriptive statistics for the variables included in the estimations 43

Table 3.2 Regression results on household income and rice profit 45

Table 3.3 The Durbin and Wu-Hausman test for endogeneity of contract participation 46

Table 3.4 Average Treatment Effects (ATE) estimations 46

Table 3.5 Average Treatment Effects on Treated and PSM by matching algorithm 48

Table 4.1 The Vietnamese rice yields by different regions (ton per hectare) 55

Table 4.2 Description of included variables $\quad 64$

Table 4.3 Descriptive statistics for the variables included in the estimations 65

Table 4.4 Stochastic trans-log estimation for export-oriented rice in the MRD 66

Table 4.5 Inefficiency estimations for export-oriented rice production in the MRD 67

Table 4.6 Technical efficiency scores for export-oriented rice production in the MRD 68

Table 4.7 Probit estimates of the Contract farming Propensity 69

Table 4.8 Mean and Standard Deviation of Technical Efficiency in PSM estimations 69 


\section{List of figures}

Figure 2.1 Export rice quantities from major suppliers worldwide in 2011-2015 13

Figure 2.2 The marketing channels of export rice sector in the MRD of Vietnam 14

Figure 2.3 The conceptual framework of households' contracting decision 18

Figure 2.4 Area of study in the Mekong River Delta of Vietnam 21

Figure 4.1 Conceptual framework for technical efficiency analysis 60

Figure 4.2 Technical efficiency distribution for export-oriented rice in the MRD 68 


\section{Definitions of key terminologies}

Smallholder (small-scale farmer)

Smallholder or small-scale farmer is frequently defined base on the landholding size of farmers refer to a certain hectare (ha) number. Some organizations such as World Bank, Consultative Group to Assist the Poor (CGAP) or and the Asia Development Bank (ADB), generally define smallholder as a farmer cultivating with up to 2 ha of land. Also, the African Development Bank (AfDB) identifies 2 ha landholding for smallholders. In Malaysia, the government defines general farmer with a landholding size below 46 ha as smallholder and rubber farmer with landholdings up to 100 ha smallholder. In Indonesia, farmer with less than 25 ha landholding is defined as smallholder while in India, smallholder is defined as occupying less than 5 ha. Oxfam International (2011) developed a report based on the current situation that African smallholders are the people that have up to 10 ha of farming land. In this dissertation, smallholder is defined as the farmer has landholding size from 0.5 to 5 ha $(\mathrm{FAO}, 1992)$.

\section{Export-oriented rice grade}

In the international rice market, there is a wide range of more than 40,000 different varieties of rice (Khush, 1997). The major types such as sticky rice, non-sticky rice, brown rice, white rice, aromatic rice, flavored rice, Sharbati rice, Basmati, Jasmine, glutinous long rice, glutinous short rice are especially traded worldwide (Gibson and Kim, 2013). Most of the high-quality (grains) fragrant (mainly Basmati and Jasmine) rice is exported to rich/ developed countries, whereas fragrant-broken grain is often exported to Africa. The most popular export-oriented rice variety from Southeast Asia is Jasmine, which is shown to be more profitable and efficient in comparison with ordinary rice (WB, 2013). Jasmine (Hom Mali or KDML 105) accounts for $15 \%$ to $18 \%$ of Thai rice export volume (Liese et al., 2014). In Vietnam, there are many varieties of rice grade such as Jasmine, glutinous, ordinary or authentic export-oriented rice and rice grade based on the broken percentage (mainly 5\%,10\%, 15\%, 25\% and 100\%) (see Appendix 2). Under the CF terms, currently, in Vietnam, there are some new types of seed developed by the firms are applied such as OM6976, OM5451, AGPPS103, OM4900.

\section{The Mekong River Delta (MRD)}

The Mekong River Delta (MRD) is dominant in Vietnam with regard to the rice quantity produced for export (VIETTRADE, 2008; Giraud, 2013). The MRD region includes 12 
provinces with a total population of 17.4 million people. Most of the GDP contribution in this region stems from agriculture, forestry, and fisheries (about 41\%) (Smith, 2013). Rice production is one of the major farm activities in the MRD accounting for about 2.1 million ha of rice farming area of the total 4 million ha of agricultural land. On this area, about 38 million tons of rice are produced during three cropping seasons per year. The production contributes approximately $51-55 \%$ of quantity to the national rice outputs and $90 \%$ of rice export quantity of the country (Loc and Son, 2011; Liese et al., 2014). The MRD has a tropical climate with dry and rainy season around the year, which is suitable for three harvests of rice with the main rice season from November to March. An Giang, Can Tho, Dong Thap, and Kien Giang are the major rice producing provinces recording very high yields in the MRD region.

\section{Contract farming $(C F)$}

$\mathrm{CF}$ is defined as an economical institution including the engagement between a firm and a grower through a document called "contract" fixing that the firm handles the processing stage of the commodity supplied by the grower (Eaton and Shepherd, 2001; Minot and Sawyer, 2016). This arrangement does not only count for farmers' business relationships to processors but it could also be the arrangement between farmers and marketing firms, supermarkets, farmer organizations ("collective action") or any other entities. Frequently, the obligation of parties needs to be specified in a written document, in which the price-setting, quantity and attributes of the products and the timing of delivery are defined (marketspecifying contract- MC) (Eaton and Shepherd, 2001; Will, 2013; Minot and Sawyer, 2016). $\mathrm{CF}$ can also include terms on the provision of agricultural inputs, such as seed and fertilizer, and/or technical assistance financed on credit-type prepayment (resource-providing contractRC) (Prowse, 2012, Minot and Sawyer, 2016). Additionally, terms on the concrete production-process-management can be fixed in the contract, such as timing and amount of pesticide use, seed rates on the plots and the concrete timing of harvest (productionmanagement contract- PC) (Minot and Sawyer, 2016).

Most of the contract participants in this study are resource-providing contract (RC) farmers who purchase their inputs from the contractors at the beginning of the cropping season. The input cost is deducted from payments at harvesting time. Contracted farmers also receive technical advisory during their production, have agreements with contractors on specified producing practices, inputs (seed, fertilizer, pesticide), and extension service advisory. Farmers can also store their product at the contractor's warehouse for up to one month if 
they want to wait for higher market selling prices (for negotiable-price term contracts). Contractors commit to purchase the products and pay for the collection and transportation of the final product at the harvesting period. Other CF arrangements only supply the inputs without purchasing outputs. Several firms purchase products without providing the inputs. For those cases, the contractors are willing to pay a premium price over the market price at harvest time to ensure their market supply. 


\section{Table of contents}

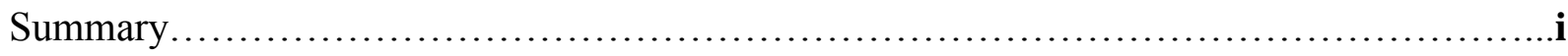

Acknowledgements .................................................................................................................................vi

List of abbreviations ......................................................................................................................viii

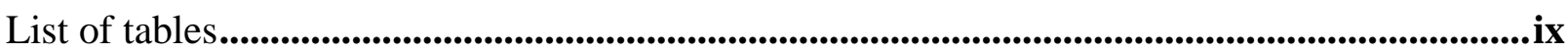

List of figures ..................................................................................................................................................... $\mathrm{x}$

Definitions of key terminologies ...............................................................................................................

Table of contents.......................................................................................................................................... xiv

1. General introduction ......................................................................................................................... 1

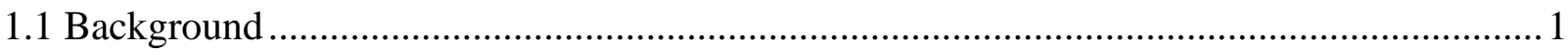

1.2 Research objectives and dissertation outline …………….............................................

2. The role of market information access for contract farming participation of smallholder farmers in developing and emerging economies: The case of rice farmers in the Mekong River Delta......................................................................................................................

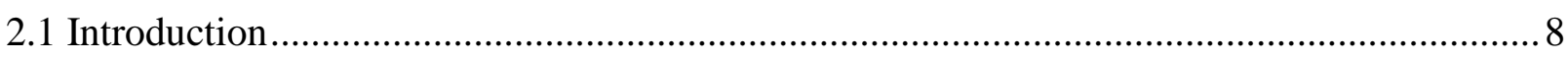

2.2 Contract farming in developing countries' modern marketing channels ............................... 8

2.3 Contract farming within the Vietnamese export-oriented rice sector .................................... 12

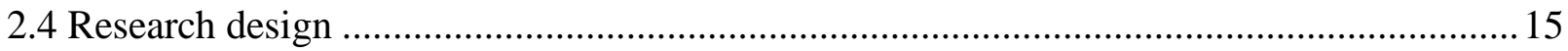

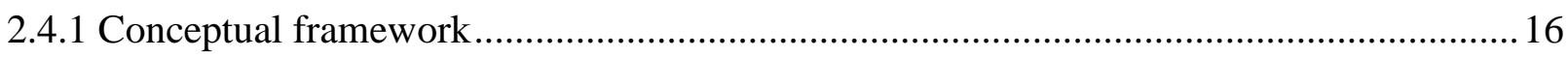

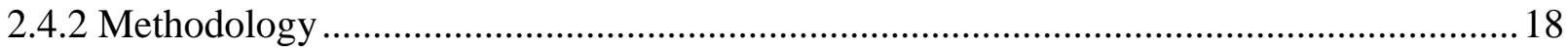

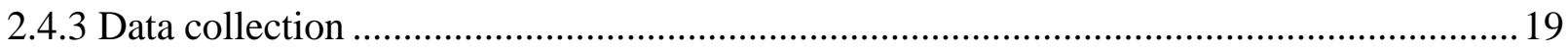

2.5. Results 21

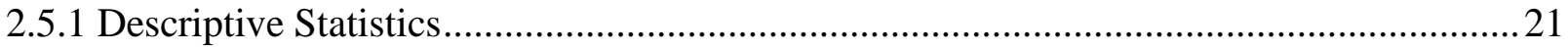

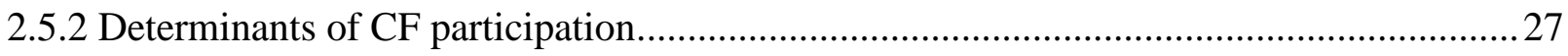

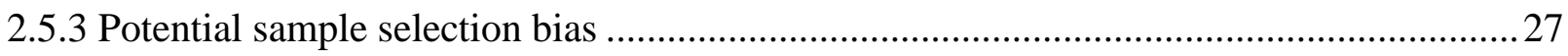

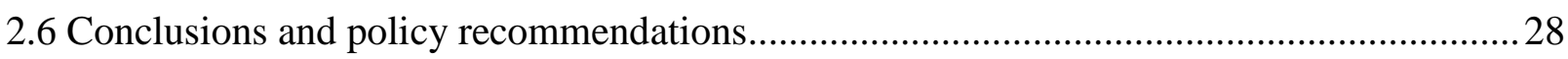

3. Do smallholders in emerging economies benefit from contract farming? Empirical evidence from the Vietnamese export rice sector........................................................................31

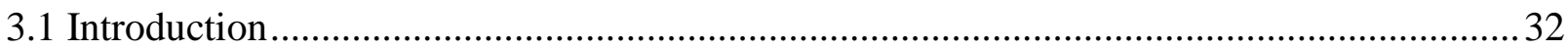

3.2 Literature review ...................................................................................................................................34

3.3 Background .........................................................................................................................................36

3.4 Data collection .........................................................................................................................38

3.5 Economic approach.......................................................................................................................39

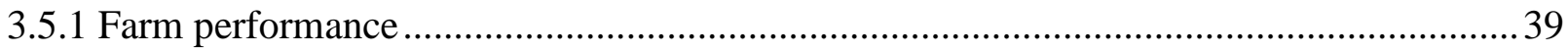




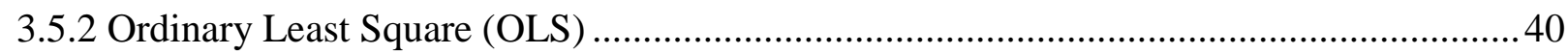

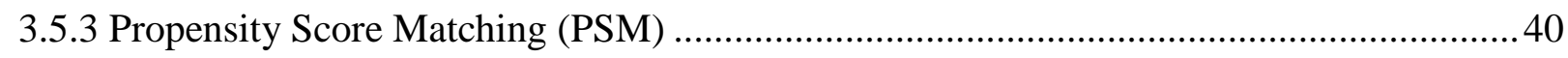

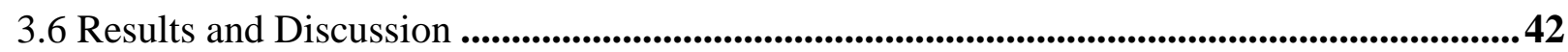

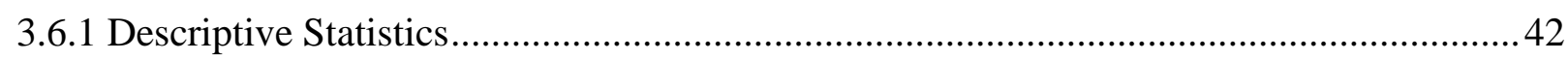

3.6.2 Effects of CF participation on household income and rice profit ................................. 44

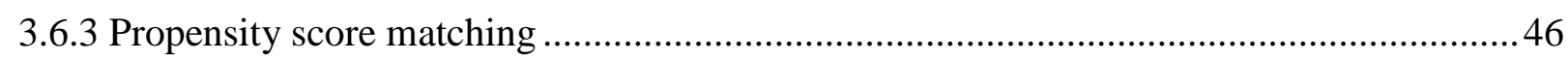

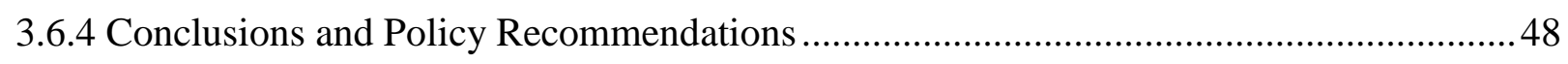

4. Contract farming effects on technical efficiency of the export-oriented rice production

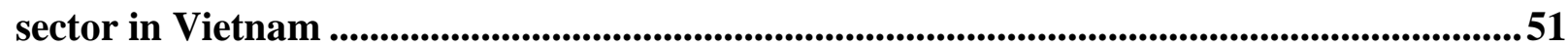

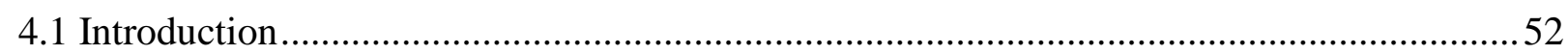

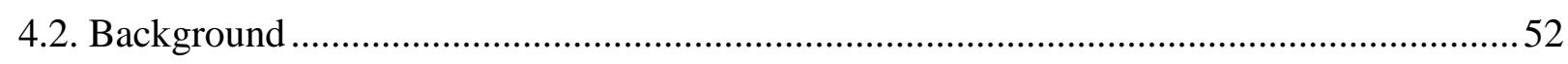

4.2.1 Economical characteristics of the export-oriented Vietnamese rice production sector ......54

4.2.2 Contract farming in the Vietnamese agricultural sector ............................................55

4.2.3 The effect of contract farming on farm technical efficiency in emerging and developing

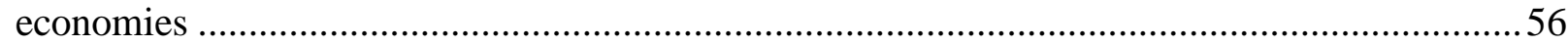

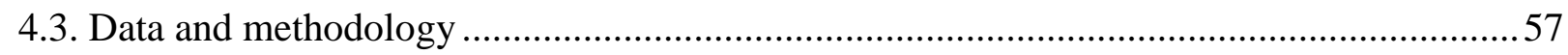

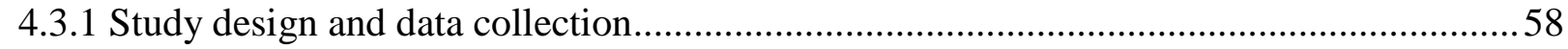

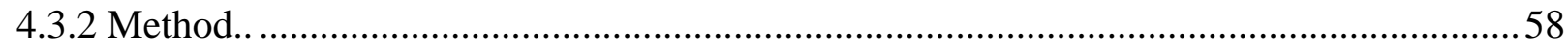

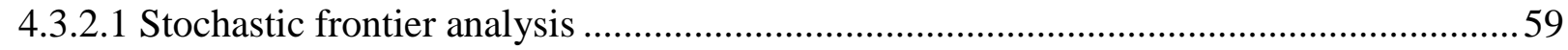

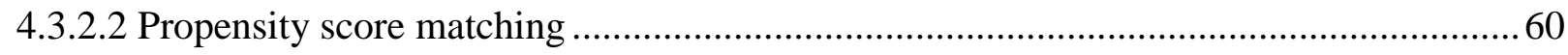

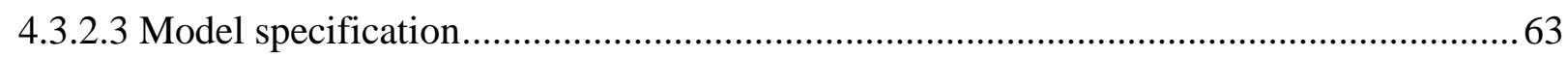

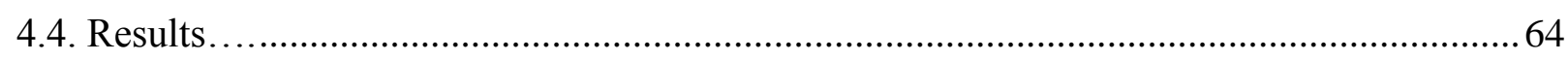

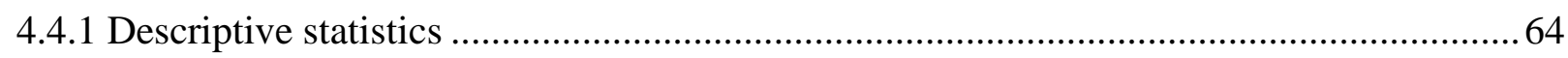

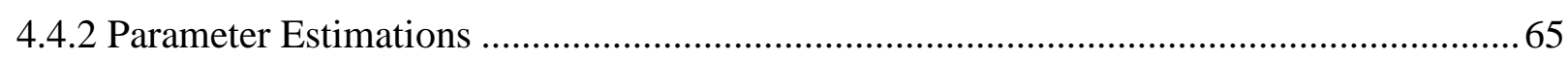

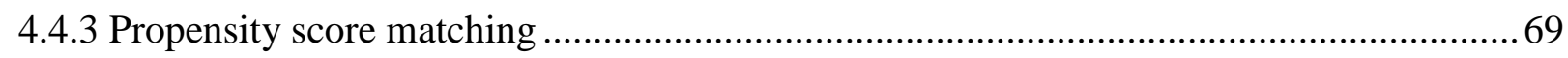

4.5. Conclusion and policy recommendation............................................................... 70

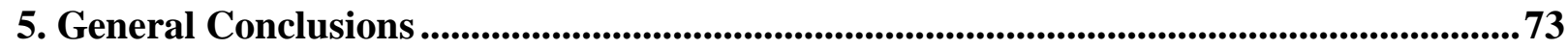

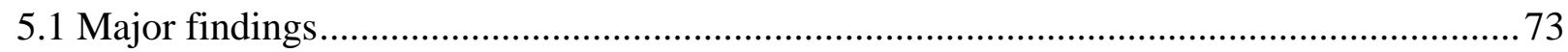

5.2. Policy implications and further research suggestions ............................................. 76

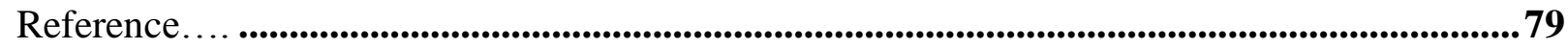

Appendices...........................................................................90

Appendix 1: Paddy yield (tons per hectare) in Southeast Asia 2005-2015 ............................ 90

Appendix 2: Vietnam exports of rice by grade 2013-2016................................................ 90

Appendix 3. Technical efficiency distribution with selection bias controlling ........................91

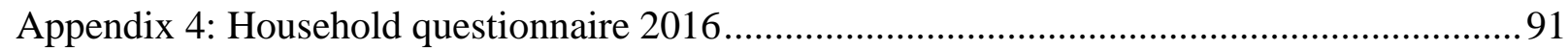


List of Publications and Presentations

107

Curriculum Vitae

Error! Bookmark not defined. 


\section{General introduction}

\subsection{Background}

Under the pressure of globally increasing demand for food, higher agricultural productivity and efficiency and sustainability in smallholder agriculture are considered to be very important (GIZ, 2013). Against the background of the sharply increasing world population, overuse of natural resources, and reduction of overall agricultural land size, improving the linkages between smallholder farmers and firms have received remarkable attention (Sartorius, 2013). In this context, contract farming (CF) has received growing attention as a way to better link smallholder farmers to food value chains. In many cases CF provides opportunities for farmers in rural areas of developing and emerging countries to overcome market barriers, increase income and improve technical efficiency (TE) in the agricultural sector (Ali and Flinn, 1989; Grosh, 1994; Battase and Broca, 1997; Eaton and Shepherd, 2001; Swain, 2008; Rahman et al., 2009; Saigenji, 2010; Barrett et al., 2012; Rao et al., 2012; Wollni and Brümmer, 2012; GIZ, 2013; Sartorius, 2013).

In general, $\mathrm{CF}$ has been widely supported by governments, NGOs, and private firms in most developing and emerging countries. It is expected that the contract-based vertical integration of farmers supports parties to take advantages of economies of scale and supply largequantity and high-quality products for processing or exporting firms. However, despite these promising characteristics, there are some major reasons leading to the failure of $\mathrm{CF}$ expansion in emerging and developing countries. In this connection, small-scale farming areas, the prevalence of small and medium-sized enterprises, and the complex judicial systems are reported as important obstacles (Key and Runsten, 1999; Carpenter and Petersen, 2002; Reardon et al., 2009). The negative effects of poor coordination among parties and unfavorable terms and conditions of contracts also restrain smallholders from extending their contracting status (Da Silva, 2005; Schipmann and Qaim, 2011). Additionally, several socio-demographic determinants are found to negatively influence farmers' willingness to participate in CF schemes. There are some major characteristics such as small and medium-sized farm size, high age of household head, low education level, a lack of farming experience and farm group preferences which prevent smallholder farmers from entering CF schemes (Simmons et al., 2005; Hongdong, 2007; Schulze et al., 2007; Kersting and Wollni, 2012; Otter et al., 2014). In this regard, the key drivers affect smallholders' marketing decisions within the groups of contract participants, non-contract 
participants and farmers who dropped from CF scheme and how smallholders' performance develops within CF schemes have received great concerns.

Among the developing countries, Vietnam is one of the key agricultural exporters worldwide for e.g. coffee, pepper, seafood, tea and rice (Saigenji, 2010). Compared to other major rice farming countries in Southeast Asia such as Cambodia, Indonesia, Laos, Malaysia, Philippines and Thailand (Baldwin et al., 2012), Vietnam has more favorable natural and social resources for rice production in bulk (Ya'kub et al., 2012). In 2015, the country produced more than 28 million tons of milled rice in total with 7.0 million tons for export, contributing approximately 5.5\% to GDP growth (USDA, 2015). Rice is one of the largest export commodities of Vietnam (Ya'kub et al., 2012; FAO, 2013; Ha, 2013) and places the country as the second largest rice exporter after Thailand (Goletti et al., 1997, Giraud, 2013, USDA, 2015).

As a key rice exporter, mainly based on small-scale farming, the Vietnamese rice production has been facing great challenges to compete in the global rice market, especially with other emerging and developing countries regarding production quantities and prices (Nielsen, 2003; Baldwin et al., 2012; Reardon et al., 2014; USDA, 2015). In terms of agricultural structure, the Vietnamese export-oriented rice sector is characterized by small- and mediumscale production. Nearly $70 \%$ of the rice producers in Vietnam have farm sizes of less than 0.5 hectares (Wang et al., 2014). With regard to rice value chains, there are many stakeholders involved along the chain. The involvement of actors such as wholesale-millers (w-millers), millers, wholesalers, retailers, and exporters leads to a great gap between export and farm-gate prices (Loc, 2011; Ya'kub et al., 2012, Reardon et al., 2014; Demont and Rutsaert, 2017). In addition, being over-dependent on traditional marketing channel may limit the ability of companies to strictly control the quality of the raw product as well as capture high-value export markets (Oliver, 2005; Loc and Son, 2011; Vinh and Dinh, 2014). Currently, the Vietnamese rice farming area is expected to decline due to the governmental promotion of corn and soybean crops, which is targeting marginal yielding rice land for this conversion program (Smith, 2013). Both winter and autumn crops lose approximately 20,000 hectares each for corn and soybean cultivation from the year 2016 on (USDA, 2015).

Since rice is the main staple food in Vietnam (USDA, 2015), it plays a key role in the economy. In 2002, the decision No 80/2002/QD-TTg dated June 24th was issued by the Vietnamese government to officially promote CF scheme between farmers and the private sector. A flexible institutional arrangement was developed for diverse economic entities in 
the national agricultural sectors. As the result, an official ground in a long-term strategy was established to improve the bargaining power of farmers in the relationship with private sectors. Due to the supportive policy, farmers have started to pay more attention to $\mathrm{CF}$ forming a basis for Vietnam to further develop its CF scheme in order to enhance the agricultural exporting activities in the world market. Nonetheless, up to date, there are quite a few successful contractors in Vietnam engaging in this system (Saigenji, 2010; Loc and Son, 2011).

In this regard, earlier research on small-scale CF has highlighted the opportunities of $\mathrm{CF}$ participation as an institutional arrangement. This engagement bears the potential for farmers to more easily access markets and to ensure raw material supplies by contractors resulting in reduced production uncertainty and increasing TE (Rawlins, 1985; Eaton and Shepherd, 2001; Da Silva, 2005; Ramaswami et al., 2005; Swain, 2008; Saigenji and Zeller, 2009; Sartorius, 2013; Wang et al., 2014). Moreover, participating in a CF scheme also supports farmers to increase their production frontiers (Rawlins, 1985) and to shift risk from producers to processors through their supply of most of the inputs such as seed, fertilizer, and pesticides (Ramaswami et al., 2005). Thus, CF could offer a solution for dealing with a number of constraints of productivity and TE arising from small-scale production including risk coverage and accessibility of inputs, capital resources, and information (Miyata et al., 2009). However, there is a lack of research on the determinants of CF participation and the effects of CF on households' performance and farm TE levels among members of the exportoriented rice sector in Vietnam. These shortcomings of prior studies are the main motivation of this research.

In general, this study contributes to the existing literature in three aspects. Firstly, it provides deeper insights into the determinants of CF participation among small-scale farmers in developing countries and an evaluation of how market information access influences farmers' marketing decisions. Both aspects have remained unclear and largely unexplored so fare (Schipmann and Qaim, 2011; Kersting and Wollni, 2012; Maina et al., 2015; Minot and Sawyer, 2016), even though the lack of market information can be an important reason that affects smallholders' decision (Oliver, 2005; Bijman, 2008; Kersting and Wollni, 2012; Abebe et al., 2013). Secondly, the study explores the influence of CF on household income and rice profit within the export-oriented rice sector in Vietnam, which is rarely mentioned in existing literature (Barrett et al., 2012; Wang et al., 2014), especially for export-oriented rice production (Loc and Son, 2011). And, thirdly, the dissertation provides a better 
understanding of the effects of CF participation on the TE of rice farming by specifying a stochastic frontier model for analyzing primary farm level data from Vietnam (Huynh and Yabe, 2011; Hoang and Yabe, 2012; Vu, 2012).

\subsection{Research objectives and dissertation outline}

In light of the elaborations mentioned above, this study aims to find the answers on the following research questions:

1. What are the determinants influencing the probability of contract farming participation within the export-oriented rice sector in Vietnam?

2. How does contract farming participation influence farming households' performance in the export-oriented rice sector in Vietnam?

3. Does contract farming participation support export-oriented rice smallholders in Vietnam to get higher farming technical efficiency and what are the technical inefficiency determinants?

To do so, we employ cross-sectional data collected in early 2016 from a sample of 250 export-oriented rice farmers in the Mekong River Delta of Vietnam using a structured questionnaire (see Appendix 4). The underlying ideas about the contract concept are derived from the New Institutional Economics perspective (Coase, 1937; Williamson, 1975) which resulted in the concepts of agency theory (Ross, 1973), transaction cost theory (Benjamin et al., 1978; Williamson, 1979), and property rights theory (Alchian and Demsetz, 1973; Grossman and Hart, 1986). Thereof, especially the transaction cost theory proposed by Williamson (1979) is particularly suitable for this study since it describes "uncertainty" as the main dimension (together with "asset specificity" and "frequency") influencing the appropriateness of governance mechanisms. This research refers to some particular aspects such as the mechanism, arrangement, improvement of smallholder farmers' marketing decisions and improved production cost management, which supports the increase of household income, farming profit as well as farming TE. Several variables regarding socioeconomic characteristics, production inputs and outputs were measured to evaluate these aspects using discrete regression models (e.g., Probit, Ordinary Least Square-OLS, Propensity Score Matching-PSM, Maximum Likelihood Estimations-MLE, Stochastic Frontier Analysis-SFA) as presented in this dissertation.

The role of CF via export-oriented rice sector in Vietnam is underscored in agricultural production participation and determinants of marketing decision and technical inefficiency 
among smallholder farmers are discovered in this dissertation. Based on the research findings, farm characteristics, market information access, and household characteristics are proved to have strong influences on smallholders' contracting decisions. Remarkably, the accessibility of world market price information significantly increases smallholder's likelihood to participate in CF. Moreover, the extension service/technical assistant offered by the contractors are considered to be an important motivator for rice smallholders to participate in CF. Additionally, there is a strong influence of CF participation on household income and rice profit. It is interesting that not only "farming size" and "the accessibility of extension services" but also "the accessibility of world price information" are found as important determinants that significantly influence farming households' performance. In addition, it becomes evident that not only larger-scale farmers but also small-scale farmers can benefit from CF participation. In this connection, we find that CF participation plays an important role in improving household income of smallholders by $20.87 \%$ and rice profit by $30.54 \%$ in Vietnam. The SFA results reveal that about $13 \%$ of the potential outputs are lost due to technical inefficiency. The TE of export-oriented rice production in the MRD ranges between $56.48 \%$ and $96.47 \%$. In total, the scale-effect is about 1.026 , which reveals that if farmers increase $1 \%$ of production inputs, the TE score can increase by $1.026 \%$. Thereby, on average, contract participants have higher TE $(88.46 \%)$ in comparison to non-contracting farmers $(86.02 \%)$. In the two-sample t-test of TE-mean values, with a t-value of 3.01, a significant difference at the $5 \%$ level could be confirmed, indicating higher TEs for contract farmers.

Against the background of the sharply increasing world population, overuse of natural resources, and reduction of overall agricultural land size, improving farming TE in emerging and developing economies' agricultural production and upgrading smallholders' position in modern value chains through participating in $\mathrm{CF}$ is one of the suitable solutions, respectively. This dissertation provides an improved understanding of the potentially important role of CF in meeting current challenges of world agriculture.

Apart from the Introduction part in chapter 1- "General Introduction", the remainder of the dissertation is structured as follows:

Chapter 2 is named "Determinants of Contract Participation". This section includes the first paper entitled "The role of market information access for contract farming participation of smallholder farmers in developing and emerging economies: The case of rice farmers in the 
Mekong River Delta". In this paper, we employed a Probit model to explore the determinants of CF participation and MLE to control sample selection bias.

Chapter 3 is named "Benefits from Contract Participation"; it presents the second paper entitled "Do smallholders in emerging economies benefit from contract farming scheme?: empirical evidence from the Vietnamese export rice sector". We evaluate the effects of CF participation on household income and rice farming profit of export-oriented rice farmers using OLS; PSM estimations are included to control for a potential self-selection bias.

Chapter 4 is named "Contract Farming Effects on Technical Efficiency". It introduces the third paper on "Contract farming effects on the technical efficiency of the export-oriented rice production sector in Vietnam". A SFA was used to examine the effect of CF on farm TE and to explore the technical inefficiency determinants for export-oriented rice production. PSM is again used to control for any sample selection bias.

The last chapter, "General Conclusions", includes the summary of major findings, study implications, limitations, and further research suggestions. 


\title{
2. The role of market information access for contract farming participation of smallholder farmers in developing and emerging economies: The case of rice farmers in the Mekong River Delta ${ }^{1}$
}

\begin{abstract}
It is the objective of this study to explore the factors that determine smallholder farmers' probability in developing and emerging economies to participate in commodity production sectors' contract farming schemes with particular focus on market information access. Based on transaction cost theory a conceptual framework was developed and applied using a probit model on quantitative cross-sectional data collected from a sample of 250 export-oriented rice farmers in the Mekong River Delta of Vietnam in early 2016. The results highlight the positive influence of price information and extension services accessibility, but negative effects of rice farming experience and household size on households' contracting decision. This study cannot give evidence of farm performance effects associated with contract farming participation in Asian commodity sectors, an aspect that should be the focus of future research. In order to increase Asian farmers' contract farming participation, rice export companies should offer constantly favorable price terms with an extension service in their contracts. This should be combined with the joint development of appropriate measures and strategies to increase farmers' access to detailed rice market information involving all stakeholders of the sector (including contracting companies, farmers association and politicians). The improvement of the contract farming scheme in an Asian developing country provides opportunities for linking farming households to financially lucrative world markets and, consequently, reducing rural poverty in such countries. The study explores the role of market information access empirically and thus uncertainty in the light of transaction cost theory, as an important driver of contract farming among smallholders in developing countries.
\end{abstract}

Keywords: Agricultural products, export rice, modern marketing channels, contract farming, smallholder farmers, Vietnam.

\footnotetext{
${ }^{1}$ This paper is a joint work with Ludwig Theuvsen and Verena Otter; the Department of Agricultural Economics and Rural Development, University of Goettingen, Germany.

*The own contribution to this paper is $70 \%$.
} 


\subsection{Introduction}

Globalization trends in the food sector in recent decades have shaped international food marketing channels according to increasing worldwide demand for higher-value products. This development goes hand in hand with the transformation and consolidation of the retail sector, the expansion of food processing, the growth of the food service industry, structural change towards larger farm sizes and the increasing commercialization of agricultural production in developing and emerging economies (Minot and Roy, 2007; Kumar et al., 2011). Smallholders from such countries therefore still tend to be underrepresented in international food value chains due to disadvantageous structural market entry barriers: diseconomies of scale, scope and density (small farms being located in remote areas) (Phil et al., 2005), absolute costs (high production and transaction costs, limited credit access) (Markelova et al., 2009; Wang et al., 2014) and a lack of differentiation (low capabilities to cope with stricter quality criteria as well as bureaucracy and traceability requirements) persisting in food export supply chains (David et al., 2012). In order to respond to this development and overcome market barriers, contract farming (CF) is generally considered to be a potential solution which allows farmers to participate in, as well as to gain market access to modern marketing channels, including export-oriented markets (Bacon, 2005; Mangala and Chengappa, 2008; Jia and Bijman, 2013). Consequently, CF is associated with lower market uncertainty (Phil et al., 2005; Hongdong Guo, 2007, Minot and Roy, 2007; Minten et al., 2009), higher producer prices and, thus, better household livelihoods for smallholder farmers (Oliver, 2005; David et al., 2012; Rao et al., 2012). In their specific practical implementation, however, the greater level of process sophistication associated with $\mathrm{CF}$ as well as an unfavorable politico-economic environment had often led to polarization in favor of better endowed smallholders with larger production areas being included in CF-schemes and, thus, in international food value chains. The poorer, more disadvantaged farmers refrain from participation or drop out of the scheme again as a result of economic failure (Da Silva, 2005; Oya, 2012; Minten et al., 2013; Otsuka et al., 2016; Minot and Sawyer, 2016).

In this regard, the ability of smallholders to constantly overcome market barriers and access export markets through $\mathrm{CF}$ in developing and emerging countries is considered to be of high interest from a research perspective (Phil et al., 2005; Shiferaw et al., 2016) and has therefore been addressed by many earlier studies (Key and Runsten, 1999; Oliver, 2005; Phil, 2005; Hongdong, 2007; Wollni and Brümmer, 2012). Previous literature has identified 
various factors, partially diminishing the likelihood of of smallholders' CF participation when influencing smallholders' marketing decisions. A number of major socio-demographic characteristics such as smaller farm size, high age of household head, low education level, less farming experience as well as farm group preference have been proven to affect the willingness to participate in CF scheme or adoption negatively (Phil, 2005; Hongdong, 2007; Schulze et al., 2007; Kersting and Wollni, 2012; Otter et al., 2014). Market failures due to underlying policy and inefficient institutions lead to low market coordination and high transaction costs and production cost (Shiferaw, Hellin and Muricho, 2016). The negative effects of poor coordination among parties, unfavorable terms and conditions of contracts also restrain smallholders in extending their contracting status (Schipmann and Qaim, 2011). However, how market information access influences farmers' participation in contracting has remained unclear and largely unexplored so far, even though the accessibility of price information fluctuation is considered to be an important reason affecting smallholders' decisions (Oliver, 2005; Bijman, 2008; Kersting and Wollni, 2012; Abebe et al., 2013; Shiferaw et al., 2016).

The aforementioned research gap motivates us to explore the factors determining the probability of smallholder farmers in developing and emerging economies to participate in $\mathrm{CF}$ schemes. The paper extends the existing research literature by focusing on the specific influences of market information access as one of the major factors affecting CF adoption decisions in commodity markets. The conceptual framework thereby developed and applied refers back to assumptions from transaction cost theory as proposed by Williamson (1979). The Vietnamese export rice sector was chosen for research due to its representative character in supply chains of globally commercialized commodities with great importance for food security (Chen et al., 2006) whilst simultaneously suffering from loose linkages between smallholder farmers and export companies in a business environment with low value added and low product quality leading to relatively low prices (Nielsen, 2003; Baldwin et al., 2012). Based on the conceptual framework developed, the decision making process with regard to farm perspectives is assumed to be influenced by three major categories of determinants: farm characteristics, market information accessibility, and household characteristics. Survey data of 250 export-oriented rice households in the Mekong River Delta of Vietnam is used of which 134 households have participated in CF scheme with two companies in the past ten years and 116 non- contract households in the same area. A probit model is applied to examine the probability of participating in the CF scheme. Based on this empirical study, policy and management implications are derived regarding the development 
of supporting programs for farmers and agribusiness. The results are specifically interesting for firms, producers and the traders of the raw products (commodity) in emerging and developing countries.

The paper is organized as follows: Section 2 introduces general information about the role of CF schemes in developing countries as a modern marketing channel to connect smallholder farmers with buyers in agricultural value chains. This is followed by Section 3 which refers to the $\mathrm{CF}$ activities in the Vietnamese export rice sector and the corresponding literatures. In Section 4, conceptual framework, methodology, and data collection are presented. Study results for the determinants of contracting decision are shown in Section 5 before drawing conclusions and policy recommendations in Section 6.

\subsection{Contract farming in developing countries' modern marketing channels}

Today, as a result of the globalization trend in the food sector, modern marketing channels have become an important alternative to traditional marketing channels for farmers and smallholders in emerging and developing countries. While traditional channels are characterized by local spot market transactions with end-consumers or small traders, modern marketing channels are dominated by supermarkets, processors, and exporters which often tend to source via $\mathrm{CF}$ to ensure consistent supply of sufficient quantities of high quality products (Hanink and Owusu, 2000; Secer et al., 2006; Minot and Roy, 2007; Shiferaw et al., 2016; Ton et al., 2017), advantages that may potentially go hand in hand with leverage effects on the farm level (Jia and Bijman, 2013).

$\mathrm{CF}$ is defined as an economical institution involving engagement between a firm and a grower through a document called "contract". This fixes the firm's handling of the processing stage or other downstream activities (e.g. export) of the commodity supplied by the grower (Eaton and Shepherd, 2001; Minot and Roy, 2007). This arrangement does not only account for farmers' business relationships with processors but could also be the arrangement between farmers and marketing firms, supermarkets, farmer organizations ("collective action"') or other entities such as exporters. Frequently, the obligation of such parties needs to be specified in a written document in which price-setting, quantity and attributes of the products and the timing of delivery are defined (market-specifying contractMC) (Eaton and Shepherd, 2001; Will, 2013; Minot and Sawyer, 2016). CF can also include terms on the provision of agricultural inputs, such as seed and fertilizer, and/or technical

\footnotetext{
${ }^{2}$ Collective action is a voluntary action taken by a group to achieve common interests (Marshall, 1998).
} 
assistance financed on credit-type prepayment (resource-providing contract- RC) (Prowse, 2012, Minot and Sawyer, 2016). Additionally, terms on the concrete production-process management can be fixed in the contract, such as timing and amount of pesticide use, seed rates on the plots and the specific timing of the harvest (production-management contractPC) (Minot and Sawyer, 2016). Alternatively, two other strategies exist for smallholder farmers to access markets, namely, "collective action" and "informal spot market". Collective action includes joint actions by farmers organized, for instance, in a cooperative. It is often fostered as an alternative or complementary institution to overcome structural market barriers, but in many cases doomed to failure due to the resulting double-burden of institutional establishment if combined with CF (Prowse, 2007). Informal spot market agreements which cover intermediate traders or directly with large companies such as supermarkets (owned by multinational companies), hotels and restaurants, and fast food chains, still receive widespread acceptance among smallholder farmers in developing countries (David et, al., 2012).

Due to its higher degree of formalization, the governance mechanism $\mathrm{CF}$ aims to ensure more planning security for the purchasing entity through exclusive procurement rights based on fixed terms and conditions and different levels of control over the production procedure and the quality of final commodities depending on the type of contract (Will, 2013). Simultaneously, the farmer as the supplying entity might also gain benefits from the decision towards modern marketing channels and $\mathrm{CF}$ on different levels, corresponding to the contract-types (Soe et al., 2015). Access to international markets in particular via modern marketing channels with lower sales-related risks (MC) (Minot and Sawyer, 2016), additional access to newest production inputs (seeds, fertilizers, pesticides) on credit and extension service (RC) (Key and Runsten, 1999; Otsuka et al., 2016) as well as the complementary shift of production-related risks to the contractor through the fulfillment of process-specifications (PC) could be strong motivators for farmers to enter CF (Abebe et al., 2013). Even though CF is associated with various potential benefits and assumed to be an increasing trend also in emerging and developing countries, it is affected by smallholder participation dynamics and failure of schemes (Minot and Sawyer, 2016; Ton, et al., 2017). The greater level of process sophistication as well as perceived marketing inflexibility, coexisting with uncertainty regarding contract enforcement due to poor legal liability in developing countries are considered to diminish its relative attractiveness (Schipmann and Qaim, 2011; Maina et al., 2015; Minot and Sawyer, 2016). 
Overall, whether or not smallholders in developing and emerging countries perceive CF to be advantageous in terms of production and transaction costs under consideration of potential benefits and constraints and consequently whether they participate in CF greatly depends on their individual characteristics and their economic, political and sociological environment (Saenger et al., 2014; Rao et al., 2012). Corresponding parameters have been used micro-analytically as indicators in previous studies on similar topics, which then have submitted arguments on the grounds of the transaction cost theory proposed by Williamson (1979) when describing smallholder decisions for or against specific governance mechanisms as a continuum of different characteristics of product marketing transactions. These studies highlight the price expected or other economic incentives received as obvious reasons to decide for one particular marketing channel over another (Schipmann and Qaim, 2011) which is also congruent with neoclassical price theory (Coase, 1972). Moreover different farm and farmer characteristics plus channel attributes were identified as influential and exceeding the neoclassical view of transaction-cost-theoretical arguments (Schipmann and Qaim, 2011). Such arguments also support observations that poor coordination among parties and (perceived) unfavorable terms and conditions listed in contracts may restrict farmers from joining CF (Da Silva, 2005). This is a perception that is greatly influenced by the availability of comprehensive and correct market information (Williamson, 1979). Especially for relatively standardized commodity products (raw products) such as rice, which is mainly exported from emerging and developing countries in Southeast Asia such as Thailand and Vietnam, information on price level and stability in output markets is considered to directly influence marketing preferences of smallholders. This exceeds any hedging asset specific investments as it is the case for products with greater degree of differentiation and product specialization (Hongdong, 2007). These particularities motivated us to investigate in this study, the determination of the contracting decisions made by smallholder rice farmers in developing countries' from a new-institutional-economics perspective and with specific focus on the availability and accessibility of market information indicating parametric and non-parametric uncertainty.

\subsection{Contract farming within the Vietnamese export-oriented rice sector}

Rice is a globally commercialized commodity and a staple food for nearly half of the world population (Chen et al., 2006). Most of the rice traded on the world market comes from developing countries (Achmad et al., 2012). In the last five years, about $85 \%$ of the export rice quantity has been exported by six countries, namely India, Thailand, Vietnam, USA, 
Pakistan and Myanmar (USDA, 2016). Of these, the Southeast Asian countries, Vietnam, Thailand, and Myanmar, export the most (see Figure 2.1).

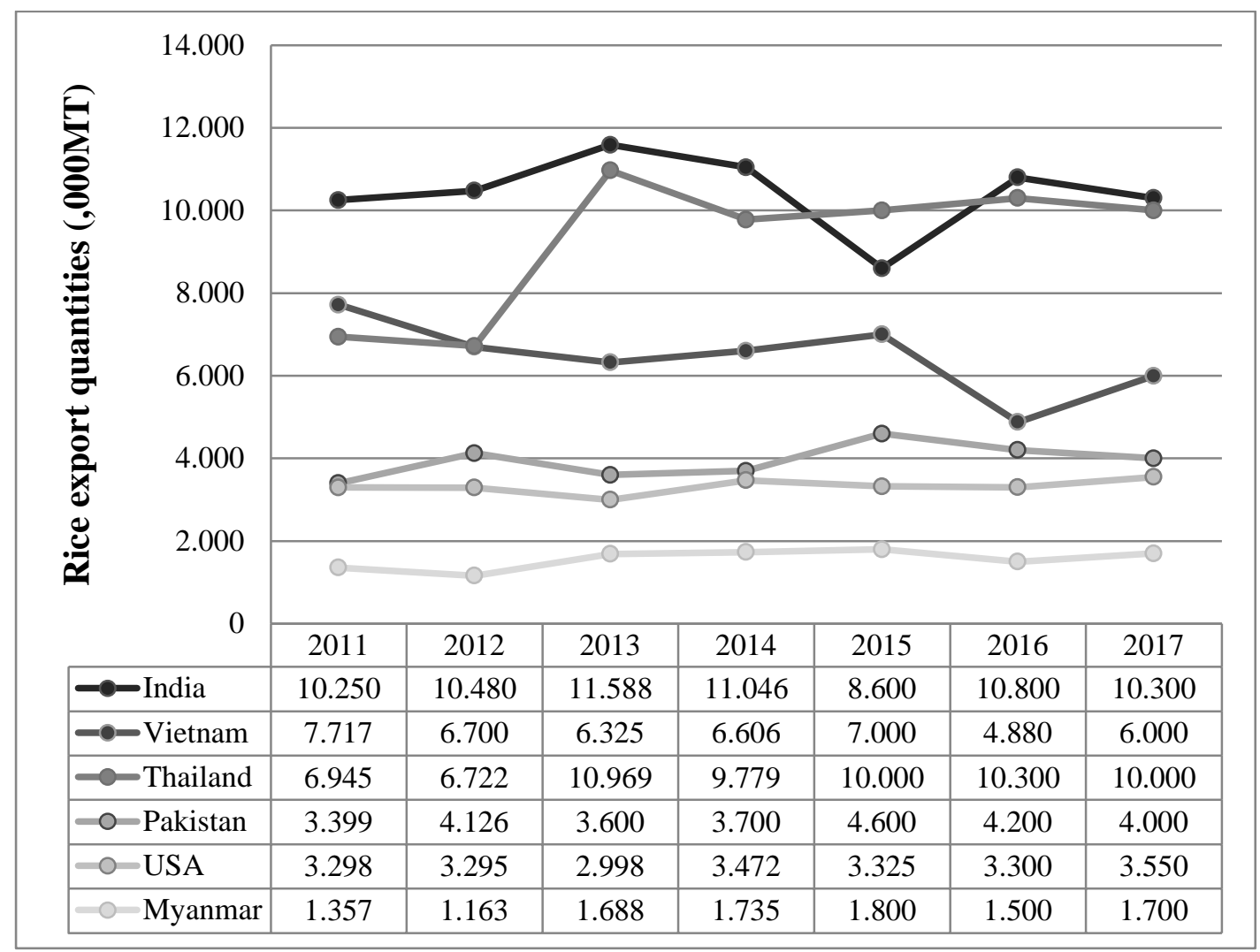

Figure 2.1: Export rice quantities from major suppliers worldwide in 2011-2017 Source: USDA (2018).

Vietnam has a great potential to become one of the key exporters for rice in addition to many other agricultural products such as coffee, pepper and tea as well as seafood (Saigenji, 2010). Since the late 1990s, Vietnam has transformed from being a major rice importer to the second largest rice exporter from Southeast Asia (Baldwin et al., 2012; Giraud, 2013), supplying about $20 \%$ of total global rice trade in the year 2015 (USDA, 2015). However, currently with more than $66 \%$ of the population working in the agricultural production and nearly $70 \%$ of small and medium-size farming households, the Vietnamese export rice sector is facing a great challenge to compete in the global rice market. The same applies to other emerging and developing countries (USDA, 2015; Reardon et al., 2014). In addition, Vietnamese rice exports are still characterized by low value added, low product quality and cost leadership, leading to low competitiveness in comparison to its major competitor, Thailand (Nielsen, 2003; Baldwin et al., 2012). Generally in the recent decade, the FOB ${ }^{3}$

\footnotetext{
${ }^{3}$ Free On Board (FOB), the term refers to the price of export products at the loading port excluding insurance and shipping fees (Ramberg, 2011).
} 
price for the main export rice varieties, such as "Viet $5 \%$ broken" or "Viet $25 \%$ broken", from Vietnam has been 20 to 30\% lower than for Thai export rice (Thawatchai, 2011; Ramberg, 2011).

Since most rice producers are smallholders, the enforcement of CF in Vietnam has the potential to support rice farmers in improving rice quality and access to target markets, reducing transaction and production costs, and controlling output quality (Tuan, 2012). In this regard, the introduction of CF scheme has been greatly supported by the Vietnamese government since the turn of the millennium. Particularly, the decision No 80/2002/QD-TTg dated June 24th 2002 named "Policy on the Promotion of Agricultural Produce and Purchase through Contracts" and decision 62/2013 QD-TTg established in 2013 have officially promoted the implementation of $\mathrm{CF}$ in Vietnamese agricultural production. These decisions also develop a flexible framework for diverse economic entities in the country. A long-term strategy has been implemented to improve farmers' bargaining power and to create an official group for smallholders. These decisions also clarify national policy efforts to support the private sector in supplying agricultural inputs such as seeds, fertilizers, pesticides, credit, and extension services to farmers (Ya'kub et al., 2012) in order to secure national food demand, improve Vietnam's competitiveness on the world market, and upgrade the bargaining power of export-oriented rice farmers (Goletti et al., 1997; ADB, 2005).

However, while large shares of other major Vietnamese agricultural export products are sold under CF (cotton: > 90\%; fresh milk: > 90\%; tea: > 40\%) (UNCTAD, 2009; Prowse, 2012), the export rice value chain still involves numerous different actors, namely; collectors, paddy millers, millers, middlemen, retailers, and wholesalers. These maintain informal trading relations (Loc and Son, 2011; Ngoc and Anh, 2014; Reardon et al., 2014). As presented in Figure 2.2, the export rice value chain is dominated by the traditional channel. A large share (93.1\%) of export-oriented rice is sold to independent paddy collectors and only $2.7 \%$ to millers directly (Loc and Son, 2011; Ngoc and Anh, 2014). Due to the numerous types of potential trading partners involved in the traditional marketing channel, the linkages between the farmers and the processing/exporting companies are generally rather loose, thereby limiting control over the raw product quality and thus diminishing prices received (Saigenji, 2010; Loc and Son, 2011). Only a few companies in Vietnam process and export rice via CF (Saigenji, 2010), translating into $4.2 \%$ of rice quantity sold under contract (Loc and Son, 2011; Ngoc and Anh, 2014). 


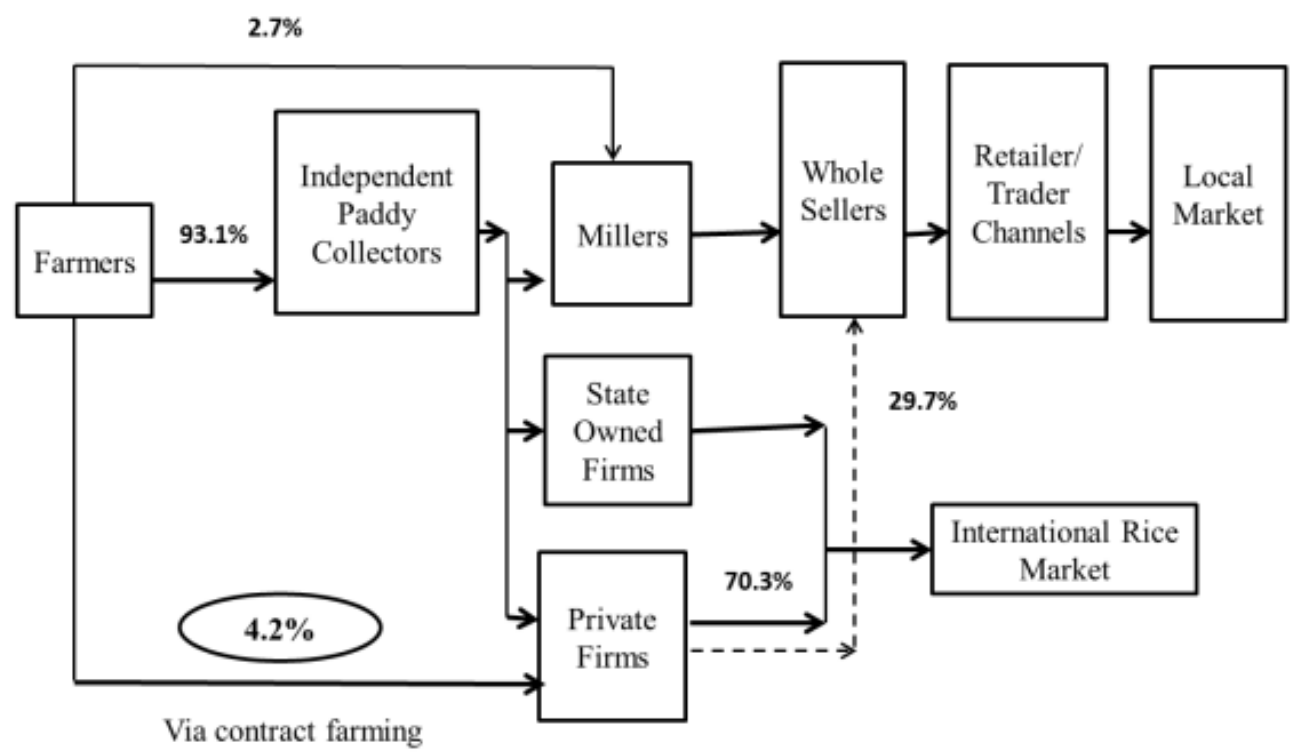

Figure 2.2: The marketing channels of export rice sector in the MRD of Vietnam. Source: (Loc and Son, 2011; Ya'kub et al., 2012; Reardon et al., 2014)

In the past, farmer organizations which had depended on the superiority of socialist forms of production called "collectivization" did not play a role in trading products between farmers and large food companies in the Vietnamese export rice supply chain; most especially in the export rice sector (Pingali and Vo, 1992; Minot and Goletti, 2000). This was in contrast to various export products from other emerging and developing countries (Minot and Sawyer, 2016), Even though such farmer associations do now exist in the export rice sector, their role to date is limited to the provision of support services (Naziri et al., 2014). In this regard, farmer associations cannot be considered a potential trading option within the modern marketing environment of the Vietnamese export rice sector but rather as providers of (market) information to their members (Moustier et al., 2010). Nowadays, due to strong incentives from the Vietnamese government, "collective action" has been established in the country (Frédéric and Dao, 2005, Naziri et al., 2014). In the Vietnamese vegetable sector, for instance, this recent collective action scheme has successfully encouraged the participation of the private sector, farmer associations and smallholder farmers (Naziri et al., 2014).

Due to its particular importance, there have been many economic studies focusing on the export rice sector in Vietnam. Apart from a few studies focusing on farm productivity and efficiency (Pingali and Xuan, 1992; Hoang and Yabe, 2012; Duy, 2012), most of the research refers to the influences of governmental policies such as price control (Ghosha, 2004; Gibson and Kim, 2013); quality control (Ryan, 1999; Nielsen, 2003; Coxhead et al., 2012), export liberalization and flexibility (Goletti et al., 1997; Pingali et al, 1997; Lutz et al. 2006; Ya'kub et al., 2012) or the de-collectivization process (Pingali and Xuan, 1992). These 
are considered not only to offer benefits for farming households but also to encourage greater participation from the private sector in the Vietnamese export-oriented rice value chain. A noticeable line of research also refers to the influence of programs carried out by non-governmental organizations in granting initial support for an enhanced marketing and trade policy (J. Ryan, 2002; Jaenicke et al., 2010). Even though the introduction of the CF scheme in Vietnam over the past 10 years and more offered greater opportunities for smallholder farmers to access modern marketing channels, there have been to date few research studies on this institutional arrangement (Reardon et al., 2014). The determinants of farmers' contracting decisions in this sector are therefore still widely unexplored. As a result, this study focuses on what determines smallholder farmers' contracting probability in the Vietnamese export rice sector.

\subsection{Research design}

\subsubsection{Conceptual framework}

The New Institutional Economics perspective proposed by Coase (1937) and Williamson (1975), resulted in the concepts of transaction costs, property rights, and agency theory. The underlying ideas about the contract concept explained, basically refer back to the three major sub-strands as follow: agency theory (Ross, 1973), transaction cost theory (Benjamin et al., 1978; Williamson, 1979), and property rights theory (Grossman and Hart, 1986). Of these, the transaction cost theory proposed by Williamson (1979) is particularly suitable for this study since it describes "uncertainty" as a main dimension (together with "asset specificity" and "frequency") influencing the appropriateness of governance mechanisms. The conceptual framework of this paper was developed based on studies by Netemeyer et al (1991), Feder (1985) and Williamson (1975) (see Figure 2.3). This theory was also applied in later studies by Fishbein and Ajzen (2011), Simmons et al. (2005), Handschuch et al. (2013) and Greiner (2015).

Based on the conceptual framework presented and the aim of this study as being an evaluation of the impact of market information as a key determinant of smallholders' contracting decisions; the decision making process from a farm perspective is assumed to be influenced by three major categories of determinants and their respective indicators: (1) farm capacities for output generation (farm characteristics); (2) the ability to consider market uncertainty (market information accessibility); and (3) managerial capacities (household characteristics). First, variables representing farm characteristics such as farming area, machine value, other crop income, and off-farm income are included. Referring to 
Schipmann and Qaim (2011) farmers with larger farming areas or off-farm income may show lower contract-aversion due to their higher time opportunity costs. Consequently, larger farmers may have greater inducement to reduce search costs through contracting, which had resulted from the "uncertainty" and "frequency" of transactions. The variables machine value and other crop income also build on ideas from Williamson (1979) by reflecting the extent of asset specific investments which might motivate farmers to decide in favor of more stable marketing relations and greater payment security through $\mathrm{CF}$. Furthermore, farms with more favorable characteristics may have advantages in responding to the requirements fixed in these contracts (Simmons et al, 2005).

The second group of variables includes indicators of market information access (and thus all reflect the degree of "uncertainty"), i.e. educational level of the household head (Cai et al., 2008), access to world market price information, previous season price information, telephone ownership, extension service accessibility, distance to the nearest market and membership in farmers associations (FAs) which are regularly mentioned in the existing literature (Ramaswami et al., 2005; Hongdong et al., 2007; Magesa et al., 2014). This literature generally supports education as empowering individuals with greater literacy and marketing skills, in turn attributes that may help farmers to assess modern marketing options independently without participating in any $\mathrm{CF}$ scheme. Better-educated farmers can therefore be expected to be less willing to participate in modern marketing channels and the corresponding $\mathrm{CF}$ scheme. The variable describing the distance to the nearest local market indicates the accessibility of up-to-date domestic market information through personal contact. Farmers with the advantage of shorter distance may have easier access, thus reducing the likelihood of CF-participation in the sense of Williamson (1979). The distanceeliminating character of farmers' telephones and the information channels extension service as well as farmer associations may have similar effects (Jensen, 2007). Simultaneously, the variables world market price information and previous season price information measure the extent of direct information availability. Generally, the market price information received shows great price volatilities on the global rice market which makes forecasting of future farm-gate prices difficult for farmers. In addition, farmers are uncertain about potential opportunistic behavior of independent paddy collectors regarding future farm-gate prices. To some extent, it is assumed that uncertainties are increasing in the case of Vietnamese rice household farmers. Further information about fluctuating rice markets, could be expected to lead to higher probabilities of participation in CF schemes. We therefore expect better the 
accessibility to market price information to result in higher probabilities of contract participation (Williamson, 1991).

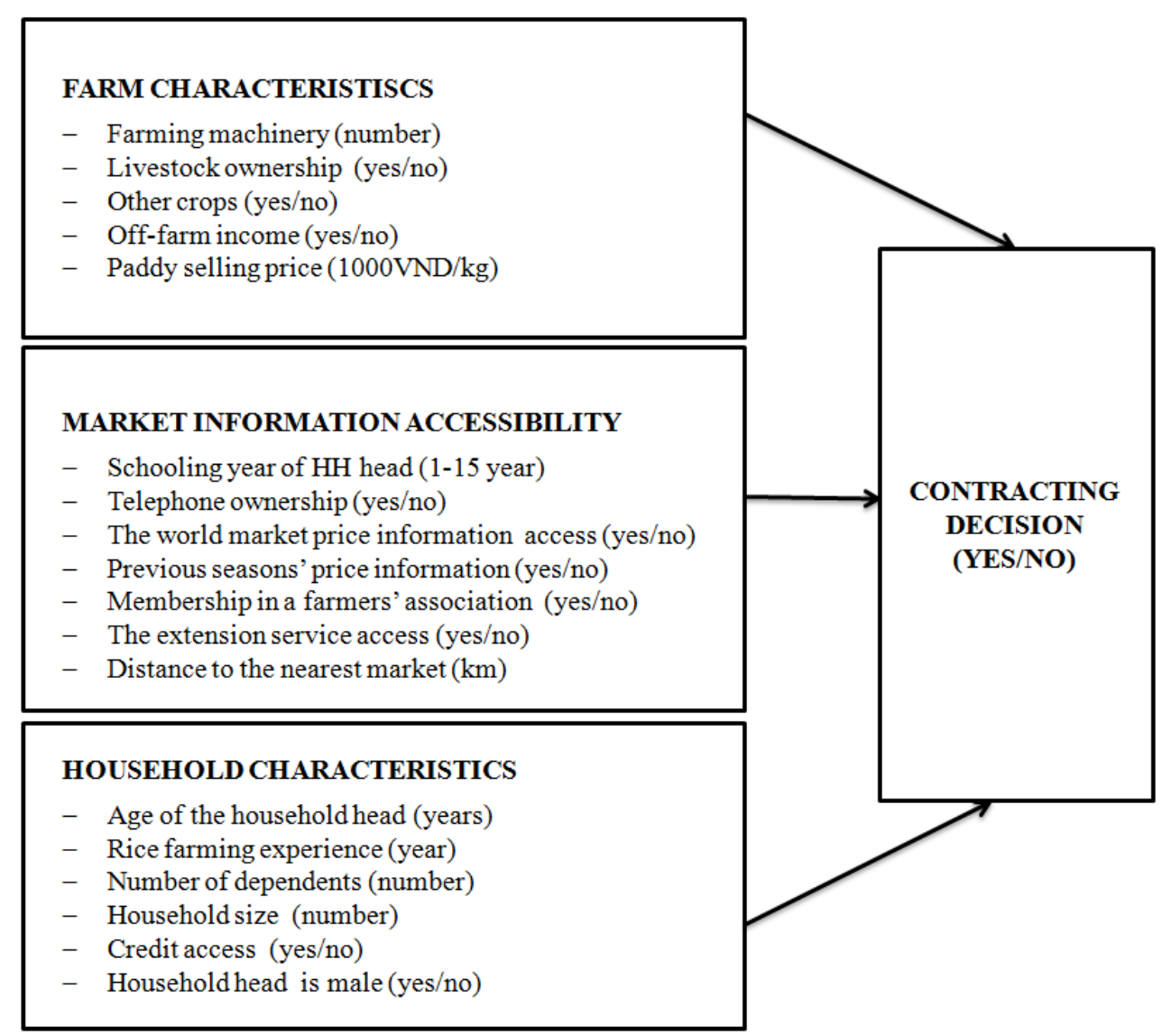

Figure 2.3. The conceptual framework of households' contracting decision

Source: adapted from Netemeyer et al., (1991); Fishbein and Ajzen (2011), Greiner (2015).

Within the third category household characteristics are grouped such as; gender, household size, farming experience and age of the household head, which are hypothesized to affect the decision making process of smallholders and have indirect influences on the accessibility of their productive resources (Kersting and Wollni, 2012; Greiner, 2015). Firstly, regarding gender characteristic, Maina et al. (2015) state that males have larger marketing networks due to their interactions with more buyers as females, are restricted to household activities. Therefore, we expect that being a man has a positive influence on any marketing channel choice. For the "household size" variable, we expect a negative sign in the probability of choosing modern marketing channels. It is assumed that the larger the number of working family members, the lower the probability of CF participation. Additionally, for a country with about $66 \%$ of the population working in the agricultural sector (WB, 2016), "rice farming experience" is a major constraint for any modern marketing strategy (Kulkarni and Grethe, 1999). For example, rice farming households with long term farming experience 
may decide not to enter contractual arrangements because the decision makers believe they do better on their own and independent from contractors (Barrett et al., 2012). Continuing with the same argument, we also expect that older farmers ("age of household head" variable) are more likely to choose traditional marketing channels (Handschuch et al., 2013). We expect these indicators to affect the probabilities of the $\mathrm{CF}$ scheme participation negatively. From the farmers' perspective participation in CF may offer better marketing options but it may also lead to a reduction in freedom of choice in farming practices, farming quantity, seed variety, and farm-gate prices (Bijman, 2008; Tuan, 2012; GIZ, 2013). All three major categories are assumed to directly or indirectly lead to Vietnamese rice farmers' decisions to participate in CF or to refrain from participation (Kersting and Wollni, 2012; Greiner, 2015).

\subsubsection{Methodology}

We have followed the methodologies which were applied in earlier studies to analyze the impact of CF programs in Senegal by Warning and Key (2002), standard adoption by Kersting and Wollni (2012), and GlobalGAP certification by Holzapfel and Wollni (2014). Thus, we choose a probit model to explore the factors that influence the probability of contract participation. In order to control the sample for selection bias, we followed Heckman's (1979) method to compare the probit results with the maximum-likelihood estimation (MLE) (Wynand and Van De, 1981).

Based on the conceptual framework, the probit model is applied with the assumption that selected variables representing farm characteristic, market information access, and household characteristic determine the households' contracting decisions. Household income and rice profit are not included in the probit model as indicators, since these variables highly correlate with rice farming area and farm size (Greene, 2002; Vanslembrouck et al., 2002). The probit model is applied to explain a dichotomous dependent variable $y^{*} ; y^{*}$ stands for the probability of CF participation and is interpreted as follows:

$$
y_{i}^{*}=\beta_{0}+\sum_{k=1}^{K} \beta_{k i} x_{k i}+\varepsilon_{i}(1) ;
$$

given $i$ representing each respondent, $x_{k}$ describes the vector of $k$ independent variables; $\beta_{k}$ are the parameters for the effects of $x_{k}$ on $y^{*} ; \beta_{0}$ is the intercept for the expected value of $y^{*}$ when all $x_{k}$ are equal to zero; $\varepsilon_{i}$ represents the error term for respondent $i$; $y_{i}^{*}$ is continuous, unobserved and ranges from $(-\infty$ to $+\infty)$. We define the relationship between the latent dummy variable $y_{i}^{*}$ and the observations as: 


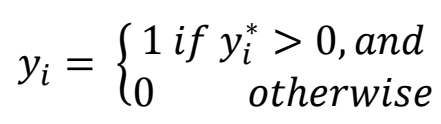

The decision to participate in CF is interpreted as follows:

$$
y_{i}=\left\{\begin{array}{lr}
1 & \text { if the farmer adopts } \\
0 & \text { and if the farmer not adopts }
\end{array}\right.
$$

As a result, the probabilities to participate in $\mathrm{CF}$ are estimated through the following equation:

$$
\mathrm{P}\left(y_{i}=1 \mid x_{i}, \beta\right)=\mu\left(F_{j i}\right) \text { and } \mathrm{P}\left(y_{i}=0 \mid x_{i}, \beta\right)=1-\mu\left(F_{j i}\right)
$$

with $F_{j i}=\ln x_{i}$ where $j=1$ for contract participation and $j=0$ for non-contract participation. By maximizing the corresponding log likelihood function the parameter $\beta_{j k}$ can be estimated (Greene, 2002). When the log-likelihood function is not sharply peaking but relatively flat at its maximum, the particular parameter is covered by limited information in the data. In this case the MLE will be an imprecise estimator (Heckman, 1979; Greene, 2002). With the assumption that the error term $\varepsilon_{i}$ in (1) is not following a normal distribution, the probit result should be considered as an approximation since the correction term is included. Thus, we compare these probit estimation results to those from the MLE with sample selection by controlling for correlations between errors (Heckman, 1979; van de Ven and van Praaag, 1981). We assume that there are underlying relationships between the unobserved, latent variables and their observed outcome. If error terms are significantly correlated, it means that a self-selection bias is existent. The error term equation adapted from Greene (2002) is estimated as follows:

$$
\varepsilon_{i} \sim \operatorname{Prob}(0,1, \rho), \operatorname{Var}\left[\varepsilon_{i}\right]=1 ; \operatorname{Cov}\left[\varepsilon_{i}\right]=\rho(4) .
$$

Thereby the error term $\varepsilon_{i}$ from equation (1) has a normal distribution with zero mean, unit variance and correlation $\rho$.

\subsubsection{Data collection}

Primary data was collected in early 2016 in the Mekong River Delta (MRD) of Vietnam where nearly $90 \%$ of the country's export rice is produced. The target population of 250,000 households is located in the three main export rice production regions, namely the Kien Giang, Can Tho, and An Giang provinces in the MRD (USDA, 2015). Using a structured questionnaire, 250 households were chosen from the aforementioned provinces. To ensure the comparability of contract and non-contract farmers and simultaneously assure representativeness of the subsamples, we randomly selected 134 contract farmers from 
contractor lists and 116 non-contract farmers from official lists of 12 villages' located in the same area as the contract participants. Most of the CF participants in the sample produce under resource providing contracts, thus, the contractors are in charge of specifying the production practices including input supply (seeds, fertilizer, pesticides) on credit, technical assistances, and the purchasing commitment (Phil et al., 2005; Minot and Sawyer, 2016). In this paper, the export-oriented rice farmers were interviewed about information on farm and household characteristics and market information access referring to the three export rice producing seasons in the year from the beginning of November 2014 till the end of October 2015.

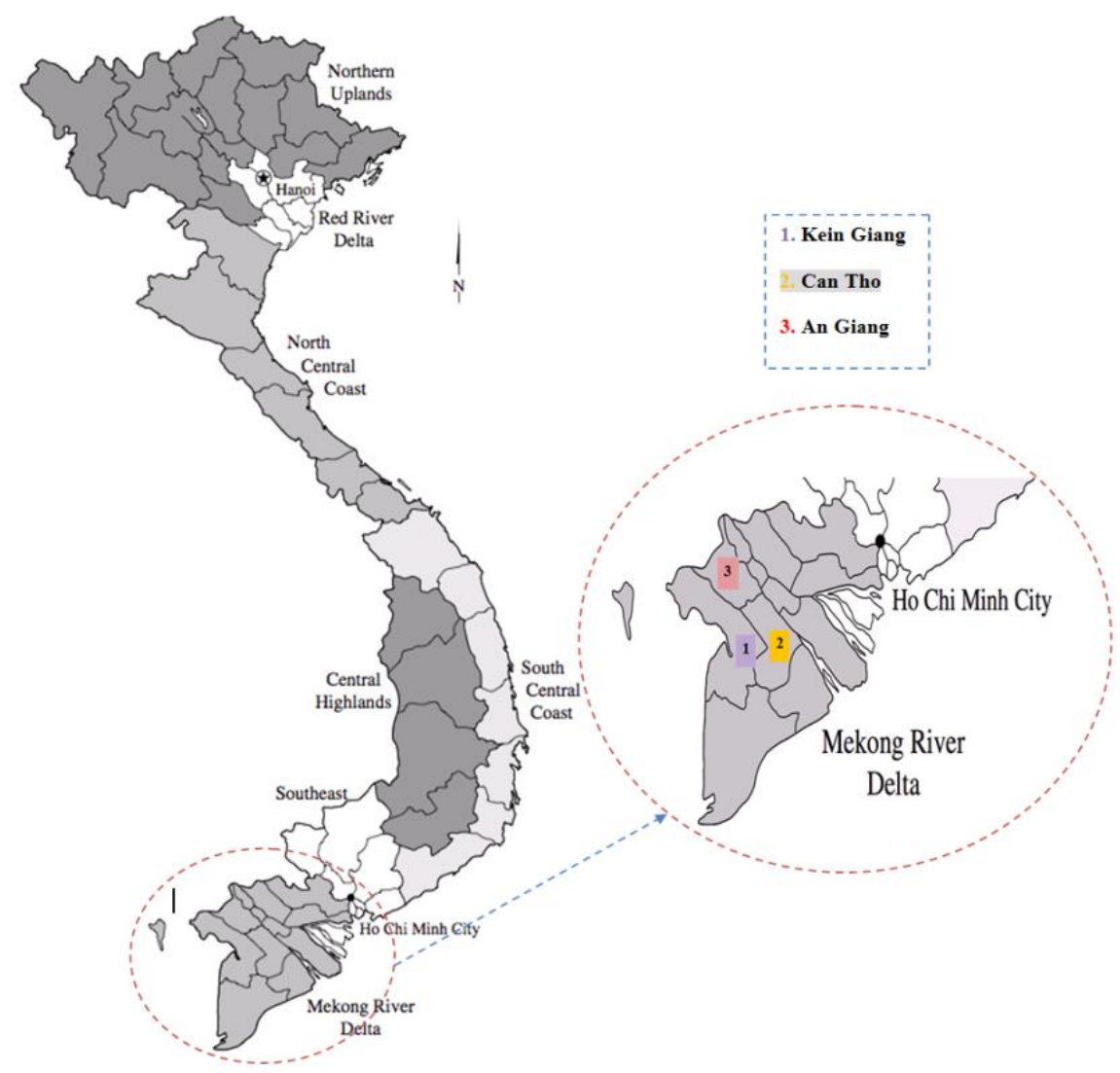

Figure 2.4 Area of study in the Mekong River Delta of Vietnam Source: Map adopted from (Minot and Golleti, 2000)

\subsection{Results}

\subsubsection{Descriptive Statistics}

Table 2.1 shows the general statistics for the included variables of the three categories in the estimated models. Regarding the farm characteristics, it becomes evident that the total farming size of the farms surveyed is on average about 3.39 ha while only $24 \%$ of the farmers own livestock and $0.236 \%$ income comes from additional crops. Simultaneously, a mean number of 1.656 machines are used indicating their important role during rice farming 
activities. The paddy farm-gate price per kilogram is on average about VND5150 ( USD0.23). The off-farm income of the farming households accounts for on average VND40.550 million per year ( USD1843.1). Regarding the second category of variables, the household heads went to school for on average 8.12 years. The rate of telephone ownership is rather high $(91.2 \%)$. The smallholder farmers surveyed have an average distance of about $2.93 \mathrm{~km}$ to the nearest market. Small channels and rivers are a specific characteristic of this area, preventing rice household farmers' access to local markets. Additionally, $45 \%$ of the respondents stated they had access to world market price information, $58.2 \%$ to the previous seasons' price information and about $45.6 \%$ to extension service. With regard to the household characteristics, we find that the farm households have on average 1.79 members ("household size"). The average age of the household head is 46.67 years, most of them are males $(94.40 \%)$ with an average rice farming experience of 23.39 years. Only $37.6 \%$ of the farming households can access credit from financial organizations.

Using $t$-tests, we compare participants in $\mathrm{CF}$ to non-contract participants regarding the differences in measures of the major categories "farm characteristics", "market information access", and "household characteristics". It can be seen from the results that there are strong differences between the two groups in some major characteristics such as: farm-gate price received, information accessibility, relationship with FAs and farming experience.

For the category farm characteristics, the results show that there are significant differences in mean values of the selected variables "paddy farm-gate price" and "other crops" between the contract participant and non-contract participant groups. A higher producer price for paddy received by contract farmers (significant at the 1\%-level) indicates that those farmers are benefiting from fair-price terms offered by the contracting companies in comparison to the spot market. This could on the one hand be explained by low bargaining power on the part of farmers on the free export-oriented rice market (spot market/traditional channels) or on the other hand by the influences of market price information (Williamson, 1991).

The second category of variables including attributes regarding the ability to access market information. Here there are significant differences in particular with respect to the accessibility of world market price information, access to extension services, and membership status of FAs between contract and non-contract participants. Based on the comparison of results, it is interesting that contract participants have better opportunities to gain access to market price information than non-contract participants at a $5 \%$ level of significance. 
In the last category of variables, the major demographic variables which are expected to affect the contracting decisions are tested. Regarding the number of households' farming members, the non-contract group has a higher percentage of household members involved in farming activities (significant at $\mathrm{p}<0.05$ ) in comparison to the contract group even though the total farm-size does not differ significantly among the groups. This result can be explained with the support of extension services and access to high quality inputs the $\mathrm{CF}$ farmers receive, which then lowers family labor demand in comparison to non-contract farmers (Phil, 2005). The significant negative effects of the "rice farming experience" variable could be interpreted as farmers, especially smallholders in rural and less developed areas, having more experience in rice farming and being less willing to change their farming habit from conventional to a modern marketing strategy (Cai et al., 2008; Kleemann et al., 2014).

With regard to the contract type status, nearly $80 \%$ of the farmers sampled producing export rice under contract in the MRD of Vietnam have production contracts. Thus, the majority of these farmers retains control over strategical farm-producing management decisions such as input purchase and production process planning, while the contractors' role is rather supportive in nature (Bijman, 2008; WB, 2013). Simultaneously, PC may provide advantages regarding transaction costs (e.g. acquisition of market information, price risks) and transportation costs (Eaton and Shepherd, 2001). Even though farmers producing under $\mathrm{RC}$ may face higher production costs than those producing under marketing and production contracts, these aspects may, according to the distribution of contract-types, not be of decisive relevance for farmers in the export-oriented rice sector of Vietnam. This interpretation is also supported by farmers' perceptions of costs and benefits under their contracts. Most of the farmers surveyed find that $\mathrm{CF}$ is helpful for them accessing the most convenient market instead of relying on traditional market channels either through middlemen or other spot market transactions. Moreover, RC allows farmers to control their farming practice and maintain control over their production process (see Table 2.2).

Among Vietnamese export rice farmers only a minority agrees on a fixed price at the time of contracting $(8.2 \%)$, while the majority determines prices later, at delivery time $(48.2 \%)$ or flexibly at any time in between (43.3\%) (see Table 2.3). Delivery and flexible prices help firms to hedge against price fluctuation on the world market that would otherwise negatively affect their export activities (Grosh, 1994). However, such price terms may diminish the possibility of risk reduction through contracting and consequently, farmers' willingness to 
produce under contracts since the "price term" is one of the most important criteria in farming households' contracting decisions (Phil, 2005). However, the farmers in this sample perceive their contracts and corresponding price-terms to be risk reducing with regard to market price fluctuations (mean: 4.11) Table 2.4). 
Table 2.1. Descriptive statistics for the variables included in the estimations

\begin{tabular}{|c|c|c|c|c|c|c|c|}
\hline \multirow[b]{3}{*}{ Description } & \multirow{2}{*}{\multicolumn{2}{|c|}{$\begin{array}{l}\text { Total sample } \\
(\mathrm{N}=250)\end{array}$}} & \multicolumn{5}{|c|}{ Contract } \\
\hline & & & \multicolumn{2}{|c|}{$\begin{array}{l}\text { Non-contract farmers } \\
\qquad(\mathrm{N}=134)\end{array}$} & \multicolumn{2}{|c|}{ farmers $(\mathrm{N}=116)$} & \multirow[t]{2}{*}{ T-test } \\
\hline & Mean & Std deviation & Mean & $\begin{array}{c}\text { Std } \\
\text { deviation }\end{array}$ & Mean & $\begin{array}{c}\text { Std } \\
\text { deviation }\end{array}$ & \\
\hline \multicolumn{8}{|l|}{ Farm characteristics } \\
\hline Farming machinery (number) & 1.656 & 1.302 & 1.69 & 1.296 & 1.63 & 1.312 & -0.282 \\
\hline Paddy farm-gate price (1000VND) & 5.15 & 0.56 & 4.96 & 0.49 & 5.31 & 0.04 & $5.127 * * *$ \\
\hline Livestock ownership (1=yes) & 0.24 & 0.427 & 0.302 & 0.461 & 0.187 & 0.391 & -1.197 \\
\hline \multicolumn{8}{|l|}{ Market information access } \\
\hline Schooling years of HH head (1-15 years) & 8.128 & 2.956 & 7.93 & 2.90 & 8.3 & 3.00 & 0.989 \\
\hline Telephone ownership ( $1=$ yes $)$ & 0.912 & 0.2896 & 0.89 & 0.30 & 0.91 & 0.28 & -0.221 \\
\hline The world market price information access ( $1=$ yes) & 0.45 & 0.4990 & 0.38 & 0.045 & 0.50 & 0.043 & $3.891 * *$ \\
\hline The previous seasons' price information ( $1=$ yes $)$ & 0.582 & 0.500 & 0.49 & 0.502 & 0.56 & 0.498 & 1077 \\
\hline \multicolumn{8}{|l|}{ Household characteristics } \\
\hline Age of household head (years) & 46.676 & 10.58 & 46.6 & 11.04 & 46.74 & 11.04 & 0.101 \\
\hline Rice farming experience (years) & 23.39 & 10.24 & 24.67 & 10.90 & 22.29 & 9.52 & $-1.843^{*}$ \\
\hline Number of dependents (number) & 1.744 & 1.367 & 1.298 & 1.427 & 1.69 & 1.427 & -0.713 \\
\hline Household size (number) & 1.79 & 0.697 & 1.9 & 0.71 & 1.7 & 0.67 & $-2.22 * *$ \\
\hline Farmer access to the credit $(1=$ yes $)$ & 0.376 & 0.4853 & 0.37 & 0.485 & 0.38 & 0.488 & 0.207 \\
\hline Household head is male ( $1=$ yes $)$ & 0.944 & 0.2303 & 0.93 & 0.254 & 0.96 & 0.208 & 0.827 \\
\hline
\end{tabular}

Note: $* \mathrm{p}<0.10, * * \mathrm{p}<0.05, * * * \mathrm{p}<0.01$

$1 \mathrm{USD}=22.000 \mathrm{VND}$ (average of currency exchange rate is applied at the time of data collection Nov-2015 to January 2016)

Source: authors' owned calculations 
Table 2.2. Distribution of contract-types in the sample

\begin{tabular}{llllr}
\hline & RC & MC & PC & Total \\
\hline Households & 106 & 26 & 2 & 134 \\
Percentages & 79.1 & 19.4 & 1.5 & 100 \\
\hline
\end{tabular}

Source: authors' owned calculations

Table 2.3. The terms of outputs price listed in the contract

\begin{tabular}{lllll}
\hline Price term & Fixed price & Delivery price & Flexible price & Total \\
\hline Households & 11 & 65 & 58 & 134 \\
Percentages & 8.2 & 48.2 & 43.3 & 100 \\
\hline
\end{tabular}

Source: authors' owned calculations

\section{Table 2.4. Farmers perception of contract farming benefits}

Frequency of farmers perception

Increase the average paddy farm-gate price

Reduce the production cost due to the contractors' seed supply

Reduce the production cost due to the contractors' technical assistance

Reduce transportation cost

Reduce using chemicals

Reduce the risk of product in comparison with spot market

Reduce risk for market price fluctuation

Reduce the risk of storing the paddy after harvesting

Other terms

Learn new farming method through CF scheme

Easily estimate the farming profit

Acceptable contract price

Make finding buyers easier

Enhance bargaining power

Number of observations (Percentages): 134 (100\%)

1

2

2

$35(26.1)$

$$
21(15.7)
$$

14 (10.4)

$1(0.7)$

17 (11.3)

$1(0.7)$

2 (1.5)

$4(3.0)$

4 (3.0)

$1(0.7)$

6 (4.5)

4 (3.0)

19 (14.2)

$1(0.7)$

2(1.5)
3

$34(25.4)$

22 (16.4)

$21(15.7)$

24 (17.9)

32 (21.3)

6 (4.5)

$23(17.2)$

28 (20.9)

4

59 (44)

58 (43.3)

68 (50.7)

73 (54.5)

62 (41.3)

47 (35.1)

$60(44.8)$

63 (47.0)

$12(9.0)$

34 (25.4)

86 (64.2)

$72(53.7)$

$28(20.9) \quad 67(50.0)$

$1(0.7)$

$6(4.5)$

$11(8.2)$

$47(35.1)$

$80(59.7)$

\begin{tabular}{lll} 
& $\begin{array}{l}\text { Mean } \\
\text { score }\end{array}$ & $\begin{array}{c}\text { Descending } \\
\text { order }\end{array}$ \\
\hline 5 & & \\
$6(4.5)$ & 3.26 & 10 \\
$33(24.5)$ & 3.76 & 7 \\
$31(23.1)$ & $3.86^{\mathrm{a}}$ & 6 \\
$36(26.9)$ & $4.01^{\mathrm{b}}$ & 5 \\
$23(15.3)$ & $3.69^{\mathrm{c}}$ & 8 \\
$78(58.2)$ & $3.86^{\mathrm{a}}$ & 6 \\
$47(35.1)$ & 4.11 & 3 \\
$39(29.1)$ & $4.02^{\mathrm{b}}$ & 4 \\
& & \\
$29(21.6)$ & $3.86^{\mathrm{a}}$ & 6 \\
$24(17.9)$ & $3.86^{\mathrm{a}}$ & 6 \\
$20(14.9)$ & $3.65^{\mathrm{c}}$ & 9 \\
$78(58.2)$ & $4.48^{\mathrm{d}}$ & 1 \\
$42(31.4)$ & $4.32^{\mathrm{d}}$ & 2
\end{tabular}

Likert scale: 1. Strongly disagree; 2. Disagree; 3. Neutral; 4. Agree; 5. Strongly agree; Bracket value is Percentage

Mean scores indicated with the same letter are not significantly different from each other at the 5\% level on the basis of a Wilcoxon sign-rank test 
Chapter 2: Determinant of Contract Farming Participation

Table 2.5. Probit model estimations on the contract farming participation

\begin{tabular}{|c|c|c|c|c|c|}
\hline Variable & Coefficient & Robust std.err. & $\begin{array}{l}\text { Marginal } \\
\text { effects }\end{array}$ & $\begin{array}{l}\text { Robust } \\
\text { std.err. }\end{array}$ & Means \\
\hline \multicolumn{6}{|l|}{ Farm characteristics } \\
\hline Farming machinery using (number) & 0.0633 & 0.0756 & 0.0250 & 0.0295 & 1.656 \\
\hline Paddy selling price (1000VND) & $0.695 * * *$ & 0.161 & $0.275 * * *$ & 0.0797 & 5.15 \\
\hline Other $\operatorname{crop}(1=$ yes $)$ & $-2,684$ & 147.7 & $-1.062 * * *$ & 0.204 & 0.236 \\
\hline Off-farm income $(1=$ yes $)$ & 0.113 & 0.181 & 0.0449 & 0.0687 & 0.492 \\
\hline Livestock ownership (1= yes) & 2,249 & 147.7 & $0.890 * * *$ & 0.191 & 0.24 \\
\hline \multicolumn{6}{|l|}{ Market information accessibility } \\
\hline Schooling years of HH head (1-15 years) & -0.00736 & 0.0339 & -0.00291 & 0.0132 & 8.12 \\
\hline Telephone ownership $(1=$ yes $)$ & -0.206 & 0.316 & -0.0817 & 0.127 & 0.912 \\
\hline The world market price information access $(1=$ yes $)$ & $0.615 * * *$ & 0.188 & $0.244 * * *$ & 0.0729 & 0.45 \\
\hline Previous seasons' price information access $(1=$ yes $)$ & -0.0102 & 0.233 & -0.00405 & 0.0954 & 0.528 \\
\hline Membership in a FA $(1=$ yes $)$ & 0.358 & 0.262 & 0.142 & 0.103 & 0.152 \\
\hline The extension service access $(1=$ yes $)$ & $0.485 * *$ & 0.235 & $0.192 * *$ & 0.0942 & 0.456 \\
\hline Distance to the nearest market $(\mathrm{km})$ & 0.0127 & 0.0434 & 0.00502 & 0.0173 & 2.93 \\
\hline \multicolumn{6}{|l|}{ Household characteristics } \\
\hline Age of household head (years) & $0.0258 * *$ & 0.0119 & $0.0102 * *$ & 0.00453 & 46.67 \\
\hline Rice farming experience (years) & $-0.0310 * * *$ & 0.0111 & $-0.0123 * * *$ & 0.00403 & 23.39 \\
\hline Number of dependants (number) & -0.0486 & 0.0697 & -0.0192 & 0.0264 & 1.744 \\
\hline Household size (number) & $-0.277^{*}$ & 0.142 & $-0.109 * *$ & 0.0547 & 1.792 \\
\hline Credit access $(1=$ yes $)$ & 0.0636 & 0.203 & 0.0252 & 0.0776 & 0.376 \\
\hline Household head is male ( $1=$ yes $)$ & 0.161 & 0.406 & 0.0639 & 0.145 & 0.944 \\
\hline _cons & $-3.933 * * *$ & 1.114 & & & \\
\hline \multicolumn{3}{|c|}{ The probability of contract participation with the rest variable are at mean values: } & $0.551 * * *$ & 0.033 & \\
\hline
\end{tabular}

Number of observation: 250

Wald chi2 $(18)=62.63$

Prob $>$ chi $2=0.0000$

Correctly classified: $71.60 \%$

Pseudo R2 = 0.1814

The marginal effects $(\mathrm{dy} / \mathrm{dx})$ are calculated at the means of the variables. For dummy variables, the marginal effect is calculated for a discrete change from 0 to 1.

Statistical significant level: * $\mathrm{p}<0.10, * * \mathrm{p}<0.05, * * * \mathrm{p}<0.01$

Source: authors owned calculations 


\subsubsection{Determinants of CF participation}

The probit model estimation illustrated in Table 2.5 shows an $\mathrm{R}^{2}$ value of 0.1814 for the variables employed in the model which is acceptable for a cross-sectional data analysis. There is no auto-correlation among the independent variables with a correctly classified level of $71.60 \%$. In addition, the probability to participate in CF is significantly influenced by three major groups of indicators, namely farm characteristics, household characteristics, and accessibility of market information as expected in our hypotheses.

Among the indicators for farm characteristics, the probability of contracting participation is strongly affected by "average paddy farm-gate price" ( $\left.\beta=0.695^{* * *}\right)$ received. This result also confirms the finding of previous literature that the farm-gate price is one of the most important factors influencing farmer's contracting decision (Key and Runsten, 1999; Hongdong, 2007; Huh et al., 2012; Schipmann and Qaim, 2011). Concerning the descriptive statistics with regard to the differences in paddy prices between the two groups, the perception of paddy price slightly increases.

Regarding the variables representing market information accessibility, we find significantly positive effects of the accessibility of extension services $\left(\beta=0.485^{* *}\right)$ and world market price information $\left(\beta=0.615^{* * *}\right)$ on households' contracting decision. The $5 \%$ significance level of the extension service variable once again is in line with previous studies (Da Silva, 2005; Phil et al., 2005; Christensen et al., 2011; David and Spencer, 2012). The extension service support, in particular technical assistances, advisory services, transportation services, financing, quality monitoring and other services positively affect households' contracting decision (Da Silva, 2005). These services could be offered from FAs, firms, and other third parties giving multiple opportunities to farmers. Thus, the more extension services a farmer works with, the higher the probability of joining CF. Remarkably, the accessibility of world market price information is found to have a great influence on households' contracting decisions $(p<0.01, \beta=0.615)$. Additionally, the producer price received for the paddy strongly influences the households' contracting decision. This result supports our research hypothesis insofar that price information positively influences the decisions of households to participate in CF. Even membership in FAs between both groups is significantly different in t-test (see Table 2.1) but there is no effect on the probit estimations (see Table 2.5). This can be interpreted as contract- farmers participating more actively in FAs but being a member of FAs or not does not cause any influence on households' decision to participate in CF scheme. 
Thirdly, demographic characteristics including "age of household head" and "rice farming experience", and "household size" are illustrated as major determinants of farmers' contracting decisions. While there are many studies showing negative effects of age on the probability of households' contracting decisions (Simmons et al., 2005; Bellemare, 2012), in our research, the "age of household head" variable $\left(\beta=0.025^{* *}\right)$ shows a positive effect, indicating that a higher age of the household head increases the probability of households' contract participation. That can be interpreted as when farmers get older, they are afraid of increasing uncertainties in rice production and trading activities. Participating in a $\mathrm{CF}$ scheme is a step towards securing their activities and reducing risk. Concerning the "household size" or the number of household members involved in farming, Phil et al., (2005) proved that household size does not affect the households' contracting decisions. However, our results indicate that a higher number of family members living in a rice farming household corresponds to a lower willingness to participate in $\mathrm{CF}(\beta=-0.27 * *)$. Since exporting and processing firms prefer to sign contracts with better performers (Briones, 2015), most of the contracting companies expect households with more farming experience to be willing to participate in CF (Miyata et al., 2009). However, the negative effect of "rice farming experience" $(\beta=-0.31)$ in our analysis confirms results from previous literature showing that the probability of $\mathrm{CF}$ participation decreases with higher numbers of years of farming experience (Ramaswami et al., 2005; Cai et al., 2008; Kleemann et al., 2014). Consequently, long experience of rice farming and corresponding marketing habits discourage smallholders to change marketing strategies. Experienced smallholders are confident enough with their farming and marketing skills (Elepu, 2009) and perceive themselves as capable of dealing with spot marketing (Kulkarni and Grethe, 1999).

\subsubsection{Marginal effect estimation}

According to Heckman (1979), in order to control for error term correlation, we employ marginal effects estimation by treating the rest variables at a mean value and consider the contract participation status as the treatment effect. As a result, the marginal effect level which is 0.551 at $1 \%$ significance level is acceptable, indicating that there is no evidence for error correlation in our model. There is not much deviation from the result of the probit model and the MLE with sample selection which supports the robustness of our estimation results (Table 2.5). We find that "age of the household head" $\left(\beta=0.01^{* *}\right)$, "accessibility of extension service" $(\beta=0.192 * *)$, average paddy farm-gate price $\left(\beta=0.275^{* * *}\right)$, and "accessibility of world market price information" $\left(\beta=0.244^{* * *}\right)$ are the most important determinants of $\mathrm{CF}$ participation, which is in line with the probit model estimation. 
Additionally, "rice farming experience" $\left(\beta=-0.123^{* *}\right)$ and "household size" $(\beta=-0.109 * *)$ in the MLE are still found to negatively influence the probability of contracting decisions.

\subsection{Conclusions and policy recommendations}

For the governance mechanism CF in emerging and developing economies, the case of the Vietnamese export-oriented rice sector under research in this study gives interesting insights at the farm level. From a new institutional economics perspective, the contracting decisions of smallholder farmers in the Vietnamese export rice sector are analyzed based on three major categories of influencing variables: farm characteristics, market information access, and household characteristics. Based on data from 250 Vietnamese rice farmers a probit model estimation granted deeper knowledge about farmers' probability to participate in a CF scheme and determinants that influence the corresponding decisions in emerging economies.

The paddy farm gate-price received, which is observed to be higher for contract farmers, is found to be an especially important determinant. Contractors offering constantly higher prices in comparison to middlemen in traditional channels might encourage farmers' contracting decisions. Such price terms, in combination with extension service provision as part of the contract is considered to be an important motivator for rice smallholders to participate in $\mathrm{CF}$ due to the improvement of farming practices.

With regard to the accessibility of market price information, the more farmers have information about the fluctuation of rice prices, the more they are willing to participate in a CF scheme to reduce risk due to rising market uncertainties. Farmers' should therefore also be encouraged and trained specifically on demanding and using such information for managerial decisions. This especially holds true for farmers who still compensate search costs with habits stemming from long-lasting experience in the rice business plus a greater number of household members and thus family labor.

Overall, to take advantage of the new agri-food trend opportunities, and to upgrade current Vietnamese rice-marketing channels, policies aiming to improve the export-oriented rice sector to avoid the opportunistic behavior by intermediaries should be considered. These should focus on the implementation of institutions that set the rules of the game and link small-scale farmers with high-end markets. As a result, farmers can avoid assets constraints and levels when otherwise depending on traditional spot markets. Therefore, based on these results, we suggest that the availability of the price information should be taken into account by the Government during the development and enhancement of the Vietnamese CF scheme proposed in the decision No. 80/2002/QD-TTg "Policy on the Promotion of Agricultural 
Produce and Purchase through Contracts" and decision No. 62/2013 QD-TTg to motivate the active participation of smallholders in contractual arrangements. Furthermore, processing and exporting companies' extension services and their adaption to smallholders' needs are of particular importance for encouraging farmers to participate in $\mathrm{CF}$.

This study is also characterized by some limitations which provide starting points for future research. It only allows for conclusions on the relevance of the pure availability of market information as a determinant of smallholder farmers' contracting decisions without distinguishing between different types of such information. Thus, future research could take different types of information into account to gain deeper insights into the relevance of information access for smallholders' decision making. Additionally, the study does not allow for conclusions on the real advantageousness of $\mathrm{CF}$ for export rice farmers in Vietnam. This limitation also implies further research on the actual effects of CF participation. 


\title{
3. Do smallholders in emerging economies benefit from contract farming? Empirical evidence from the Vietnamese export rice sector ${ }^{4}$
}

\begin{abstract}
Contract farming participation is proposed as a better solution for smallholder farmers from emerging and developing economics to earn higher farming benefits from global aspects. Whether this is also true for the case of contract farming scheme in Vietnam has rarely been examined before. This study addresses the influences of contract farming participation on farming households' performance in the Vietnamese export-oriented rice sector using quantitative cross-sectional data from a sample of 250 rice farmers. Results from OLSregression and Propensity Score Matching confirm the positive effects of contract farming on improving household income and rice farming profit.
\end{abstract}

Keywords: Contract farming, farming households' performance, Propensity Score Matching, Vietnam, export rice sector.

\footnotetext{
${ }^{4}$ This paper is a joint work with Ludwig Theuvsen and Verena Otter; the Department of Agricultural Economics and Rural Development, University of Goettingen, Germany.

* The own contribution to this paper is $80 \%$.
} 


\subsection{Introduction}

Rural poverty reduction in emerging and developing economies through improving farming productivity, profitability and sustainability has received great attention from politicians, non-governmental organizations (NGOs) and researchers in recent years. However, the development of global food supply chains with the strengthen of modern marketing channels and the arising role of large-scale farmers still puts smallholders from emerging and developing countries, such as Vietnam, under the scenario of under-representation in global food value chains (Simmons et al., 2005; Sartorius, 2013, Verhofstadt and Maertens, 2014). Institutional innovations are considered to play an important role in supporting smallholder farmers to overcome market failures and improve their livelihoods (Hazell et al., 2010; Vandeplas et al., 2013). In this connection, contract farming (CF) is considered to be an potential solution to link small-scale farmers to modern marketing channels, support them in increasing household welfare and, consequently reduce rural poverty (Simmons et al., 2005; Minot and Roy, 2007; Maertens and Swinnen, 2009; Barrett et al., 2012; Rao et al., 2012; Sartorius, 2013, Gatto et al., 2017).

In this regard, $\mathrm{CF}$ scheme has been addressed by many earlier studies on smallholder farmers livelihood improvement and poverty reduction (Key and Runsten, 1999; Oliver, 2005; Simmons, 2005; Hongdong, 2007; Maerten and Swinnen, 2009; Miyata et al., 20009; Bellemare, 2012, Wollni and Brümmer, 2012, Rao et al., 2012, Shiferaw et al., 2016). Thereby, previous literature has confirmed such positive contributions of CF schemes through increases in farm performance livelihood (Maerten and Swinnen, 2009; Miyata et al., 20009; Bellemare, 2012, Wollni and Brümmer, 2012, Rao et al., 2012; Maertens and Vande Velde, 2017) besides the influence of different structural farm and socio-demographic farmer characteristics such as rice farming size, educational level of household head as well as rice farming experience (Simmon, 2005; Hongdong, 2007; Schulze et al., 2007; Kersting and Wollni, 2012; Miwambi et al., 2014). The effectiveness of agricultural CF scheme in improving overall farm performance, farm technical efficiency and household livelihood has been approached in several contexts (Schipmann and Qaim, 2011: Rao et al., 2012, Shiferaw et al., 2016). However, how CF scheme influences farmers' performance in emerging and developing economies staple food cropping sectors, especially rice, still remains underexplored in existing literature, even though $\mathrm{CF}$ is considered a promising institutional arrangement for smallholder to overcome under-representation in global food value chains 
and improve smallholders' performance (Oliver, 2005; Bijman, 2008; Kersting and Wollni, 2012; Abebe et al., 2013; Shiferaw et al., 2016, Maerten and Vande Velde, 2017).

Transforming from a major rice importer to one of the worldwide biggest exporters since the late 1990s, Vietnam has become one of the major rice export countries in Southeast Asia (Baldwin et al., 2012; Giraud, 2013, FAO, 2017). However, about 70\% of the rice farmers in Vietnam are small and medium-sized farming households (less than 0.5 ha) with low income of approximately 1USD per day per person (Reardon et al., 2014; USDA, 2015). Thereby the generally relatively low shares of rice quantity traded under contract at the production stage are even decreasing since the turn of the millennium, from about 10\% in 2004 (ADB, 2005), about 4.2\% in 2010 (Loc and Son, 2011) down to 2.12\% in 2013 (Smith, 2013). Since the traditional rice marketing channel involves numerous types of trading partners and is dominated by middlemen and other entities, rice farmers suffer from low bargaining power, low farm-gate prices, and, thus, lower farm income and greater poverty (Saigenji, 2010; Loc and Son, 2011; Wang et al., 2014). Therefor the CF scheme in agricultural production has been officially promoted by the Vietnamese government with the aim to improve farm performance and farmers' livelihood. The Vietnamese export rice sector is relevant due to its representative character for supply chains of globally commercialized commodities with great importance for food security (Chen et al., 2006) simultaneously suffering from loose linkages between smallholder farmers and export companies in a business environment with low value added and low product quality leading to relatively low prices (Nielsen, 2003; Baldwin et al., 2012). It , thus, represents an interesting case under research to obtain further insights on whether $\mathrm{CF}$ schemes in developing and emerging economies export-oriented commodity sectors could support to improve smallholder farm performance and livelihood rural household income, as this is the aim of this study.

The paper extends the existing research literature by focusing on the specific influences of $\mathrm{CF}$ affects in commodity markets. Thereby, we look at the CF status among export-oriented rice farmers production and evaluate the impact of this status on household income and rice profit. We employ ordinary least square (OLS) regression in combination with propensity score matching technique (PSM) to estimate treatment effects of CF scheme on household income and rice profit. We then analyze how the estimated treatment effect varies over various farm and household characteristics and over the propensity score matching level. Survey data of 250 export-oriented rice households in the Mekong River Delta of Vietnam is used of which 134 households have participated in CF scheme with two companies in the recent ten years and 116 non-contract households in the same area. The results reveal that 
contract participation has significantly benefited smallholder rice farmers but that the effect varies with farming size, extension service access, and household size. Based on the results, policy and management implications are derived regarding the development of supporting programs for farmers and agribusiness. The results are specifically interesting for firms, producers and the traders of the raw products (commodity) in emerging and developing countries.

The rest of the paper is structured as follows: section 3.2 introduces the literature review of the related research on $\mathrm{CF}$ topic, especially focusing on searching for research gap among the latest literatures about farm performance in emerging and developing economics. Section 3.3 refers to general information about $\mathrm{CF}$ schemes within agricultural production and export-oriented rice sector in Vietnam. This is followed by section 3.4 which refers to data collection and section 3.5 is about econometric approach including methodology and hypothesis explanation. Study results for the farming households' performances regarding two criteria: household income and rice profit are shown in section 3.6 together with conclusions and policy recommendations.

\subsection{Literature review}

In the academic literature, modern marketing channels and $\mathrm{CF}$ are associated with various benefits for smallholders in developing countries corresponding to different contract-types existing (Soe et al., 2015). For marketing contracts (MC) particularly access to international markets via modern marketing channels at lower sales-related risks (Minot and Sawyer, 2016) are highlighted in the literature. The MC is appropriated when both the producer and the buyer gain from having the terms of sale arranged in advance to respond to price risk or price enhancement (Minot, 2009). MC targets the specifications of quantity and quality of the delivered commodity at a future date, either at a predetermined price or a pricing formula (Gyau et al., 2008). For resource-providing contracts (RC), additional access to newest production inputs (seeds, fertilizers, pesticides) on credit and extension service (RC) is described to be advantageous (Key and Runsten, 1999; Reardon et al., 2009; Otsuka et al., 2016). Resource-providing contracts can only focus on providing inputs and an output market (Bijman, 2008). The producer has full autonomy regarding production decisions (Minot, 2009). This type of contract is considered advantageous when the buyer owns keyinformation about production methods or wants to ensure a certain level of quality or food safety required by export markets. Dries and Swinnen (2004) find that a number of dairy companies in Poland used resource-providing contracts with small-scale farmers which 
motivate dairy farmers to increase land size and machinery inventory. The resourceproviding contract can secure farmers' access to and reduce the costs of obtaining credit, inputs and extension services, including the cost of screening and selecting these services. In the case of production-management contracts (PC) the complementary shift of productionrelated risks to the contractor through the fulfillment of concrete process-specifications might increase smallholder welfare (Abebe et al., 2013). Such PCs include terms on the particular manner in which the commodity is grown such as the planting density, use of pesticides and fertilizer, timing of harvest (Minot, 2009). The PC exists where the buyer supplies and manages all the inputs on the farm and the farmer usually becomes just a supplier of land and labour (Singh, 2000). The production-management contract specifies cultivation practices to achieve quality, timing and low-cost production and thereby supports skills development of the producer, and thereby reduce future transaction costs. Weatherspoon and Reardon (2003) find that farmers in Kenya prefer acquiring PC for export products and $\mathrm{MC}$ for domestic supermarkets since quality and safety requirements on export markets are more stringent.

There is a growing body of studies evidencing contracting activities as beneficial for farmers in developing and emerging countries through resolving several market failures (Simmons et al., 2005; Minot and Roy, 2007; Maertens and Swinnen 2009; Barrett et al., 2012; Rao et al., 2012; Sartorius, 2013; Bellemare and Novak 2017; Gatto et al., 2017). The study by Maerten and Vande Velde (2017) confirms the positive contribution of CF on rice quality, higher farm-gate prices and household income of rice farmers in Benin. Another study about the vegetable export chain in Senegal also finds CF as a scheme to enabling to fulfill highstandards persisting in international trade, which directly contributes to rural incomes and poverty reduction (Maertens and Swinnen, 2009). In addition, there is evidence that CF participation leads to sharing risk for the case of poultry farmers in India which leads to higher profits for contract participants than for non-contract participants due to less variation in yield and lower price volatility (Ramaswami et al., 2005). Warning and Key (2002) evaluate the impact of $\mathrm{CF}$ in the Senegalese peanut production sector, finding an increase in gross margin which is significantly associated to the CF status. Simmons et al (2005) also conclude with a positive contribution of CF in increasing household income and welfare, reducing absolute poverty for poultry and maize seed contractors in Indonesia.

However, the implementation of CF in developing countries still also faces constraints (Rao et al., 2012; Saenger et al., 2014). Thus, earlier research has shown that in developing countries, certain farm and farmer characteristics may advantages some farmers over others 
regarding the participation in CF schemes (Simmons, 2005; Hongdong, 2007). Although agricultural production in those countries is overall based on small and medium-sized farms and most of the farmers are low educated with less farming experience ( Schulze et al., 2007; Kersting and Wollni, 2012; Otter et al., 2014) it's mostly the farm and household characteristics that apart from the CF status also directly positively influence household income, such as farming size, age, household head educational level and rice farming experience that increase the livelihood of CF participation (Bernard and Spielman, 2009; Fischer and Qaim 2012). In this regard, comprehensive research on the inclusiveness of CF schemes simultaneously to its contribution to the improvement of rice farming households' performance in emerging and developing countries is necessary (Barrett et al., 2012; Abebe et al., 2013; Wang et al., 2014; Maerten and Vande Velde, 2017).

\subsection{Background}

As a country based on agricultural production, annually, the Vietnamese agricultural accounts for about $21.8 \%$ of the gross domestic product (GDP), creates about $66 \%$ of the jobs to the population (WB, 2016). Thereby, the rice sector contributes about $20.4 \%$ in total of agricultural value in the year 2016 (WB, 2016). There are two major rice production areas in the county, being the Red River Delta and the Mekong River Delta (MRD) (Linh, 2012). Annually, the MRD accounts for about $55 \%$ of the total rice production quantity, and nearly 90\% of the export rice production quantity (Loc and Son, 2011, Demont and Rutsaert, 2017). In the international rice market, there is a wide range of more than 40,000 different varieties of rice (Gibson and Kim, 2013). The major types are: sticky rice, non-sticky rice, brown rice, white rice, aromatic rice, flavored rice, Sharbati rice, Basmati, Jasmine, glutinous long rice and glutinous short rice. Due to the large number of rice varieties traded internationally, normally, rice exporters decide the export variety, quality and price based on the percentage of broken rice $(5 \%, 10 \%, 15 \%$ or $25 \%)$, which is also common for Vietnamese rice (Demont and Rutsaert, 2017).

Compared the other major competing countries in Southeast Asia, mainly Thailand, on the international rice market the Vietnamese rice exporters perceive competitive advantages due to relative large quantities supplied (Baldwin et al., 2012; Ya'kub et al., 2012). However, Vietnam, as a country which entered the rice world market as an exporter lately at times when the rice price was steadily declining, is also still known as low quality rice supplier receiving 20 to $30 \%$ lower prices than suppliers from Thailand and, thus, caught in the cost leadership position (Reardon et al., 2014; Kubo, 2013). A better differentiation through 
higher product qualities of the rice supplied by Vietnamese exporters to the world market might support them to escape the pure price competition and also lead to better performances among farmers and exporters (Demont and Rutsaert, 2017). Even though, there is overall a large number of rice exporters in Vietnam (more than 100 private enterprises and two statedowned companies) in practice, the Vietnamese rice export sector is dominated by the two state-owned companies, Vinafood I and Vinafood II accounting for $15 \%$ and $41 \%$ of the country's total rice exports respectively (Demont and Rutsaert, 2017). In 2001, the government set targets for the national export volume to control the rice export market, thereby removing of the previous quota allocation for rice exports and fertilizer imports fixed in the so called Doi Moi (renovation) policy reform program from 1986, to strengthen the role of private companies with the goal to transform Vietnam into one of the biggest rice exporters worldwide, thereby upgrading the position of export-oriented rice farmers and contributing to national food security (Loc and Son, 2011; Kubo, 2013; Demont and Rutsaert, 2017). A price control regime applied later on also serve to insulate domestic and export markets from external fluctuations and to reduce transactions costs (Ghosha and Whalley, 2004). As part of the overall reforming of Vietnamese agricultural policy, in 2002 also the decision No 80/2002/QD-TTg dated June $24^{\text {th }}$ named "Policy on the promotion of agricultural produce and purchase through contracts" to promote contractual arrangements between farmers and processors/traders was implemented. This decision included a flexible framework for diverse economic entities of the country, particularly, established a long-term strategy to improve farmers' bargaining power and an official ground for smallholders directly dealing with private sectors. Additionally, the decision No. 80 also clarifies government efforts to support the private sector in supplying agricultural inputs to farmers, such as seeds, fertilizers, pesticides, credit, and extension services (Ya'kub et al., 2012). In order to support the wider implementation of the CF scheme, the circulars 05/2002/TTNHNN by the State Bank and 04/2003/TT-BTC by the Ministry of Finance guiding credit access and financial support were issued. In 2008, the Directive 25/2008/CT-TTg signed by the Prime Minister also serves to enhance the implementation of contract farming. The announcement of other law on associate, cooperative, partnership activities and a large number of supportive programs issued for specific commodities have created a legal frame for CF empowerment. Later on, the decision 62/2013 QD-TTg announced in 2013 for officially promoting the implementation of $\mathrm{CF}$ in agricultural production once again confirms the governmental support for a greater enforcement of this program in long term. 
Accordingly, the report by ADB (2005) also recommends several agricultural supply-chains in Vietnam that would perceive institutional advantages from a wider adoption of the $\mathrm{CF}$ frame such as those of "vegetables, jute and cotton, tobacco, roses, pineapple, and pork". This is supported by Catelo and Costales (2008) who describe the possibility for smallholders in Vietnam to overcome barriers of credit access through $\mathrm{CF}$ participation. Accordingly, within a short time, over $90 \%$ of cotton, over $90 \%$ fresh milk and over $40 \%$ of tea produced for export was commercialized under CF in the year of 2012 (Prowse, 2012; Ngoc and Anh, 2014). In the Vietnamese export rice sector, there are currently only few companies processing and exporting rice procured via contractual arrangements (Saigenji, 2010). Still the major share of the export rice quantities is traded over middlemen and millers (Loc and Son, 2011) and only a small proportion of rice quantity is produced and directly purchased under contract (Smith, 2013) to export and processing companies via CF which leads to the persistence of rather loose linkages between farmers and those companies and, thus, to limited control over the raw product quality (Loc and Son, 2011; Reardon et al., 2014; Key and Runsten, 1999). This sobering observation motivates us to focus on the export rice sector in our study when aiming to find out about the benfits of the Vietnamese $\mathrm{CF}$ scheme and how CF schemes improve farm performance during the time on the farm level.

\subsection{Data collection}

Primary data has been collected in early 2016 in the Mekong River Delta (MRD) of Vietnam where nearly $90 \%$ of the country's export rice is produced. The target population of 250.000 households is located in the three main export rice production regions, namely the Kien Giang, Can Tho, and An Giang provinces in the MRD (USDA, 2015).Using a structured questionnaire, 250 households were chosen from the aforementioned provinces. To thereby ensure the comparability of contract and non-contract farmers and simultaneously asure representativeness of the subsamples, we randomly selected 134 contract farmers from contractor lists and 116 non-contract farmers from official lists of 12 villages' located in the same area as the contract participants. Most of CF participants in the sample produce under resource providing contracts, thus, the contractors are in charge of specifying the production practices including input supply (seeds, fertilizer, pesticides) on credit, technical assistances, and the purchasing commitment (Simmons, 2005; Minot and Sawyer, 2016). In this paper, the export-oriented rice farmers were interviewed about information on farm and household characteristics, agricultural production, off-farm income, household income, rice production, 
credit referring to the three export rice producing seasons in the year from the beginning of November 2014 till the end of October 2015.

\subsection{Economic approach}

\subsubsection{Farm performance}

Based on the previous literature review, farming households' performance (household income and rice profit) is assumed to be influenced by two major categories of determinants. First, determinants representing farm characteristics such as farming area, machine value, other crop assets, and off-farm income are included. These variables are hypothesized to support farm households in responding to the requirements fixed in the contracts (Simmons et al., 2005; Minot and Roy, 2007; Barrett et al., 2012; Sartorius, 2013). The second group of determinants are attributes of household characteristics including household size, gender and age of the household head educational level, information access, telephone ownership, and the membership in farmers associations (FAs) (Wollni and Zeller, 2007; Kersting and Wollni, 2012) which support farmer to do better within CF activities. We expect these indicators to positively support contract participants in increasing household income and rice profit. The two major categories are assumed to directly or indirectly influence farming households' performance (Kersting and Wollni, 2012; Mwambi et al., 2014; Greiner, 2015).

Approaching the "household income" as a dependent variable in our concept is considered to be more appropriate in comparison to "farm income" (Simmons et al., 2005; Minot and Roy, 2007; Bellemare, 2012). This is due to the assumption that contracting households are supplied with modern inputs and, thus, needs less family labor for their farming activities. Since family members who are not involved into rice farming may receive income from other business activities, the household income, in contrast to farm income, reflects also these spillover effects (Simmons et al. 2005; Wollni and Andersson, 2014). The annual household income is defined as the total value generated from farm income (sales of farm crops, livestock products, and poultry) and off-farm income/non-farm income (paid work, small business, and income from gifts, grants, and pension or retirement benefits) deducted by input costs except for the costs of family labor in a period of time (a year) (Mwambi et al., 2014). Additionally, it is necessary to differentiate the rice profit from household income to evaluate the role of contractors for reductions in production costs (Sartorius, 2013). Rice profit is generated from rice production exclusively which is determined by input costs (hired land, hired labor, seeds, fertilizers, pesticides etc.) excluding family labor cost and output benefits (yield, price). 


\subsubsection{Ordinary Least Square (OLS)}

OLS regression is applied to estimate the impacts of contract participation on household income and rice profit. If it is true that farming households' performance is not a fixed constant but influenced by observed and unobserved variables, then, OLS regression is suitable to measure the concrete effect of the treatment $T$ (contract participation or not) on outcome $Y i$. In our analysis two different OLS-regressions are estimated separately: first, $Y i$ is represented by household income and secondly, $Y i$ is represented by rice profit (Aakvik, 2001). $T i$ is measured as a dummy variable with $i=1$ for contract participation and $i=0$ for non-contract participation. The impacts of CF participation, thus, can be estimated as one of the independent variables in the OLS regression (Maertens and Swinnen, 2009). The OLS regression is estimated as follows:

$$
Y_{i=} \beta_{0}+\beta_{1} T_{i}+\beta_{2} X_{i}+\varepsilon_{i}
$$

Given $X$ as the vector of farm characteristics and household characteristics; $\varepsilon_{i}$ represent the error term for respondent $i$. In this regression, the variables presented in the conceptual framework are employed to estimate the influences of contracting status and other indicators on household income and rice profit.

In order to control for unobserved variables as well as sample selection bias, the Durbin and $\mathrm{Wu}$-Hausman test for endogeneity is employed with the hypothesis that the dummy variable for contract participation is exogenous from household income and rice profit (Simmons et al., 2005). Furthermore, the Breusch-Godfrey LM test is applied to control for autocorrelation (Greene, 2002).

\subsubsection{Propensity Score Matching (PSM)}

Since normal OLS regression applied for impact evaluation is very sensitive with regard to the differences in covariates, propensity score matching (PSM) is adequate for correcting potential sample selection bias during the analyses (Caliendo and Kopeinig, 2008; Imbens and Rubin, 2015). Thus, farming households' performance should in principle allow for computing the average treatment effect of CF participation (Li et al., 2008; Bellemare, 2012). PSM is used in our analysis to estimate whether there is the difference in mean value of outcome indicators between contract participants and non-contract participants (Rao et al., 2012). The similar outcome indicators (socio-demographic variables) from both groups except for contract participation status are considered (Huber et al., 2013). Since unobservable indicators which are not included in the model may influence the household outcomes, PSM results in a less biased estimation (Imbens and Rubin, 2015). Thereby, the 
ATE is estimated based on bootstrapping technique as follows in order to make the estimation for the larger population less sensitive (Austin and Small, 2014) :

$$
\mathrm{ATE}=\mathrm{E}(\Delta \mid D=1)=\mathrm{E}\left(Y^{1} \mid D=1\right)-\mathrm{E}\left(Y^{0} \mid D=0\right)
$$

Where, $\mathrm{E}\left(Y^{1} \mid D=1\right)$ represents the outcome for the contract farmers and $\mathrm{E}\left(Y^{0} \mid D=0\right)$ represents the outcome for the non-contract farmers. Technically, we take into consideration the variables that significantly influence household income and rice profit in the OLS regressions. In combination with the binary model (probit model), we follow Marco and Kopeinig (2008) in employing three methods of estimating PSM to estimate the fundamental lack of comparability between the groups, namely nearest-neighbor matching, Radius matching, and Kernel matching, due to the differences in the propensity score of the outcomes.

Based on the ATE results, we continue to estimate the ATET to evaluate PSM results and to measure how reliable ATE results are, which is required to adjust for the differences in covariate distribution within the two samples (Abadie and Imbens, 2009). The evaluation framework of ATET is based on the potential outcomes (household income and rice profit) of the individual rice farmer and the treatment indicator (contract participation). Given $D i$ as the binary variable represented for the treatment indicator, then $D=1$ indicates contract participation and $D=0$ non- participation. The potential outcome is defined as $Y i(D)$ for each individual contract participant. If we could observe household $i$ in both situations of contract participation and non-contract participation, then the changes in the outcomes (household income and rice profit) of household $i$ should be:

$$
\Delta Y_{i}=Y_{i}(1)-Y(0)_{i}
$$

However, the question is how an individual household $i$ would have performed without contract participation. Thus, for a contract participant, we observe $\operatorname{Yi}(1)$, while $\operatorname{Yi}(0)$ is the unobserved outcome (counterfactual outcome) which can be considered as the missing data problem. ATET estimation can account for this problem and allows to estimate the missing data of a set of random conditional covariates (Wooldridge, 2007). The corresponding equation is interpreted in the followings:

$$
\mathrm{ATET}=\mathrm{E}(Y(1)-Y(0) \mid D=1)=\mathrm{E}(Y(1) \mid D=1)-\mathrm{E}(Y(0) \mid D=1)
$$

Thus, $\mathrm{E}[\mathrm{Y}(0) \mid \mathrm{D}=1]$ represents the unobserved outcomes for the contract participants (Duy and Flaaten, 2016). 


\subsection{Results and Discussion}

\subsubsection{Descriptive Statistics}

Table 3.1 shows the general statistics for the included variables in the estimated models. For the first criteria regarding to farm characteristics, it can be seen from the table that the total rice farming area is about 3.36 ha. While the average live-stock ownership is rare, machinery plays an important role during rice farming activities. The paddy farm-gate price per kilo gram is about VND5150 VND (about USD0.23). The income from other crops and off-farm activities contribute about VND14.086 million (around USD640.2) and VND40.550 million (around USD1843.1) per year, respectively. For the second category of variables, the average educational level of household head is about 8.12 years, the rate of telephone ownership is rather high (91.2\%) and the distance to the nearest market is about $2.93 \mathrm{~km}$ on average. In the second category of variables, the number of household members is 1.79 on average. The mean age of the household head is 46.67 years. Rice farmers in the area have an average of 23.39 years rice farming experience. Remarkably, the number of households having access to credit is with $37.6 \%$ rather low in comparison with the other area of the country. In addition, $94.40 \%$ of the export rice farming households is headed by males.

Using $t$-tests, we compare participants in $\mathrm{CF}$ to non-contract participants regarding the differences in major categories including farm characteristics and household characteristics. It can be seen from the results that there is strong difference between the two groups in some major characteristics such as: household income, rice profit, output price, information accessibility and farming experience. For the category farm characteristics, the results show that there is significant difference in mean values of the selected variables such as: rice farming profit, household income, and producer price for paddy between the contract participant and non-contract participant groups. Higher producer price for paddy received by contract farmers (significant at $\mathrm{p}<0.01$ ) indicates that those farmers are benefiting from fairprice frames offered by the contracting companies in comparison to the spot market. This could on the one hand be explained by low bargaining power of farmers on the free exportoriented rice market (spot market/traditional channels) and on the other hand by missing market information (Jia and Bijman, 2013). 
Table 3.1. Descriptive statistics for the variables included in the estimations

\begin{tabular}{|c|c|c|c|c|c|c|c|c|}
\hline \multirow[b]{2}{*}{ Variable } & \multirow[b]{2}{*}{ Description } & \multicolumn{2}{|c|}{ Total sample $(\mathrm{N}=250)$} & \multicolumn{2}{|c|}{$\begin{array}{l}\text { Non-contract farmers } \\
(\mathrm{N}=116)\end{array}$} & \multicolumn{2}{|c|}{$\begin{array}{c}\text { Contract farmers } \quad(\mathrm{N} \\
=134)\end{array}$} & \multirow[t]{2}{*}{ T-test } \\
\hline & & Mean & $\begin{array}{l}\text { Std. } \\
\text { deviation }\end{array}$ & Mean & $\begin{array}{l}\text { Std. } \\
\text { deviation }\end{array}$ & Mean & $\begin{array}{l}\text { Std. } \\
\text { deviation }\end{array}$ & \\
\hline & Farm characteristics & & & & & & & \\
\hline Agarea & Total farm size (ha) & 3.390 & 2.460 & 3.301 & 2.254 & 3.467 & 2.563 & -0.532 \\
\hline Ricefarm & Rice farming area (ha) & 3.361 & 2.460 & 3.297 & 2.256 & 3.417 & 2.563 & -0.391 \\
\hline Machine & Farming machinery using (number) & 1.656 & 1.302 & 1.69 & 1.296 & 1.63 & 1.312 & -0.180 \\
\hline Nonrice & Non-rice income (million VND) & 14.086 & 63.498 & 19.315 & 64.118 & 9.665 & 63.082 & 1.197 \\
\hline Rice profit & Rice farming profit (million VND) & 169.295 & 138.714 & 140.993 & 114.216 & 193.795 & 153.102 & $3.051 * * *$ \\
\hline Income & Household income (million VND) & 230.819 & 158.960 & 201.947 & 133.022 & 255.813 & 175.073 & $2.706 * *$ \\
\hline Avpadprice & Average paddy farm-gate price (1000VND/kg) & 5.15 & 0.681 & 4.99 & 0.639 & 5.35 & 0.75 & $4.304 * * *$ \\
\hline Offarm & Off-farm income (millionVND) & 40.550 & 68.329 & 34.617 & 64.303 & 45.690 & 71.473 & -1.280 \\
\hline \multirow[t]{2}{*}{ Livestock } & Livestock ownership (number) & 16.184 & 103.878 & 23.87 & 144.301 & 9.52 & 45.849 & -1.197 \\
\hline & Household characteristics & & & & & & & \\
\hline Edulevel & Schooling years of HH head (1-15 years) & 8.128 & 2.956 & 7.93 & 2.90 & 8.3 & 3.00 & -0.980 \\
\hline Tele & Ownership of a telephone $(1=$ yes $)$ & 0.908 & 0.2896 & 0.89 & 0.30 & 0.91 & 0.28 & -0.221 \\
\hline Wprice & Accessibility of world market price information ( $1=$ yes) & 0.456 & 0.4990 & 0.38 & 0.045 & 0.50 & 0.043 & $3.891 * *$ \\
\hline Lastprice & Accessibility of last price information ( $1=$ yes) & 0.582 & 0.500 & 0.49 & 0.502 & 0.56 & 0.498 & 1.077 \\
\hline Orghhmb & Membership in Farmer Associations ( $1=$ yes) & 0.152 & 0.3597 & 0.103 & 0.30 & 0.186 & 0.39 & $1.9997 * *$ \\
\hline Extservice & Accessibility of extension services ( $1=$ yes $)$ & 0.456 & 0.4990 & 0.39 & 0.489 & 0.51 & 0.502 & $2.019 * *$ \\
\hline Distance & Distance to the nearest market $(\mathrm{km})$ & 2.9 & 2.1 & 3.05 & 2.18 & 2.83 & 2.05 & 0.80 \\
\hline Age & Age of household head (years) & 46.676 & 10.58 & 46.6 & 11.04 & 46.74 & 11.04 & -0.101 \\
\hline Ricexper & Rice farming experience (years) & 23.396 & 10.24 & 24.67 & 10.90 & 22.29 & 9.52 & $1.843^{*}$ \\
\hline Hhsize & Number of farming members & 1.79 & 0.697 & 1.9 & 0.71 & 1.7 & 0.67 & $2.019 * *$ \\
\hline Credit & Accessibility of credit (1= yes) & 0.376 & 0.4853 & 0.37 & 0.485 & 0.38 & 0.488 & -0.207 \\
\hline Gen & Household head is male & 0.944 & 0.2303 & 0.93 & 0.254 & 0.96 & 0.208 & -0.827 \\
\hline
\end{tabular}

Note: $* p<0.10, * * p<0.05, * * * p<0.0$ 
Also the second category of variables including the major demographic variables which are expected to affect the contracting decision is tested. Regarding the number of households' farming members, the non-contract group has higher percentage of household members involved in farming activities (significant at $\mathrm{p}<0.05$ ) in comparison to the contract group even though the total farm-size does not differ significantly among the groups. This result can be explained with the support of extension services and the access to high quality inputs $\mathrm{CF}$ farmers perceive which leads to lower family labor demand in comparison to noncontract farmers and confirm the existing study results (Simmons et al., 2005). The significantly negative effects of "rice farming experience" variable could be interpreted insofar that farmers, especially, smallholder in rural and low developed areas, who have more experience in rice farming are less willing to change their farming habit from conventional to modern marketing strategy.

\subsubsection{Effects of CF participation on household income and rice profit}

Based on the OLS regression results, we find that there are many factors significantly affecting both household income and rice profit of farmers involved in the export-oriented rice production (see table 3.2). Indicators such as "contract participation", "rice farming area", "accessibility of extension services", and "accessibility of world market price information" are reported as the most important determinants influencing farming households' performance. Firstly, there can be observed a strong influence of CF participation on household income $\left(\beta=2.63^{*}\right)$, and rice profit $\left(\beta=3.28^{* *}\right)$, as hypothesized. These results reconfirm the statements from previous literature that participating in CF helps smallholders to increase household income and rice profit, respectively (Simmons et al., 2005; Minot and Roy, 2007; Bellemare, 2012). Particularly, in comparing with the mean values of variables and the calculation in table 3.2 and table 3.5, the results illustrates that "contract participation" supports rice farmers to increase their household income by $20.87 \%$ and rice profit by $30.54 \%$. Secondly, the OLS results confirm the positive and significant influence of the "rice farming area" on household income $\left(\beta=0.43^{* * *}\right)$, and rice profit $\left(\beta=0.45^{* * *}\right)$ (Simmons et al., 2005; Reardon et al., 2014). This also proves the existence of economies of scale due to cost optimization in production processes. The OLS regression also confirms the influence of extension services on household income $\left(\beta=6.25^{* * *}\right)$ and rice profit $\left(\beta=6.04^{* * *}\right)$. The $1 \%$ significance level of the extension service variable once again is in line with previous studies (Da Silva, 2005; Simmons et al., 2005; Mwambi et al., 2014). Extension service support, in particular, technical assistances, advisory services, 
transportation services, financing, quality monitoring and other services are found to positively affect farming households' performance in this study. Surprisingly, the membership in FAs only influences household income $\left(\beta=6.65^{* * *}\right)$, but not the rice profit $(\beta=0.44)$. This can be interpreted insofar that households preferred to get access to the market information, extension services and other technical assistances conducted by contractors within the CF scheme than by FAs. Finally, the educational level also significantly influences household income $\left(\beta=0.65^{*}\right)$ but not rice profit $(\beta=0.25)$ which can be explained by off-farm employment of higher educated household members contributing to the household income, but not through rice production.

Table 3.2. Regression results on household income and rice profit

\begin{tabular}{|c|c|c|c|c|}
\hline \multirow[t]{2}{*}{ Variables } & \multicolumn{2}{|c|}{ Household Income (I) } & \multicolumn{2}{|c|}{ Rice Profit $(\mathrm{P})$} \\
\hline & coef. & $\mathrm{t}$ & coef. & $\mathrm{T}$ \\
\hline Contract (1=yes) & 2.63 & $1.81 *$ & 3.28 & $3.07 * *$ \\
\hline Agarea (m2) & 0.43 & $14.78 * * *$ & 0.45 & $21.39 * * *$ \\
\hline Distance (km) & 0.53 & 1.50 & 0.27 & 0.99 \\
\hline Edulevel (1 to 15$)$ & 0.65 & $2.54 * *$ & 0.25 & 1.35 \\
\hline Extservice (1= yes) & 6.25 & $2.73 * *$ & 6.04 & $4.11 * * *$ \\
\hline Ricexper & 0.087 & 1.11 & 0.017 & 0.26 \\
\hline Hhsize (persons) & -0.2608 & -0.31 & -0.45 & -0.64 \\
\hline Orghhmb (1= yes $)$ & 6.65 & $3.45 * * *$ & 0.44 & 0.32 \\
\hline Wprice $(1=$ yes $)$ & 3.70 & $2.36 * *$ & 2.38 & $2.1 * *$ \\
\hline Lastprice $(1=$ yes $)$ & 1.88 & 1.03 & 7.40 & 0.55 \\
\hline $\mathrm{N}$ & & 250 & & 250 \\
\hline $\mathrm{F}(10,240)$ & & 30.10 & & 52.56 \\
\hline R2 & & 0.5574 & & 0.6874 \\
\hline Adjusted R2 & & 0.5389 & & 0.6743 \\
\hline Prob> Chi2 & & 0.1388 & & 0.0144 \\
\hline Prob $>F$ & & 0.0000 & & 0.0000 \\
\hline VIF & & 1.24 & & 1.24 \\
\hline
\end{tabular}

Note: $* \mathrm{p}<0.10,{ }^{*} * \mathrm{p}<0.05, * * * \mathrm{p}<0.01$, Unit: million VND

Source: authors owned calculations.

Regarding the endogeneity of contract participation status on household income and rice profit, the Durbin and Wu-Hausman test results (see table 3.3) show the significant level of the estimations. For the hypothesis that the instrument variables are exogenous, the Durbins score $\left(17.244^{* * *}\right)$ and Wu-Hausman $\left(18.3^{* * *}\right)$ for household income and Durbins score $(7.93 * * *)$ and Wu-Hausman $(8.09 * * *)$ for rice profit indicators are acceptable for the endogenous test and in line with the OLS results. These tests once again confirm the positive influence of CF participation on household income and rice profit within export-oriented rice farmers. 
Table 3.3. The Durbin and Wu-Hausman test for endogeneity of contract participation

\begin{tabular}{|c|c|c|c|}
\hline & & Durbin score $\mathrm{Chi}^{2}$ & Wu-Hausman F(1,247) \\
\hline \multicolumn{4}{|l|}{ HH income } \\
\hline & & 17.244 & 18.3 \\
\hline $\mathrm{p}$-value & & $0.000 * * *$ & $0.000 * * *$ \\
\hline $\mathrm{n}$ & 250 & & \\
\hline Coef. & 317.212 & & \\
\hline Z & $3.66 * * *$ & & \\
\hline Prob $>\mathrm{Chi}^{2}$ & 0.0003 & & \\
\hline Wald $\mathrm{Chi}^{2}$ & 13.36 & & \\
\hline \multicolumn{4}{|l|}{ Rice profit } \\
\hline & & 7.93 & 8.09 \\
\hline $\mathrm{p}$-value & & $0.0048 * * *$ & $0.0048 * * *$ \\
\hline n & 250 & & \\
\hline Coef. & 208.080 & & \\
\hline $\mathrm{Z}$ & $3.13^{* * *}$ & & \\
\hline Prob> $\mathrm{Chi}^{2}$ & 0.0017 & & \\
\hline Wald $\mathrm{Chi}^{2}$ & 9.8 & & \\
\hline
\end{tabular}

\subsubsection{Propensity score matching}

The ATE results calculated for both groups of farmers with similar characteristics except of contract participation significantly fit with our hypothesis. By selecting nearest-neighbor matching algorithm in the PSM estimation, the ATE results confirm that the differences in household income and rice profit among contract participants and non-contract participants are significant at the $1 \%$ level and the results perfectly fit and satisfy the requirement of $1: 1$ level of comparison (min: 1, max: 1) (see table 3.4).

Table 3.4. Average Treatment Effects (ATE) estimations

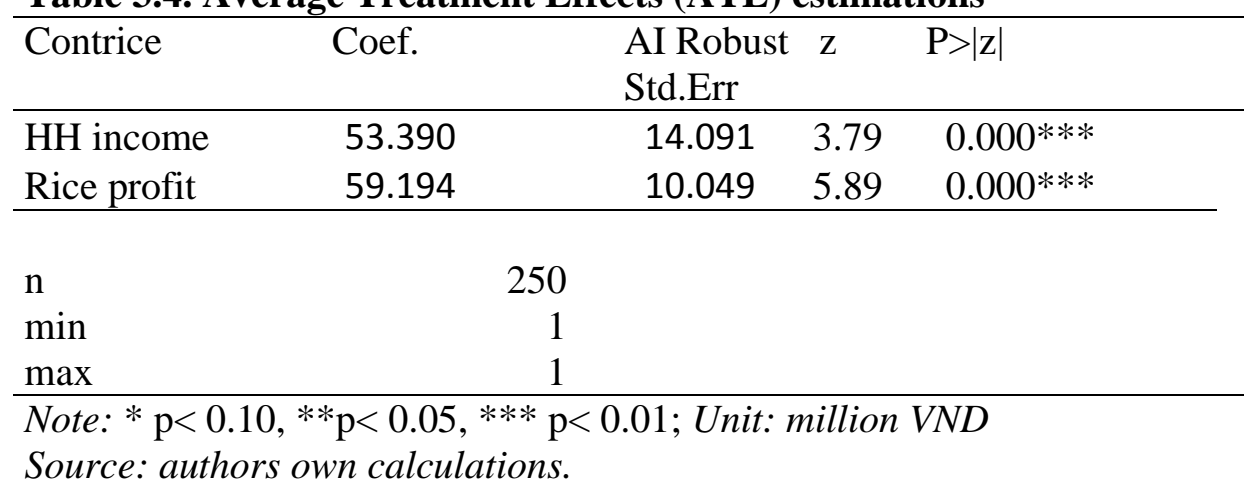

Given the similar socio-demographic characteristics of both groups, the propensity score of the comparison before and after matching shows that the differences in both household income and rice profit are resulting from the CF participation. These figures also confirm the 
OLS regression results insofar that CF participation strongly supports smallholders farm benefits represented by the two attributes: household income and rice profit (Mwambi et al., 2014). Table 3.5 illustrates the positive contribution of the CF program on households' income and rice profit (at $1 \%$ level of significance). In particular, the contracting status helps them to increase the average household income by USD2.519,3/year and to contribute with USD2.793,06/year to the average rice profit (see table 3.4). In comparison the mean value of household income and rice profit of both groups (see table 3.1) with the ATE results in 3. 4, it becomes evident that contract participation supports households to increase their income by $20.87 \%$ and rice profit by $30.54 \%$ higher than non-contract farmers. This result once again confirms the previous literature about the positive impacts of contractual arrangement on household welfare is convincible.

Based on the ATET syntax, the balancing property is satisfied (see table 3.5). Regarding the results of nearest-neighbor matching, Radius matching, and Kernel matching, the average treatment effects on treated are positively satisfied. The number of block is higher than 5 (the minimum acceptable score). The significant levels in the three procedures also confirm the differences in mean values of both groups. 
Table 3.5. Average Treatment Effects on Treated and PSM by matching algorithm

\begin{tabular}{|c|c|c|c|c|c|c|}
\hline & \multicolumn{2}{|c|}{ NN matching } & \multicolumn{2}{|c|}{ Radius Matching } & \multicolumn{2}{|c|}{ Kernel Matching } \\
\hline & ATT & t-stat & ATT & t-stat & $\overline{\text { ATT }}$ & t-stat \\
\hline \multicolumn{7}{|l|}{$\mathrm{HH}$} \\
\hline income & $51.526(16.357)$ & $3.150 * * *$ & $54.385(11.052)$ & $4.921 * * *$ & $51.830(20.705)$ & $2.503 * *$ \\
\hline Rice profit & $55.487(20.499)$ & $2.707 * *$ & $49.940(8.420)$ & $5.931 * * *$ & $53.891(21.947)$ & $2.455 * *$ \\
\hline \multicolumn{7}{|c|}{$\begin{array}{l}\text { The final number of blocks is } \\
6 \\
\text { The region of common support is }[.26560052, .86424676]\end{array}$} \\
\hline \multicolumn{7}{|c|}{ The balancing property is satisfied } \\
\hline
\end{tabular}




\subsubsection{Conclusions and Policy Recommendations}

It was the aim of this study to analyze the effect of CF participation on rice farming profits and household incomes of smallholder farmers in the Mekong River Delta of Vietnam. We employed data from a sample of 250 households living in the three main export rice production regions namely the Kien Giang, Can Tho, and An Giang provinces using OLS regression and PSM. The results reveal that contracts have significantly benefited smallholder farmers that participated in the contract schemes. Furthermore, the OLS and PSM address a strong influence of CF participation on household income and rice profit. It is also interesting that not only larger-scale farmers but also small-scale farmers can benefit from contract participation. In this connection, the findings give noticeable evidence for the role of CF in improving household income by $20.87 \%$ and rice profit by $30.54 \%$ of smallholders and contribute to reduce the rural poverty in the country.

In addition, we found some major socio-economic characteristics that strongly effect households' performances. Among the groups, we found that the non-contract group has higher percentage of household members involved in farming activities in comparison to the contract group even though the total farm-size does not differ significantly among the groups. This result can be explained so far that with the technical support and high quality inputs from contractors, perceived by CF participants perceived lead to lower family labor demand in comparison to non-contract farmers (Simmons et al., 2005). In addition, the significantly negative effects of "rice farming experience" variable also revealed that smallholders in rural and low developed areas, who have more rice farming experiences, are less willing to change their farming habit from conventional to contract schemes. Educational levels, in contrast, do not play any role in this contracting process. Furthermore, not only "contract farming participation" status play an important role in improving rice profit and household income but also "farming size", "the accessibility of extension services" and "the accessibility of world price information" are found as the important determinants that significantly influence on farming households' performance.

The positive contribution of contract farming scheme on smallholders' performance found in this study is in line with recent research about contract farming among export-oriented rice sector in Vietnam (Tuan, 2012) and existing literature on the positive contribution of contract farming in general (Simmons et al., 2005; Minot and Roy, 2007; Barrett et al., 2012; Rao et al., 2012; Sartorius, 2013; Gatto et al., 2017). Due to the economic benefits resulting from $\mathrm{CF}$ scheme in the Vietnamese export rice production sector, a further development and 
enhancement of the Vietnamese CF scheme fixed in the decision No. 80/2002/QD-TTg named "Policy on the Promotion of Agricultural Produce and Purchase through Contracts" and decision 62/2013 QD-TTg is greatly suggested.

Findings in this paper are based on cross-sectional data that has been collected for rice production during one year since $\mathrm{CF}$ is in a very early stage of implementation in Vietnam currently preventing the accessibility of panel data. However, a long term observation with panel data over three or five years would offer deeper insights into Vietnam's CF scheme in the export rice sector. Thus, future research based on farm level data is needed to compare long-term and short-term effects of $\mathrm{CF}$ on rice production among smallholders. In this regard, there should be follow up studies on the influence of CF duration on households' performance within Vietnamese export-oriented rice sector which captures the households' behaviors during a certain time to observe how CF empowers, respectively. 


\title{
4. Contract farming effects on technical efficiency of the export-oriented rice production sector in Vietnam ${ }^{5}$
}

\begin{abstract}
Measures to increase technical efficiency in emerging and developing economies' agriculture have received great attention from governments, NGOs, private firms and researchers in times of urgent need for poverty reduction, globally increasing demand for food and growing resource rivalry in the world. A cross sectional sample of 250 Vietnamese export-oriented rice households is employed to investigate if contract farming improves farming technical efficiency in the country. Stochastic Frontier Analysis was applied to estimate the production frontier and technical inefficiency determinants and Propensity Score Matching is used to control self-selection bias. The results show an average technical efficiency score of $87.33 \%$ and suggest there are convincing opportunities for farmers to increase productivity of export-oriented rice in the country by nearly $13 \%$. Expenditures on seed, land, and fertilizer are the key determinants of the technical efficiency level in this region. The results reveal the positive relationship between contract farming participation and technical efficiency improvement.
\end{abstract}

Keyword: export-oriented rice sector, contract farming, stochastic frontier analysis, technical efficiency, Vietnam.

\footnotetext{
${ }^{5}$ This paper is a joint work with Ludwig Theuvsen, Caetano Luiz Beber and Verena Otter; the Department of Agricultural Economics and Rural Development, University of Goettingen, Germany.

*The own contribution to this paper is $70 \%$.
} 


\subsection{Introduction}

Under the pressure of increasing global demand for food, growing resource rivalry and the need for poverty reduction, the improvement of agricultural productivity, gains in efficiency, and more sustainable production methods in smallholder agriculture are considered to be of great importance for the rural poor in developing and emerging economies in order to generate higher incomes (GIZ, 2013). Simultaneously, improving agricultural efficiency and productivity in developing countries might counter overuse of natural resources as a result of the sharp increase in world population and changing consumer patterns (Demont, 2017; Zulfiquar et al., 2017). In this regard, there have been a large number of research studies analyzing the determinants of technical efficiency (TE) in agricultural production. Some of these studies focus on the role of contract farming (CF) participation as an important facilitator of TE (Battase and Broca, 1997; Eaton and Shepherd, 2001; Swain, 2008; Rahman et al., 2009; Rao et al., 2012; Wollni and Brümmer, 2012; Sartorius, 2013). In general, CF has been greatly encouraged by governments, NGOs, and private firms from developing and emerging economies to achieve higher productivity and efficiency through provision of agricultural extension services, higher quality inputs and credit access in a process of vertical integration in modern supply chains (Hernandez et al., 2006; Reardon et al., 2009).

Rice, which is a worldwide, commercialized commodity and a vital food for about a half of the world population. In addition, $22 \%$ of caloric intake by the global population mostly comes from small-scale farming households in emerging and developing countries (Chen et al., 2006; Giraud, 2013). Even though increasing rice TE in emerging and developing economies therefore receives great attention by governments, NGOs, private firms from developing and emerging economies and researchers (Coelli; Ramaswami et al, 2005; Kolawole, 2006; Duy and Flaaten, 2012; Otsuka, 2016; Demont, 2017), only few studies focus on rice farming TE in developing countries and even fewer investigate the effects of CF schemes in this connection (Tana et al., 2010; Bellenare, 2015; Ochieng et al., 2017; Shifera et al., 2016). These studies come to the conclusion that participating in a CF scheme has significant effects on farming TE among rice farming households, however they do not cover countries in South-East Asia which represent a large share of the worlds' rice production (Baldwin, 2012, Demont, 2017).

Among the major rice farming countries in Southeast Asia - Cambodia, Indonesia, Laos, Malaysia, Philippines, Thailand and Vietnam - especially Vietnam is characterized by very favorable natural and social conditions for irrigated rice production in bulk such as; high soil 
quality, tropical monsoon weather, numerous water-flows and a large share of more than $70 \%$ of the population working in the agricultural sector (Reardon et al., 2014; USDA, 2016). Due to the lack of information, the shortage of technical assistance and low input qualities, it is assumed that there is still high potential to improve the country's rice yields, e.g. by further promoting the $\mathrm{CF}$ scheme introduced by the Vietnamese government in 2002 (Kompas, 2002; Huynh and Yabe, 2011; Hoang and Yabe, 2012; Vu, 2012). Even though, existing empirical literature has investigated TE in the Vietnamese rice production sector from various perspectives such as by analyzing environmental effects on profit efficiency (Hoang and Yabe, 2012), vocational training effects on TE (Ulimwengu and Badiane, 2010), rice farming TE determinants (Khai and Yabe, 2011; Linh, 2012), and market reform effects on TE (Kompas, 2002), the effects of CF on the TE in this sector have still been neglected.

To close this research gap, this study aims at evaluating the influence of CF participation on farming technical efficiency and assessing the technical inefficiency determinants in the export-oriented rice sector in the country. In line with the existing literature, the conceptual framework was developed based on a Stochastic Frontier Analysis (SFA) including a production frontier and technical inefficiency determinant analysis. Propensity score matching (PSM) has been included to control for self-selection bias. The empirical study is based on a sample including 250 export-oriented rice households in the Mekong River Delta of Vietnam of which 134 are CF-participants over past 10 years or more and 116 are nonCF-participants in the same area. The research contributes the first analysis on TE in the Vietnamese rice exporting farming sector with special focus on the influences of CFparticipation in the body of previous studies. Finally, based on the empirical findings, policy implications are derived regarding the development of supporting programs for farmers and agribusiness to improve rice farming TE level.

This paper is structured as follows: after the introduction, Section 2 introduces a general background of existing studies about rice production in Vietnam and the role of $\mathrm{CF}$ for improving farm TE in emerging and developing countries and the economical characteristics of the export-oriented Vietnamese rice production. In Section 3, study design and methodology are presented. Section 4 describes the results and discussion. Finally, the last section draws up the major findings, conclusions, and policy recommendations of the paper. 


\subsection{Background}

\subsubsection{Economical characteristics of the export-oriented Vietnamese rice production sector}

Since the late 1990s, Vietnam has developed from being a larger importer of rice to the second largest rice exporter from Southeast Asia, supplying about $20 \%$ of total quantity of rice traded globally in 2015 (Baldwin et al., 2012; Giraud, 2013; USDA, 2015). Since Vietnamese rice is exported to nearly 100 countries and territories around the world, rice is nowadays one of the countries' largest export commodities by quantity (Ya'kub et al., 2012; FAO, 2013; Ha, 2013). The Vietnamese rice farming area covers about 7.7 million hectares on which rice is planted in three different irrigated seasons per year (Tran, 2016). In 2015, the country produced more than 28.07 million tons of milled rice in total with an average rice yield of about 5.77 tons per ha (see Table 1). Thereof, roughly 7.0 million tons were exported, contributing approximately $5.5 \%$ to national GDP growth (USDA, 2015). Due to its vital role, rice production contributes a great deal to rural livelihoods of which, $80 \%$ of the 11 million farming households participate in rice production (Tran, 2016).

As presented in Appendix 1, Vietnam stands at the highest position among the Southeast Asian exporters regarding average rice yield and records twice as high yields per ha (134\%) as the country with the lowest yield, Cambodia. Since 1993, Vietnam has experienced annual increases in rice production quantities averaging about 0.8 million tons and resulting in an overall doubling of annual paddy production by 2016. This may be caused by the fact that Vietnamese rice production is also associated with intensive cultivation methods including high input levels of fertilizer and seed in comparison to other Asian countries (Liese et al., 2014; Tran, 2016).

In Vietnam, the Mekong River Delta (MRD) and Red River Delta (RRD) are the two leading rice farming regions of the country. The MRD is dominant in Vietnam with regard to the quantity of rice produced for export, in contrast to the RRD in which rice is mainly produced for domestic markets (VIETTRADE, 2008). The MRD region includes 12 provinces with a total population of 17.4 million people. A large share of the GDP contribution in this region stems from agriculture, forestry, and fisheries (about 41\%) (Smith, 2013). Rice production is one of the major farm activities in the MRD accounting for about 2.1 million ha of the total 4 million ha of agricultural land. Over this paddy area about 38 million tons of rice are produced during three cropping seasons per year contributing approximately $51-55 \%$ of quantity to national rice production and $90 \%$ of the country's rice exports by quantity (Loc and Son, 2011; Liese et al., 2014). The MRD has a tropical climate with dry and rainy 
seasons around the year, which is suitable for three harvests of rice with the main rice season from November to March. Together with rice farming, households in the area also produce different green vegetables, livestock, and aquaculture, but most of these outputs are for selfconsumption. Apart from farming, they also participate in small scale local trading and other off-farm activities.

An Giang, Can Tho, Dong Thap, and Kien Giang are the major rice producing provinces recording very high yields in the MRD region (see Table 4.1). For instance, in 2015, with 6.33 tons per hectare on average, An Giang province reached the highest yield of paddy in the country. In the winter-spring cropping season, which provides the best rice production conditions, most of the leading rice production provinces achieve even higher average yields of more than 7.2 tons per hectares (Smith, 2013; Nguyen, 2016).

Table 4.1 Vietnamese rice yields by different regions (ton/hectare)

\begin{tabular}{lllllll}
\hline \multicolumn{1}{c}{ Region } & 2010 & 2011 & 2012 & 2013 & 2014 & 2015 Prel. \\
\hline The country & 5.34 & 5.54 & 5.64 & 5.57 & 5.75 & 5.77 \\
1. Mekong River Delta & 5.47 & 5.68 & 5.81 & 5.76 & 5.94 & 5.96 \\
An Giang & 6.23 & 6.31 & 6.31 & 6.27 & 6.43 & 6.33 \\
Kien Giang & 5.44 & 6.35 & 5.91 & 5.80 & 6.01 & 6.06 \\
Can Tho & 5.71 & 5.80 & 5.78 & 5.79 & 5.89 & 5.91 \\
2. Red River Delta & 5.92 & 6.09 & 6.04 & 5.89 & 6.02 & 6.06 \\
3. Northern midlands and mountain areas & 4.63 & 4.77 & 4.82 & 4.74 & 4.85 & 4.87 \\
4. North Central and Central coastal areas & 5.07 & 5.32 & 5.44 & 5.36 & 5.66 & 5.62 \\
5. Central Highlands & 4.78 & 5.76 & 4.96 & 4.95 & 5.24 & 5.1 \\
6. South East & 4.48 & 4.64 & 4.75 & 4.80 & 4.94 & 5.03 \\
\hline
\end{tabular}

Sources: $(G S O, 2016)$

However, the Vietnamese export rice sector is nowadays facing great challenges in competing on the global rice market especially from other emerging and developing countries regarding production quantities and prices (Nielsen, 2003; Baldwin et al., 2012; Reardon et al., 2014; USDA, 2015). About $40 \%$ to $50 \%$ of the cost of exportable rice are related to fertilizer and agro-chemical expenditure so the high pressure of increasing production cost in the Vietnamese export rice sector means it can no longer rely on low cost competitiveness (Demont and Rutsaert, 2017). Additionally, under the recent government program, the Vietnamese rice farming area is expected to decline due to the promotion of corn and soybean crops (Smith, 2013). The government is targeting marginal yielding rice land for this conversion program. Both winter and autumn crops have lost approximately 20,000 hectares each for corn and soybean cultivation since 2016 (USDA, 2015). In order to deal with these issues, increases in TE and productivity are necessary to maintain rice production and export quantities (Young et al., 2002; USDA, 2015). 


\subsubsection{Contract farming in the Vietnamese agricultural sector}

As a consequence of the renovation policy reform program established in the year 1986 and the removal of rice fertilizer export and import quota allocation in 2001, Vietnam has transformed into one of the largest rice exporters worldwide (Pohl and Nielsen, 2002; Loc and Son, 2011). Additionally, a price control regime and export quotas applied from the mid1990 served to protect domestic and export markets from external fluctuations (Ghosha and Whalley, 2004). In 2002, the decision No 80/2002/QD-TTg dated June $24^{\text {th }}$ was issued by the Vietnamese government to officially promote contractual arrangements between farmers and private sector actors including processors, traders, retailers and exporters. A flexible institutional arrangement was developed for diverse economic entities in the national agricultural sector. As a result, an official long term strategy was established to improve the bargaining power of farmers in the relationship with the private sector. With regard to firm benefits, this policy also formulated the government intentions to support the private sector by selling key agricultural inputs to farmers directly (Ya'kub et al., 2012). Additionally, those policies aim to support secure national food demand and achieve competitive advantages on the world markets (Goletti et al., 1997; ADB, 2005).

Due to supportive policies, farmers in various agricultural sectors of Vietnam have paid more attention to the CF scheme forming a basis for Vietnam's agriculture. Consequently in 2005 , about $90 \%$ of fresh milk and cotton and $50 \%$ of tea were sold under contracts (Da Silva, 2005; Tuan, 2012; Demont, 2017). However, up to now only a small and even declining share of rice quantity is purchased under contract; about 10\% in 2004 (ADB, 2005), about 4.2\% in 2010 (Loc and Son, 2011), and 2.12\% in 2013 (Smith, 2013) as several reports reveal. In the year 2014, from more than 100 rice exporting enterprises, including two state-owned companies, there were only 15 companies offering contract arrangements to rice farming households (Vinh and Dinh, 2014). Currently, being over-dependent on traditional marketing channels could be one of the reasons for the companies' limited control over raw product quality as well as their problems in capturing high-value export markets (Oliver, 2005; Hernandez et al., 2006; Dries et al., 2009; Loc and Son, 2011; Vinh and Dinh, 2014). In the study area, i.e. the MRD, there are two major contractors namely LocTroi Group (An Giang Plant Protection Joint-Stock Company- AGPPS) and Gentraco providing written CF arrangements to rice farmers. In 2015, Gentraco implemented the GlobalGAP standard and branded products in the area to promote higher quality rice production. Other 
firms such as AFIEX, Angimex, etc, supply different type of contracts which offer particular terms and conditions for purchasing rice in the region (Demont and Rutsaert, 2017).

\subsubsection{The effect of contract farming on farm technical efficiency in emerging and developing economies}

In agricultural production, farming TE is used to measure how production inputs, such as land, labor, seeds, pesticides, fertilizers, etc. are spent to produce an optimal level of output (Krugman, 1994; Kumbhakar and Lovell, 2000). In principle, CF is not only an institutional arrangement supporting farmers by reducing production uncertainty but also can play a major role in improving TE and the production frontier (Rawlins, 1985; Eaton and Shepherd, 2001; Da Silva, 2005; Ramaswami et al., 2005; Swain, 2008; Saigenji and Zeller, 2009; Sartorius, 2013; Wang et al., 2014). CF schemes also support the shift of risk from growers to processors as the buyers supply most of the inputs such as seed, fertilizer, and pesticides (Ramaswami, Birthal, and Joshi, 2005). Thus, CF could offer a solution for dealing with a number of productivity and technical efficiency constraints arising from small-scale production including risk coverage and accessibility of inputs, capital resources, and information (Miyata et al., 2009).

$\mathrm{CF}$ and its positive impact on agricultural TE is generally well-established in scientific research with special attention to emerging and developing economies (Coelli and Battese, 1996; Binam et al., 2004; Ramaswami et al, 2005; Kolawole, 2006; Duy, Flaaten, et al., 2012). By considering CF as a tool for rural development and livelihood sustainability, there is evidence that smallholders could improve their farm profitability, productivity, TE, and household welfare by participating in such schemes (Ali and Flinn, 1989; Battase and Broca, 1997; Ramaswami et al, 2005; Cai et al., 2008; Rahman et al., 2009; Rao et al., 2012; Wollni and Brümmer, 2012). Ramaswami et al. (2005) refer to the production efficiency of CF by taking into account the costs of both poultry farming contract and non-contract participants in India and reveal that contract producers achieve higher efficiency than independent producers. Moreover, the evidence from the study of tea production by Saigenji and Zeller (2009) also confirms that participating in CF arrangements supports tea farmers in Vietnam to increase TE and household income by VND 8.000 (about USD 0.4) per capital and day.

Generally, TE analysis for the Vietnamese rice sector has been conducted by earlier studies. A study by Khai and Yabe (2011) reveals that the rice farming TE score in Vietnam is around $81.6 \%$ compared to about $75 \%$ of rice profitability on average (Hoang and Yabe, 
2012). In addition, the average rice farming TE score in MRD is about $90 \%$ (Vo and Nguyen, 2016) and the most important factors influencing the TE ratio are intensive labor, irrigation and educational levels (Khai and Yabe, 2011). Generally, since the current TE score of the Vietnamese rice farming varies between $70 \%$ and $90 \%$, farmers could increase their efficiency up to $30 \%$ without changing their inputs. Therefore farm and socio-economic characteristics such as rice farming size, expenditure on pesticides (Duy, 2012), years of education (Khai and Yabe, 2011) and credit access (Hoang and Yabe, 2012; Duy, 2012) are identified as having especially positive influences on rice farming TE in the Vietnamese MRD region. However, the participation of Vietnamese rice farmers, as a prime-example from South-East Asia, in CF schemes has not been taken into account in any empirical quantitative study on farm TE as yet, even though it can be assumed to improve the TE.

Thus, there is a gap for further research about CF-effects on TE in the export rice sector of Vietnam, a prime-example for other rice exporting countries in Southeast Asia. This study aims to close that gap by conducting a SFA of a quantitative data set from this sector as explained in the following sections.

\subsection{Data and methodology}

\subsubsection{Study design and data collection}

The data set consists of farm level data collected in 2015/2016 from smallholder rice farmers in the Mekong River Delta (MRD). MRD is the dominant export-oriented rice producing region in Vietnam (Young et al., 2002; Demont and Rutsaert, 2017). The target population of 250,000 households in the three main export rice production regions of the area, namely the Kien Giang, Can Tho, and An Giang provinces were selected (Duy, 2012; USDA, 2015). Together with rice farming, households have some other income sources which come from green vegetables, livestock, and aquaculture, but most of these outputs are for selfconsumption. Apart from farming, they also participate in small scale local trading and other off-farm activities. Using a structured questionnaire, 250 households from the aforementioned provinces were randomly chosen. To ensure the comparability of contract and non-contract farmers, 134 contract farmers from five different contractors' lists and 116 non-contract farmers from the village official lists of 12 villages were randomly selected. All the respondents had to be located in the same area and produce rice for export. Most of the contract participants in this study purchase their inputs from the contractor at the beginning of the cropping season and the cost is deducted from payments at harvesting time. 
Contracted farmers also receive technical advice during production, have agreements with contractors on specified production practices, inputs (seed, fertilizer, pesticide), and other services. Farmers can also store their products at the contractor's warehouse for up to one month if they want to wait for higher market selling prices (this applies to negotiable-price term contracts). Contractors guarantee to purchase the products, and pay for collection and transportation of the final product during the harvesting period. Other CF arrangements only supply the inputs without purchasing outputs. Some firms only purchase products without providing the inputs. In those cases, some contractors are willing to pay a premium over the market price at harvest time to ensure their market supply.

\subsubsection{Method}

\subsubsection{Stochastic frontier analysis}

In order to observe the influences of CF on farm TE, we followed the approach proposed by Meeusenand (1977) and Lovell et al. (1977) on efficiency measurement of a firm with a given level of output at the lowest expenditure of inputs. In this paper, SFA is applied to estimate the production function of export-oriented rice farming in Vietnam (Kumbhakar et al., 2000) since the SFA serves to correct for controlling errors and other noise measurement in the data set which tends to occur in primary farm level data in developing countries like Vietnam (Kolawole, 2006).

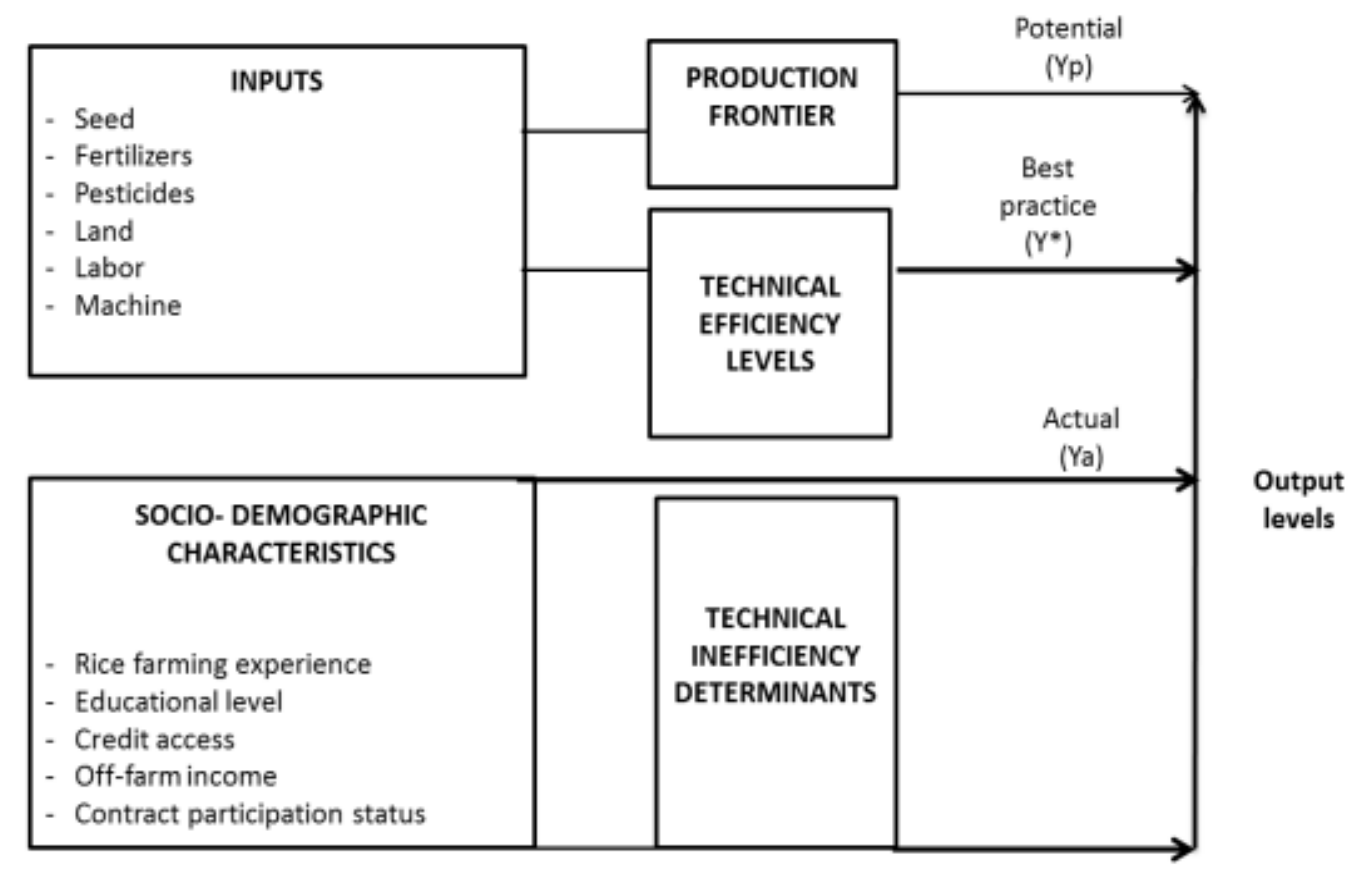

Figure 4.1. Conceptual framework for technical efficiency analysis Sources: adapted from Hoang (2013) 
The conceptual framework of our empirical analysis was developed based on the study by Hoang (2013) (see Figure 4.1). This conceptual framework describes the inputs and socioeconomic characteristics influencing the output-level in the export-oriented rice production sector. We thereby analyze the production frontier of contract and non-contract participants to compare the TE levels as well as to evaluate the effects of technical inefficiency determinants on rice production in particular. Since we specifically pay attention to the hypothesis that contract participants have higher TE, CF participation status is treated as a dummy variable. Because this treatment variable could be endogenous due to self-selection bias, a stochastic frontier approach is necessary.

Following Battese and Coelli (1993) and Coelli and Battese (1996), we used the maximum likelihood method in order to estimate the production frontier with the assumption that all the farmers apply the same technology. Additionally, variables representing household characteristics are hypothesized to influence technical inefficiency (Wollni and Brümmer, 2009; Mayen et al., 2010) namely; rice farming experience, educational level, contract participation status (yes or no), accessibility to credit and off-farm income. These are included to check possible determinants of TE.

Therefore, the TE score is evaluated by $\mathrm{Y}_{\mathrm{a}}$ divided by $\mathrm{Y}^{*}\left(\mathrm{TE}=\frac{\mathrm{Y}_{\mathrm{a}}}{\mathrm{Y}^{*}}\right)$ where $\mathrm{Y}$ is the observed current output and $\mathrm{Y}^{*}$ is the optimal output (maximum) level (Battese and Coelli, 1993; Kumbhakar and Lovell, 2000). The stochastic frontier model is employed as follows:

$$
y_{i}=f\left(x_{i} ; \alpha\right) \exp \left(\varepsilon_{i}\right)(1)
$$

Where $\mathrm{Yi}$ is the scalar output quantity of export rice household $\mathrm{i}$; $\mathrm{Xi}$ is representing the vector of input quantities; $\alpha$ is the vector of unknown parameters referring to production technology, and $\varepsilon_{\mathrm{i}}$ is a two-sided error component including two independent components which can be described as $\varepsilon_{\mathrm{i}}=\mathrm{v}_{\mathrm{i}}-\mathrm{u}_{\mathrm{i}}$. The $\mathrm{v}_{\mathrm{i}}$ is the noise error, which is assumed as independent and identically normal distributed as $\mathrm{N}\left(0, \sigma_{\mathrm{v}}{ }^{2}\right)$. The $\mathrm{u}_{\mathrm{i}}$ is the inefficiency component, which is assumed to be half-normally distributed with zero modes $\left(\mathrm{u}_{\mathrm{i}} \sim N^{+}\left(0, \sigma_{u}^{2}\right)\right)$ and variance parameter $\sigma_{u}^{2}$. The $\mathrm{u}_{\mathrm{i}}$ vector is a function of non-negative unobservable variables related to the technical inefficiency of production (Battese and Broca, 1997; Battese and Broca, 1997). The stochastic terms $v_{i}$ and $u_{i}$ are assumed to be uncorrelated. The variation of $u_{i}$ is specified by:

$$
\operatorname{VAR}\left(\mathrm{u}_{\mathrm{i}}\right)=\frac{\pi-2}{\pi} \sigma_{u}^{2}=\frac{\operatorname{VAR}\left(\mathrm{u}_{\mathrm{i}}\right)}{\operatorname{VAR}\left(\mathrm{u}_{\mathrm{i}}\right)+\sigma_{v}^{2}}
$$


Based on Battese (1992), the farmer-specific technical inefficiency is the ratio of the observed output and the farmer-specific stochastic frontier output. In this sense, the TE of rice farmer i can be estimated as:

$$
\mathrm{TE}_{\mathrm{i}}=\exp \left(-\mathrm{u}_{\mathrm{i} ;}\right)=\frac{q_{i}}{\exp \left(x_{i}^{\prime} \beta+\mathrm{v}_{\mathrm{i}}\right)}=\frac{\exp \left(x_{i}^{\prime}+\mathrm{v}_{\mathrm{i}}-\mathrm{u}_{\mathrm{i}}\right)}{\exp \left(x_{i}^{\prime}+\mathrm{v}_{\mathrm{i}}\right)}(3)
$$

Where $\mathrm{TE}_{\mathrm{i}}$ is the scalar vector of TE of farmer $\mathrm{i}$. We calculate a trans-log model to estimate the relationship between y and $x_{i}$ in equation (1) as follows:

$$
\mathrm{y}_{\mathrm{i}}=\exp \left(\beta_{0}+\sum_{n=1}^{N} \beta_{n} \ln x_{n}+\frac{1}{2} \sum_{n=1}^{N} \sum_{m=1}^{N} \beta_{n m} \ln x_{n} \ln x_{m}\right)(4)
$$

Regarding the trans-log model for the $\beta_{n}$ parameter, the logarithms of the equation (3) in both sides are calculated as follows:

$$
\mathrm{Lny}_{\mathrm{i}}=\beta_{0}+\sum_{n=1}^{N} \beta_{n} \ln x_{n}+\frac{1}{2} \sum_{n=1}^{N} \sum_{m=1}^{N} \beta_{n m} \ln x_{n} \ln x_{m}+\mathrm{v}_{\mathrm{i}}-\mathrm{u}_{\mathrm{i}}(5)
$$

The variation in production $(\gamma)$ (Coelli and Battese, 1996) is estimated as follows:

$$
\gamma=\frac{\sigma_{\mathrm{u}}^{2}}{\sigma^{2}} \quad \text { With } \sigma^{2}=\sigma_{\mathrm{u}}^{2}+\sigma_{\mathrm{v}}^{2}
$$

The value of $\gamma$ must range between zero and one; $\gamma$ represents the deviations from the frontier due to noise, and values of 1 refers to the technical inefficiencies (Aigner et al., 1977).

\subsubsection{Propensity score matching}

Among the efficiency studies to date, controlling for self-selection bias has been neglected when estimating divergent technology sets using production frontiers (Tzouvelekas et al., 2001; Latruffe et al., 2005; Wollni and Brümmer, 2012). Yet, if households decide to participate in contractual arrangements (or not) based on their expectations, the two groups will be systematically different in social-economic characteristics (Heckman, 1979). In this paper, the production frontier is estimated with the assumption that all farmers in the sample have access to the same technology and they are free to join the CF scheme.

For the observed variables, with regard to the contract group, some contract participants would have higher TE levels before participating in contract scheme, consequently increasing the self-selection bias. The decision to participate in the CF scheme is assumed to depend on observed socio-demographic characteristics specified as follows:

$$
\partial_{i}=w_{i} \alpha+e_{i}
$$


where $\alpha$ is a vector of parameters and $e_{i}$ is a random error. If any of the determinants of technology choice (in this case CF), $w_{i}$, also affects rice production but is not included explicitly in the equation (1), then the contract participation variable in (1) is correlated with the error term $\varepsilon_{\mathrm{i}}$. In this case, estimations of $\beta_{n}$ in the equation (5), which do not account for the endogeneity of the technology choice, are biased. For those observed variables, we employ the PSM technique proposed by Mayen et al. (2010) which is appropriate for productivity and TE analysis to control for any self-selection bias. The matching approach allows us to measure the effects of adopting CF on TE score of contract participants based on a three-step procedure.

First, a probability of CF participation is estimated (probit estimation) and used to calculate the probability or propensity score of being contract participant rather than non-participant for each observation. It can be estimated as:

$$
\mathrm{ATT}=\mathrm{E}(\Delta \mid Z, D=1)=\mathrm{E}\left(Y^{1} \mid Z, D=1\right)-\mathrm{E}\left(Y^{0} \mid Z, D=1\right)
$$

Where, $Y^{1}$ represents the TE score of contract participant $(\mathrm{D}=1)$ and $Y^{0}$ represents the TE score of non-contract participant $(\mathrm{D}=0)$. $Z$ represents for conditioning variables including $\mathrm{x}_{\mathrm{i}}$ input variables (see equation (1)) and other observed variables from socio-demographic characteristics or technical inefficiency determinants (see equation (7)). The mean value $\mathrm{E}\left(Y^{1} \mid Z, D=1\right)$ can be promptly identified through the contract group data. But for the counterfactual mean $\mathrm{E}\left(Y^{0} \mid Z, D=1\right)$ the assumption has to be done regarding the TE of $\mathrm{CF}$ participants if they had not adopted CF. The self-selection bias can be identified through the differences in outcomes of self-selected non-contract participation $\mathrm{E}\left(Y^{0} \mid \mathrm{Z}, \mathrm{D}=0\right)$ and approximate $\mathrm{E}\left(Y^{0} \mid \mathrm{Z}, \mathrm{D}=1\right)$. The self-selection bias results are illustrated as follows:

$$
\mathrm{B}(\mathrm{Z})=\mathrm{E}\left(Y^{0} \mid \mathrm{Z}, \mathrm{D}=1\right)-\mathrm{E}\left(Y^{0} \mid \mathrm{Z}, \mathrm{D}=0\right)
$$

Secondly, every single contract household is continuously matched to a non-contract household with the similar propensity score. During the step, the nearest-neighbor matching is employed in which each contract participant is paired with the non-contract participant that has the closest propensity score. All other non-contract households are ignored for this step (Dehejia and Wahba, 2002). The matching procedure serves to find an alternative result for $\mathrm{E}\left(Y^{0} \mid \mathrm{Z}, \mathrm{D}=1\right)$ "based on the statistical independence of $\left(Y^{0}, Y^{1}\right)$ and $\mathrm{D}$ conditional on $\mathrm{Z}$ (technology is exogenous after conditioning on $\mathrm{Z}$ )". This condition is also referred to as "selection on observables" (Imbens, 2004, P.7-8). By conditioning on a propensity score $\mathrm{P}(\mathrm{Z})$, the independence condition is also satisfied (Rosenbaum and Rubin, 1983). For this 
method, there is no need to match dimensionally on $Z$, then $\mathrm{E}\left(Y^{0} \mid \mathrm{P}(\mathrm{Z}), \mathrm{D}=1\right)=\mathrm{E}\left(Y^{0} \mid \mathrm{P}(\mathrm{Z})\right.$, $\mathrm{D}=0)=\mathrm{E}\left(Y^{0} \mid \mathrm{P}(\mathrm{Z})\right.$, allowing unbiased estimates of $\mathrm{E}\left(Y^{1}-Y^{0} \mid \mathrm{Z}, \mathrm{D}=1\right)$.

Finally, we estimate the SFA on the contract participant group and match non-contract participant group to test the hypothesis that these farms employ a homogeneous technology and we compare their TE levels.

\subsubsection{Model specification}

Table 4.2 presents the detailed information of the variables used in the TE estimation. In this study, the rice production information refers to up to three harvests (at least 2) per year in the MRD. The exported rice in total volume per year is the single output. The inputs include labor, fertilizer, seeds, machinery, land, and pesticides. For the labor variable, the total costs for labor are calculated by the expenditure for hired labor per man per day and estimated family labor (by permanent hired labor paid). The rice farming area for land is in hectares. Total costs of fertilizer, seeds, and pesticides are calculated. Machinery costs such as irrigation, machine purchasing, and tools are also included in the total expenditure. A household that produces at the production frontier is assumed to have a TE level of $100 \%$. The CF participation status is treated as a dummy variable as suggested by Coelli and Battese (1996). Derived from the literature review, the four major socio-economic characteristics, namely off-farm income, educational level (year of schooling), rice farming experience and credit accessibility are included in the technical inefficiency estimations. We expect that those variables would support rice farming households in the MRD to optimize their rice production (Khai and Yabe, 2011; Duy, 2012). 
Table 4.2: Description of included variables

\begin{tabular}{ll}
\hline Variable & Description \\
\hline Production model & Expenditure on seed per year (ton) \\
Fertilizer & Expenditure on fertilizer year/ton \\
Pesticide & Expenditure on pesticide and chemical per year (1000VND) \\
Machine & Expenditure on machine (1000VND per year) \\
Labor & Expenditure on labor per year (1000VND) \\
Land & Total land use for rice production per year (ha) \\
Output & Total output of export rice household (ton per year ) \\
Technical inefficiency model & \\
Off-farm & Off-farm income (1000.VND) \\
Contrice & Dummy for contract farming participation (1= yes; $0=$ no) \\
Edulevel & Schooling years of HH head (1-15 years) \\
Riceexper & Rice farming experience (years) \\
Credit & Dummy for the accessibility of credit (1= yes) \\
$P S M-$ Probit estimates & \\
Landhh & Total agricultural land size for rice farming of HH \\
Agmem & Total family member work in agricultural \\
Gender & Gender of household head \\
Age & Age of household head \\
\hline $1 U S D=22.000 V N D$ (average of currency exchange rate is applied at the time of data collection)
\end{tabular}

\subsection{Results}

\subsubsection{Descriptive statistics}

Table 4.3 presents the mean values and standard deviations of the variables included in the estimations. Additionally, using t-test, $\mathrm{CF}$ participants are compared to non-contract participants and the sub-matched sample regarding the differences in production inputs and socio-demographic characteristics. For the input variables, the results reveal no significant differences in mean values. The average output of the total sample is about 63.705 tons per year. The rice farmers in the sample use about 4.394 tons of fertilizer per year on average. The average expenditure on pesticides and chemicals is nearly equal to labor expenditure representing VND43.44 million (USD1,975) and VND43.759 million (USD1,989), respectively. The mean values and standard deviation of the expenditure on fertilizer, pesticide, and labor are higher for contract participants even though there is no significant difference among the groups. However, the differences in expenditure on seed and the total output per year are slightly below the threshold of significance and, thus, allow the hypotheses of their appropriateness as part of the production frontier and inefficiency estimations. Regarding the variables representing socio-economic characteristics which are expected also to affect farmers' ability to achieve higher TE, most of the variables do not show any significant difference between the groups. 
Table 4.3 Descriptive statistics for the variables included in the estimations

\begin{tabular}{|c|c|c|c|c|c|c|c|c|}
\hline \multirow[b]{2}{*}{ Variable } & \multicolumn{2}{|c|}{ Total sample } & \multicolumn{2}{|c|}{ Non-contract } & \multicolumn{2}{|c|}{ Contract } & \multicolumn{2}{|c|}{ Sub-sample } \\
\hline & Mean & Std. dev. & Mean & $\begin{array}{l}\text { Std. } \\
\text { dev. }\end{array}$ & Mean & $\begin{array}{l}\text { Std. } \\
\text { de. }\end{array}$ & Mean & Std.de \\
\hline \multicolumn{9}{|c|}{ Production model } \\
\hline Seed & 1.534 & 2.147 & 1.71 & 2.95 & 1.38 & 1.001 & 1.77 & 0.45 \\
\hline Fertilizer & 4.394 & 4.448 & 4.133 & 4.302 & 4.619 & 4.574 & 4.40 & 0.67 \\
\hline Pesticide & 43.442 & 41.193 & 41.937 & 40.720 & 45.556 & 41.805 & 45.87 & 4.808 \\
\hline Machine & 33.608 & 93.732 & 36.920 & 104.486 & 30.740 & 83.611 & 45.693 & 16.802 \\
\hline Labor & 43.759 & 41.193 & 42.479 & 37.046 & 44.867 & 33.709 & 44.473 & 5.123 \\
\hline Land & 10.297 & 7.978 & 10.281 & 8.296 & 10.309 & 7.722 & 9.49 & 0.88 \\
\hline Output & 63.705 & 3.26 & 61.99 & 5.04 & 65.18 & 4.27 & 58.678 & 5.59 \\
\hline \multicolumn{9}{|c|}{ Techincal inefficiency model } \\
\hline Off-farm & 40.550 & 68.329 & 34.617 & 64.303 & 45.690 & 71.473 & 35.287 & 8.161 \\
\hline Edulevel & 8.128 & 2.956 & 7.93 & 2.90 & 8.3 & 3.00 & 8.29 & 0.36 \\
\hline Riceexper & 22.992 & 9.08 & 23.76 & 10.03 & 22.32 & 9.58 & 22.230 & 1.11 \\
\hline Credit & 0.376 & 0.4853 & 0.37 & 0.485 & 0.38 & 0.488 & 0.41 & 0.061 \\
\hline
\end{tabular}

Source: authors owned calculations

\subsubsection{Parameter Estimations}

\subsubsection{Determinants of rice production technical efficiency in the MRD}

The coefficients of the production frontier estimation conducted with total sample data are illustrated in Table 4.4. For the log-normalized values, the input coefficients represent the production elasticity at the mean value. The partial production elasticity of expenditures for most of the inputs is significantly positive at the 1.5 , and $10 \%$ level. In particularly, if a farmer increases expenditures on seeds and fertilizer by $1 \%$ each the output increases by 0.259 and $0.172 \%$ (significant at the $1 \%$ level for both). With regard to the expenditures on labor, it becomes evident that an increase by $1 \%$ leads to output increase of $0.1 \%$ (significant at the $5 \%$ level). Noticeably, land size is found to affect the output $(0.49 \%)$ at the $1 \%$ significance level. Expenditure on machinery is also found to positively influence farm output, however only by $0.0028 \%$ at the $10 \%$ level of significance. Still, this result for expenditure on machines confirms the particular importance of investments in machine inventory for the rice production in a developing country such as Vietnam (Pingali et al., 1997). However, as it is typical for developing countries in contrast to developed ones, the effect of labor intensity on the output still exceeds those of machines (Khai and Yabe, 2011), most likely because of the small plot sizes. Of even higher values are the coefficients of land use and seed expenditure confirming the importance of these inputs for rice production in the 
MRD (Duy, 2012). Only the (very low) positive result for expenditure on pesticides $(0.009 \%)$ does not show any significance.

Table 4.4 Stochastic translog estimation for export-oriented rice in the Mekong River Delta

\begin{tabular}{|c|c|c|c|c|}
\hline \multirow[t]{2}{*}{ Variable } & \multicolumn{2}{|c|}{ Full sample (250) } & \multicolumn{2}{|c|}{ Sub-matched group (199) } \\
\hline & Coeff. & Std.error & Coeff. & Std.error \\
\hline Lnseed & $0.25986^{* * *}$ & 0.04307 & $0.310401 * * *$ & 0.0519671 \\
\hline Lnpesticide & 0.00917 & 0.02460 & 0.0023999 & 0.0298567 \\
\hline Lnfertilizer & $0.17266^{* * *}$ & 0.03415 & $0.1369919 * * *$ & 0.043012 \\
\hline Lnlabor & $0.10017 * *$ & 0.04430 & $0.1141643 * * *$ & 0.0537549 \\
\hline Lnland & $0.49204 * * *$ & 0.04632 & $0.4735377 * * *$ & 0.0507841 \\
\hline Lnmachine & $0.00279 *$ & 0.00169 & -0.0015767 & 0.0062302 \\
\hline Lnseed x lnseed & $-0.25315^{* * *}$ & 0.05786 & $-0.5112465 * * *$ & 0.1269272 \\
\hline lnpesticide $\mathrm{x}$ lnpesticide & 0.02068 & 0.03405 & 0.035153 & 0.0413255 \\
\hline lnfertilizer x lnfertilizer & $-0.19891 * *$ & 0.09788 & -0.0248053 & 0.1334538 \\
\hline lnlabor x lnlabor & -0.20408 & 0.15830 & -0.0356796 & 0.18888 \\
\hline lnland $x$ lnland & $0.40716^{* * *}$ & 0.13637 & $-0.3729227 * * *$ & 0.2243556 \\
\hline lnmachine $\mathrm{x}$ lnmachine & -0.0014089 & 0.0012329 & -0.0007494 & 0.001243 \\
\hline Lnseed $\mathrm{x}$ lnpesticide & -0.05792 & 0.06118 & -0.0208557 & 0.0723636 \\
\hline Lnseed x lnfertilizer & 0.09578 & 0.12611 & 0.0859865 & 0.1443597 \\
\hline Lnseed x lnlabor & 0.21412 & 0.14206 & 0.1022833 & 0.2047012 \\
\hline Lnseed $\mathrm{x}$ lnland & 0.01010 & 0.12553 & $0.4395752 * * *$ & 0.2002246 \\
\hline Lnseed x lnmachine & 0.00094 & 0.00664 & 0.0008259 & 0.0067744 \\
\hline Lnpesticide $\mathrm{x}$ lnfertilizer & -0.04789 & 0.05234 & -0.0205589 & 0.0590875 \\
\hline Lnpesticide x lnlabor & 0.00368 & 0.07421 & -0.0551594 & 0.0842733 \\
\hline Lnpesticide $\mathrm{x}$ lnland & 0.09554 & 0.07788 & 0.0580271 & 0.0904588 \\
\hline Lnpesticide x lnmachine & 0.00419 & 0.00329 & 0.0029647 & 0.004323 \\
\hline Lnfertilizer x lnlabor & $0.19923 *$ & 0.11746 & 0.0260494 & 0.1439669 \\
\hline Lnfertilizer $x$ lnland & -0.04780 & 0.10025 & -0.0775044 & 0.1009701 \\
\hline Lnfertilizer x lnmachine & 0.00307 & 0.00556 & -0.0030802 & 0.0062466 \\
\hline Lnlabor x lnland & $-0.36491 * * *$ & 0.13282 & -0.0980056 & 0.1692907 \\
\hline Lnlabor x lnmachine & $-0.01244^{*}$ & 0.00693 & -0.0047026 & 0.0074467 \\
\hline Constant & $0.16148 * * *$ & 0.04751 & $0.202 * * *$ & 0.0707063 \\
\hline Number of observation: 250 & & & \multicolumn{2}{|c|}{199} \\
\hline Prob>chi2: 0.0000 & & & \multirow{2}{*}{\multicolumn{2}{|c|}{$\begin{array}{r}0.0000 \\
86.535 .502\end{array}$}} \\
\hline Log-likelihood: 97.147427 & & & & \\
\hline
\end{tabular}

Note: $* * * p<0.01, * * p<0.05, * p<0.1$

Sources: authors' own calculations

Table 4.5 illustrates the results for the determinants of inefficiency. It can be seen that there is no strong significant effect of the major variables on TE. However the near significance and the signs of the coefficients of contract participation status $(\beta=-0.410, z=1.25)$, nonfarm income $(\beta=-4.10 \mathrm{e}, \mathrm{z}=1.29)$ and credit accessibility $(\beta=-0.404, \mathrm{z}=1.22)$ may indicate a 
positive influence of $\mathrm{CF}$ on TE. These results are explainable with the circumstance that the $\mathrm{CF}$ scheme in Vietnam is still at an early stage. Thus, some effects potentially involve time lags and may become visible in following years. Off-farm activities and the resulting income may support farm TE through increases in knowledge about and affordability of inputs. Additionally, higher educational levels and longer rice farming experience may represent better managerial and production skills, so reflecting better farm TE than observed in earlier analyses (Khai and Yabe, 2011). Exactly the opposite is true for the accessibility of credits. Here there is evidence of a negative effect (insignificant) on TE. This could be explained in three ways: first interest rates of loans in the region are high, second, many credits are still not measurable in the initial years as long-term effects, third, since control is missing in many credit schemes, farmers use their loans for other urgent expenses unrelated to farming activities (Duy, 2012).

Table 4.5 Inefficiency estimations for export-oriented rice production in the MRD

\begin{tabular}{|c|c|c|c|c|}
\hline \multirow[t]{2}{*}{ Variable } & \multicolumn{2}{|c|}{ Full sample } & \multicolumn{2}{|c|}{ Sub matched group } \\
\hline & Coeff. & $\mathrm{z}$ & Coeff. & $\mathrm{Z}$ \\
\hline Contract participation $(1=$ yes $)$ & -0.4108349 & -1.25 & -0.5264824 & -1.35 \\
\hline $\begin{array}{l}\text { Household income from non-farm } \\
\text { activities }\end{array}$ & $-4.10 \mathrm{e}-06$ & -1.29 & $-3.63 e-06$ & -1.16 \\
\hline The accessibility of credit (1=yes) & 0.4042186 & 1.22 & 0.399199 & 1.04 \\
\hline $\begin{array}{l}\text { Schooling year of household head } \\
\text { (number) }\end{array}$ & -0.0316746 & -0.63 & -0.0372751 & -0.73 \\
\hline Rice farming experience (years) & -0.003418 & -0.24 & -0.0122209 & -0.74 \\
\hline Constant & $-2.936974 * * *$ & -4.09 & $-2.469596 * * *$ & -4.05 \\
\hline Observation & 250 & & & \\
\hline
\end{tabular}

\subsubsection{Effects of contract farming participation on technical efficiency}

The levels of production performance for export-oriented rice farmers represented by TE scores are shown in Table 4.6 and the frequency distribution of predicted TE is visualized in Figure 4.2. The mean of the TE score for the full sample equals 0.8702 , implying that on average, the export-oriented rice farmers in the MRD produce $87.33 \%$ of the maximum possible output. This result is in line with findings from earlier studies about the TE score of rice production in Vietnam and other developing countries (Khai and Yabe, 2011; Vo and Nguyen, 2016). Vice versa, about $13 \%$ of the potential output is lost due to technical inefficiency. The TE of export-oriented rice production in the MRD ranges between $56.48 \%$ and $96.47 \%$ (see Table 4.6) also confirming the range observed in the comparative study 
(Khai and Yabe, 2011; Vo and Nguyen, 2016). In total, the scale-effect is about 1.026 which reveals that farmers are operating under increasing returns of scale (see Table 4.3). Therefore contract participants have a higher average TE (88.46\%) in comparison to non-contract participants (86.02\%) (see Figure 4.2 and Appendix 2). In the two-sample t-test of TE-mean values, there is a significant difference at the $5 \%$ level with a t-value of 3.01, indicating higher TEs for contract farmers.

Table 4.6 Technical efficiency score for export-oriented rice production in the MRD

\begin{tabular}{|c|c|c|c|c|c|c|}
\hline & Observation & Mean & Std. Dev. & $\begin{array}{l}\text { Std. } \\
\text { Err. }\end{array}$ & Min & Max \\
\hline \multicolumn{7}{|l|}{ TE (full sample, $\mathrm{N}=250$ ) } \\
\hline Full sample & 250 & .8733 & .064 & .0040 & .5648 & .9647 \\
\hline Non-contract farmers & 116 & .8602 & .074 & .0068 & & \\
\hline Contract farmers & 134 & .8846 & .053 & .0045 & & \\
\hline Degrees of freedom: 248 & $\mathrm{t}=-3.01 * * *$ & & & & & \\
\hline \multicolumn{7}{|c|}{ TE (Sub-matched sample, N=199) } \\
\hline Full sample & 199 & .8668 & .074 & .0052 & .5397 & .9698 \\
\hline Non-contract farmers & 65 & .8460 & .0928 & .8230 & & \\
\hline Contract farmers & 134 & .8769 & .0611 & .8664 & & \\
\hline Degrees of freedom: 197 & $\mathrm{t}=-2.79 * * *$ & & & & & \\
\hline
\end{tabular}

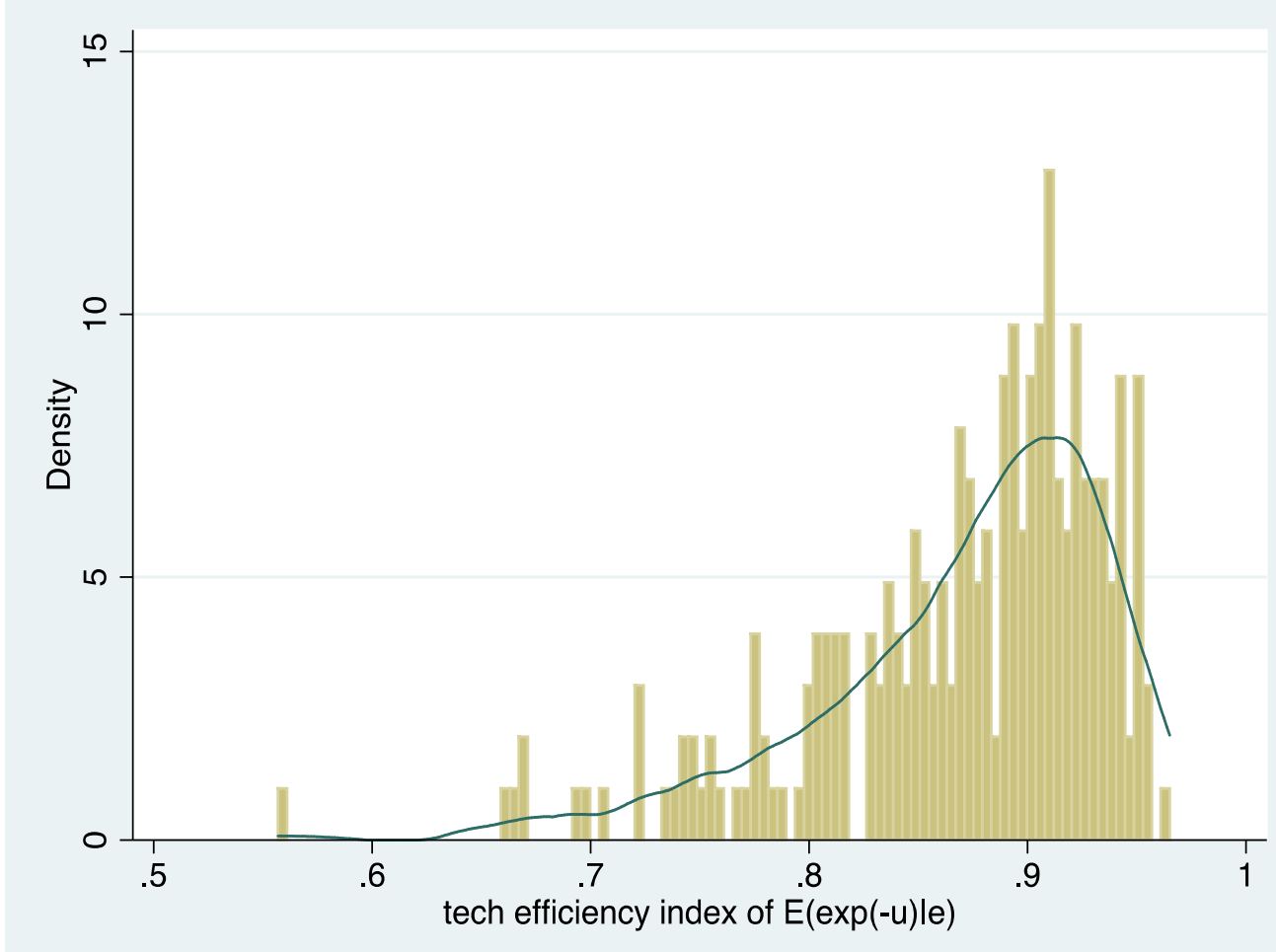

Figure 4.2: Technical efficiency distribution for export-oriented rice in the MRD Sources: authors' own calculations 


\subsubsection{Propensity score matching}

The propensity of CF participation based on the probit estimations is presented in Table 4.7. There are some significant variables associated with the probability of CF scheme participation. Regarding the "rice farming experience" variables, it can be seen that the more farming experience households have, the less willingness they show to participate in $\mathrm{CF}$ ( $\beta=$ $0.023, z=2.26$ ). There is a strong propensity in the rice farming household participating in $\mathrm{CF}$ of expecting to reduce the expenditure on hired labor since the more household farming members they have, the more the propensity to engage in $C F(\beta=-0.2935, z=2.30)$. In addition, older farmers have higher propensity to join $\mathrm{CF}$ in comparison to younger farmers which is convincing evidence for the case of Vietnamese rice production in which young farmers perceive independency from arrangements with contractors to be more beneficial $(\beta=0.02, z=1.91)$. Nevertheless, educational level is not strongly associated with farmers' marketing decisions.

We then apply the probit estimations to generate a PSM in which the balancing property is satisfied. Given the similar socio-demographic characteristics of both groups, the propensity score of the comparison before and after matching shows that the significant differences in TE scores are resulting from the CF participation.

Table 4.7: Probit estimates of the contract farming propensity

\begin{tabular}{llll}
\hline Variable & Coef. & Std. Err. & Z \\
\hline Riceexper & -0.0231188 & 0.0102184 & $-2.26^{*}$ \\
Edulevel & 0.0266692 & 0.0291315 & -0.92 \\
Credit & 0.050614 & 0.1770455 & 0.29 \\
Offfarm & $1.37 \mathrm{e}-06$ & $1.29 \mathrm{e}-06$ & 1.06 \\
Hhland & $-1.60 \mathrm{e}-07$ & $5.83 \mathrm{e}-06$ & -0.03 \\
Labor & $1.48 \mathrm{e}-06$ & $3.98 \mathrm{e}-06$ & 0.37 \\
Machine & $-3.96 \mathrm{e}-07$ & $9.27 \mathrm{e}-07$ & -0.43 \\
Age & 0.0200568 & 0.0105241 & $1.91^{*}$ \\
Hhmember & -0.2935064 & 0.1277223 & $-2.30^{* *}$ \\
Gender & 0.4277729 & 0.3674826 & 1.16 \\
cons & -0.5170229 & 0.6041934 & -0.86 \\
N & 250 & & \\
Log likelihood & & -16.516 .629 \\
Correctly classified & & $60.80 \%$ \\
\hline
\end{tabular}

Note: $* p<0.10, * * p<0.05, * * * p<0.01$

Sources: authors' own calculations 
Table 4.8. Mean and Standard Deviation of Technical Efficiency in PSM estimation

\begin{tabular}{|c|c|c|c|c|}
\hline & Contract & Non-contract & Difference & T-test \\
\hline & Mean & Mean & in Means & \\
\hline $\begin{array}{l}\text { TE-Probit } \\
\text { 250) }\end{array}$ & & & & \\
\hline Unmatched & .8846 & .8602 & 0.024 & $3.02 * * *$ \\
\hline ATT & .8846 & .8569 & 0.027 & $2.05 * *$ \\
\hline
\end{tabular}

Based on nearest-neighbor matching estimations, the average treatment effects on the treated results are positively significant. Table 4.8 presents a strongly positive contribution of the CF participation on TE scores (at $1 \%$ level of significance). In more detail, participating in the CF scheme helps Vietnamese export rice farmers to increase TE score levels from $85.69 \%$ to $88.46 \%$ in comparison to the case of non-participation in the CF scheme. This result supports, on the one hand the rejection of the hypothesis that there is self-selection bias for the sample and on the other hand the previous literature about the positive impacts of $\mathrm{CF}$ scheme on household welfare and agricultural productivity from emerging and developing economies (Ramaswami et al., 2005; Rahman et al., 2009; Rao et al., 2012). After matching estimation, we have the result of a sample of 199 observations including 134 contract households and 65 non-contract household with the same socio-economic characteristics. Table 4.5 presents the TE score value of the matched sub sample which is at $1 \%$ significant difference $(\mathrm{t}=2.79)$, confirming the $\mathrm{t}$-test of the full sample of 250 observations and prove that there is no sample selection bias in our estimations (see Appendix 3).

\subsection{Conclusion and policy recommendation}

Export-oriented rice farming under $\mathrm{CF}$ frame in Vietnam is an important topic when considering global poverty reduction and resource rivalry. Correspondingly, it was the aim of this study to analyze the CF effects on TE in Vietnams' export rice production sector based on the cost-frontier approach for the efficiency measurement of a firm, given a level of output at the lowest expenditure of inputs. Using survey data from 250 rice farmers located in three major rice farming areas in the MRD of Vietnam, a SFA was applied to evaluate the effects of CF scheme on farming TE levels and estimate the production function. Overall, the results highlight the influence of $\mathrm{CF}$ participation on TE at the farm level. Although there was no strong effect of CF status on inefficiency determinants for the whole sample, we still found that there is significant difference in TE levels between the two groups (CFparticipants and -non-participants). CF is found to greatly support export-oriented farmers in 
increasing their TE levels. In this regard, contract participation could support not only largerscale farmers but also small-scale farmers in developing and emerging economies by improving their production patterns which, in turn, is associated with increases in household incomes. Thus, CF bears the potential to contribute to poverty reduction in the rural areas of developing countries, such as Vietnam.

The research findings are in line with previous research about CF effects on TE (Ali and Flinn, 1989; Battase and Broca, 1997; Ramaswami et al, 2005; Cai et al., 2008; Rahman et al., 2009; Rao et al., 2012; Wollni and Brümmer, 2012; Ramaswami et al, 2005), as well as about TE in the Vietnamese rice sector (Khai and Yabe, 2011; Duy, 2012; Hoang and Yabe, 2012; Vo and Nguyen, 2016). In more detail, the results from the SFA reveal that the average TE of export-oriented rice production in Vietnam is $87.33 \%$ implying that TE levels could be increased by nearly $13 \%$ at the current input level and socio-economic conditions which confirms previous findings by Duy (2012) and Hoang and Yabe (2012). Furthermore, participating in CF schemes helps farmers to increase TE score level from $85.69 \%$ to $88.46 \%$ in comparison to the case of non-participations. Land, seeds, fertilizer, machinery, and labor are identified as the major inputs determining the production frontier. Remarkably, in our study "educational level", "rice farming experience" and "off-farm income" are found as positive determinants influencing rice farming TE in contrast to the low negative effect of credit accessibility.

$\mathrm{CF}$ has been proved to be a promising institutional arrangement for small-scale farmers in the Vietnamese export rice sector, and potentially also for other countries and similar cases by creating additional farm benefits from improving rice farming TE levels. Consequently, further development and enhancement of the CF scheme raised in the 80/2002/QD-TTg decision named "Policy on the Promotion of Agricultural Produce and Purchase through Contracts" and the 62/2013 QD-TTg decision is highly recommended. In addition, based on the empirical results, the availability of credits with lower interest rates and the improvement of control systems should be considered by the government in order to increase TE effects. Furthermore, contracting companies should also carefully consider the role of input supply when drawing up their contract conditions since price, quantity and appropriate training for seed and fertilizer usage are especially important drivers of farm TE.

This paper's findings are based on cross-sectional primary data gained in the MRD of Vietnam for rice production under the $\mathrm{CF}$ scheme over a period of one year (three rice cropping seasons). Since the CF scheme was at a very early stage of implementation in the 
country during the year of analysis, future research with panel data is required to explore the households' performance over a long term of observation. In this regard, further research should take into consideration the influence of CF implementation on households' performance and $\mathrm{CF}$ empowerment within the Vietnamese export-oriented rice sector, particularly. With regard to the effects of the agricultural credit system derived from this paper, there should be a more specific evaluation to identify pitfalls which diminish its success at the farm level. Further research should also propose a comparison of production frontiers between the two groups surveyed. A detailed cost analysis based on production functions could reveal more detailed insights into the hypothesis that inputs supplied by contractors through $\mathrm{CF}$ schemes would be more expensive than the free market but with higher quality and more efficient use. The results would be very interesting for policy makers, firms and farms as well. 


\section{General Conclusions}

The objectives of the dissertation have been achieved as presented in the three papers. This study contributes to the current literature in several aspects. Firstly, we explore the driver of information accessibility and other demographic and social-economic characteristics of household marketing behavior and the determinants of CF participation. Secondly, we analyze the effects of CF scheme on households' performances within the export-oriented rice production sector from developing countries that have limitedly been explored in the body of existing literature. We find that the CF scheme supports export-oriented rice producers in Vietnam to improve their household farming performance through two criteria: household income and rice profit. Finally, we evaluate the farming TE levels and the technical inefficiency determinants to estimate how CF scheme support household to improve their rice farming TE.

\subsection{Major findings}

The introduction chapter of this thesis presents an overview of the existing literature and the characteristics of the Vietnamese export-oriented rice sector. Especially, chapter 1 emphasizes the importance of improving smallholders' market linkages to modern value chains. Based on this point of view, we addressed the following research objectives. Firstly, we explored the determinants influencing smallholders' contracting decisions within the export-oriented rice sector in Vietnam. Secondly, we analyzed the effects of CF participation on farming households' performance based on two categories: household income and rice profit. Thirdly, we evaluated the influences of CF participation in farming TE levels. We also explored the determinants of technical inefficiency in export-oriented rice production. The study employed Probit, OLS, MLE, PSM and SFA on a cross-sectional data set from a sample of 250 export-oriented rice smallholder farmers in the MRD of Vietnam to address the research objectives. Based on the research findings, farm characteristics, market information access, and household characteristics are proved to have strong influence on smallholders' contracting decisions. Additionally, there is a significant influence of CF participation on household income and rice profit. It is interesting that CF participation plays an important role in improving household income by $20.87 \%$, rice profit by $30.54 \%$ and $\mathrm{TE}$ level by $2.44 \%$ in Vietnam. The SFA results also reveal that about $13 \%$ of the potential output is lost due to technical inefficiency determinants. In total, the scale-effect is about 1.026, which reveals that if farmers increase $1 \%$ of production inputs, the TE score can increase by $1.026 \%$. 
In chapter two, the study contributes to the existing research about CF scheme with regard to the determinants of contracting decisions. The accessibility of world market price information is found to play a key role in smallholder farmers' marketing decision. The variables "the accessibility of world market price information" significantly increases the probability of $\mathrm{CF}$ participation, which is found as a contribution to the existing literature. The results highlight the influence of various categories on smallholder farmers' contracting decisions. Although farmers with long-term farming experience and sufficient family members have greater priority to join traditional marketing channels based on their own experiences, it cannot be denied that participating in the CF scheme offers farmers higher benefits based on fair-price frames in comparison to the more volatile spot markets. CF is also helpful for smallholder farmers to more conveniently access the market instead of relying on the traditional market through middlemen and other spot transactions. Several characteristics are found to influence smallholders' marketing decisions. Firstly, we find that low percentage of credit accessibility could be one of the reasons that lead to the current situation that a vast majority of farmers prefer dealing with middlemen in spot markets to get more flexible credit inputs. Secondly, more extension service accessibility could offer better farming practices and more farming experience. Family labors play an important role in smallholders' marketing decisions. Thirdly, gender and education do not influence the contracting decision. Finally, it is also interesting to learn from the case that for farmers who have greater access to market information are more willing to participate in modern marketing channels.

In chapter three, we evaluate the influences of CF participation on households' performance based on two criteria: household income and rice profit. The finding contributes to the existing literature that not only larger-scale rice farmers but also small-scale rice farmers can get benefits from contract participation. We find that there is a positive and significant influence of $\mathrm{CF}$ participation status on household income and rice profit. It becomes evident that CF participation supports smallholder farmers to increase their income by $20.87 \%$ and rice profit by $30.54 \%$ in comparison with the non-contract group. In addition, we discover some major socio-economic characteristics that strongly affect households' performance. Apart from the positive significant sign of "the accessibility of world price information" (i) variable, we also find that "farming size" (ii) and "the accessibility of extension services" (iii) are key determinants of improving farming households' performance. Results on the effects of farm size and extension services once again confirm previous research results, 
whereas our insights into the role of access to information on world market prices is considered to fill an existing research gap. As a result, it is very important to take into consideration the availability of market price information to encourage CF participation. Due to the economic benefits resulting from the $\mathrm{CF}$ scheme in the Vietnamese export rice production sector, a further development and enhancement of the $\mathrm{CF}$ scheme is strongly suggested. Thus, more favorable CF terms and conditions and more availability of market information and extension services offered by contractors could be helpful to attract more participants.

Chapter four includes the analysis of the mechanism on how $\mathrm{CF}$ participation influences farming TE levels and the technical inefficiency determinants. The study contributes to the body of previous literature by exploring the determinants of CF participation and the effects of CF on farm TE levels among the export-oriented rice sector in Vietnam. These aspects have never been thoroughly analyzed before. The SFA results reveal that about $13 \%$ of the potential output is lost due to technical inefficiency. The TE of export-oriented rice production in the MRD ranges between $56.48 \%$ and $96.47 \%$. In total, the scale-effect is about 1.026, which reveals that if farmers increase $1 \%$ of production inputs, the TE score can increase by $1.026 \%$. Thereby, on average, contract participants have higher TE $(88.46 \%)$ in comparison to non-contract participants $(86.02 \%)$. In the two-sample t-test of TE-mean values, the significant differences at the $5 \%$ level with a t-value of 3.01indicate the higher TEs for contract farmers. Land, seed, fertilizer, machine, and labor are identified as the major inputs of the production frontier. Moreover, the farm and household characteristics in the sample also show influences on the TE of rice farming, however non-significantly. Remarkably, in our study, not only "educational level" and "rice farming experience", but also "off-farm income" is found as positive determinants influencing rice farming TE in contrast to the low negative effect of credit accessibility. By participating in CF scheme, not only larger-scale but also small-scale farmers in developing and emerging economies can improve their production patterns.

Overall, based on the study, the development and enhancement of the Vietnamese CF scheme proposed in the decision No. 80/2002/QD-TTg named "Policy on the Promotion of Agricultural Produce and Purchase through Contracts" and decision 62/2013 QD-TTg are highly recommended. Simultaneously, also the availability of market price information and extension services are very important to encourage farmers' contracting participation. Additionally, the CF scheme is also a tool to support improving household livelihoods and 
the TE level of agricultural production in the rural areas of Vietnam, especially, with regard to export-oriented rice production. The findings are in line with the existing literature about marketing preferences, contract farming, productivity, and TE in emerging and developing countries (Mayer and Zignago, 2005; Wollni and Zeller, 2007; Khai and Yabe, 2011; Wollni and Brümmer, 2012). As suggested by Demont and Rutsaert (2017) to differentiate the price and improve Vietnamese rice quality, CF would be a potential method to deal with the issue. Derived from the research findings, we have proposed some policy recommendations for different stakeholders in the export-rice value chain such as the government, local authorities, processing and exporting companies, and farmers to improve the national rice sector.

\subsection{Policy implications and further research suggestions}

The research findings suggest some necessary policy recommendations regarding $\mathrm{CF}$ participation in the country. These are greatly proposed in the decision No. 80/2002/QD-TTg named "Policy on the Promotion of Agricultural Produce and Purchase through Contracts" and decision 62/2013 QD-TTg of the Vietnamese government. This is also in line with the restructuring strategy for converting about 20.000 ha the marginal yielding rice land into corn and soybean crops from the year 2016 on (Smith, 2013; USDA, 2015). Thus, we consider that the $\mathrm{CF}$ scheme offered by the firms will have a crucial relevance to increase the overall performance and can be an incentive for more farmers to be linked to vertically integrated value chains in the country.

The results of the first paper draw the government's attention to the accessibility of world market price information to encourage more CF participation. The information could be supplied through firms, third party and public information channels via TV, radio where the information is available and secured for farmers. Additionally, the extension service assistance offered by the contractors is considered to be an important factor to improve production quantity and quality. Furthermore, contractors should also take socio-economic characteristics such as farming experience, household size, and rice farming area as important criteria into account before offering the contract; especially they should pay attention to the price term.

The second paper highlights the importance of farming size as one of the key factors to improve household income and rice profit. It is important to remain the current rice farming size to secure rice production. Moreover, the accessibility of extension services and the 
accessibility of world price information are found to strongly influence farming households' performance, which are very important aspects to be paid attention to by the government and contractors. Based on the third paper, it becomes obvious that the TE level for exportoriented rice production is significantly influenced by $\mathrm{CF}$ participation. The levels of production frontier are determined by the expenditure on land, seed, fertilizer, machine, and labor. Yet, CF participation is considered to have an influence on rice smallholders' increase of farm TE. In order to improve the TE levels in the area, further improvement of the CF scheme is greatly suggested. More support for contractors should be considered by the government to encourage further CF availability in the MRD, as well as in the whole country. Moreover, the availability of credits with lower interest rates and the improvement of control systems should be considered by the government to increase farm TE-effects.

We acknowledge some limitations of this study. This empirical research about the implementation of the CF scheme in the export-oriented rice sector in the Mekong River Delta of Vietnam reveals many valuable findings. However, with a limited sample size of a 250 export-oriented rice farmers of this quantitative cross-sectional research, there is still a need of a larger sample observation to evaluate the CF scheme enforcement in the area. In addition, this study is only focusing on the Mekong River Delta of Vietnam with a 250.000 targeting smallholder farmers. A comparison with regards to the differences in geographic characteristics and its influences on smallholders' performances would reveal more interesting insight information about CF schemes in the whole country.

This study provides manifold starting points for future research. Further studies should evaluate the Vietnamese rice farming households' behavior on and attitudes towards different types of contract options and their willingness to participate in group contracts. Another research based on farm level data is needed to compare long-term and short-term effects of CF on rice production among smallholders. In this regard, there should be follow up studies on the influence of CF duration on households' performance within the Vietnamese export-oriented rice sector. These studies should also capture the households' behavior during a certain time to observe CF empowerment, respectively. Group contract with the FAs participation as the third party in the CF cooperation would also be interesting to conduct a further research. With regard to the agricultural credit system, there should be more in-depth research to identify concrete pitfalls diminishing its success on the farm level. Another research should propose a comparison on production frontiers between the two groups of CF participants and non-participants. A detailed cost analysis based on farmers' 


\section{Chapter 5: General Conclusions}

production functions will reveal more detailed insights into the hypothesis that inputs supplied by contractors through the $\mathrm{CF}$ scheme would be more expensive than inputs purchased on the free market but with high quality and, thus, are more efficient in farming practices. The following study could explore more valuable information for policymakers, agribusiness activities and farmers. Overall, this dissertation conceptualizes the importance of $\mathrm{CF}$ scheme and its contribution to rice farming households, not only with regard to largescale but also small-scale households. 


\section{Reference}

Aakvik, A. (2001). Bounding a Matching Estimator: The Case of a Norwegian Training Program. Oxford Bulletin of Economics and Statistics, 63, 115.

Abadie, a, and Imbens, G. W. (2009). Matching on the estimated propensity score. NBER Working Paper, 15301(December), 781-807.

Abebe, G. K., Bijman, J., Kemp, R., Omta, O., and Tsegaye, A. (2013). Contract farming configuration: Smallholders' preferences for contract design attributes. Food Policy, 40, $14-24$.

Achmad Ya'kub Wahyu Agung Perdanan, Irma Yanny, Young Mi, Kayoung Kim, E. K. S. (2012). Revisiting Vietnam Rice Farming: Moving Towards Industrialization. La Via Campesina 2012.

ADB. (2005). Linking farmers to markets through contract farming. Asian Development Bank, Making Markets Work Better for the Poor (M4P) Project and An Giang University.

Aigner, D., Lovell, C. A. K., and Schmidt, P. (1977). Formulation and estimation of stochastic frontier production function models. Journal of Econometrics, 6, 21-37.

Ali, M., and Flinn, J. C. (1989). Profit Efficiency Among Basmati Rice Producers in Pakistan Punjab. American Journal of Agricultural Economics, 71(2), 303-310.

Allen, D. W. and Dean, L. (1995). Risk preferences and the economic of contracts. The American Economic Review, 85(2), 447-451.

Austin, P. C., and Small, D. S. (2014). The use of bootstrapping when using propensity-score matching without replacement: A simulation study. Statistics in Medicine, 33(24), 43064319.

Bacon, C. (2005). Confronting the coffee crisis: Can Fair Trade, organic, and specialty coffees reduce small-scale farmer vulnerability in Northern Nicaragua? World Development, 33(3), 497-511.

Baldwin, K., Childs, N., Dyck, J., and Hansen, J. (2012). Southeast Asia's Rice Surplus. Economic Research Services/USDA, RCS-121-01, 1-38.

Barrett, C. B., Bachke, M. E., Bellemare, M. F., Michelson, H. C., Narayanan, S., and Walker, T. F. (2012). Smallholder Participation in Contract Farming: Comparative Evidence from Five Countries. World Development, 40(4), 715-730.

Battase, G., and Broca, S. (1997). Functional Forms of Stochastic Frontier Production Functions and Models for Technical Inefficiency Effects: A Comparative Study for Wheat Farmers in. Journal of Productivity Analysis, 8, 395-414.

Battese, G. E., and Coelli, T. J. (1993). A stochastic frontier production function incorporating a model for technical inefficiency effects. Working Papers in Econometrics and Applied Statistics No 69, Department of Econometrics. University of New England. Armidale.

Battese, E. (1992). Frontier production functions and technical efficiency: a survey of empirical applications in agricultural economics. Agricultural Economics, 7, 185-208.

Bellemare, M. F. (2012). As You Sow, So Shall You Reap: The Welfare Impacts of Contract Farming. World Development, 40(7), 1418-1434.

Bijman, J. (2008). Contract farming in developing countries: an overview. Working Paper , Department of Business Administration, Wageningen University, The Netherland, May.

Briones, R. M. (2015). Small Farmers in High-Value Chains: Binding or Relaxing Constraints to Inclusive Growth? World Development, 72, 43-52. 
Cai, J., Ung, L., Setboonsarng, S. and Leung, P. (2008). Rice Contract Farming in Cambodia: Empowering Farmers to Move Beyond the Contract Toward Independence. Working paper No. 109, Asian Development Bank Institute, Tokyo.

Caliendo, M., and Kopeinig, S. (2005). Some Practical Guidance for the Implementation of Propensity Score Matching. DIW Discussion Paper, 485(1), 1-29.

Caliendo, M., and Kopeinig, S. (2008). Some practical guidance for the implementation of propensity score matching. Journal of Economic Surveys, 22(1), 31-72.

Carpenter, R. E., and Petersen, B. C. (2002). Is the growth of small firms constrained by finance? The Review of Economics and Statistics, 84(2), 298-309.

Catelo, M. A. O., and Costales, A. C. (2008). Contract Farming and Other Market Institutions as Mechanisms for Integrating Smallholder Livestock Producers in the Growth and Development of the Livestock Sector in Developing Countries. Production, (45), 1-11.

Chen, C. C., McCarl, B. a., and Chang, C. C. (2006). Estimating the impacts of government interventions in the international rice market. Canadian Journal of Agricultural Economics, 54(1), 81-100.

Christensen, T., Pedersen, A. B., Nielsen, H. O., Mørkbak, M. R., Hasler, B., and Denver, S. (2011). Determinants of farmers' willingness to participate in subsidy schemes for pesticide-free buffer zones-A choice experiment study. Ecological Economics, 70(8), $1558-1564$.

Coase, R. H. (1937). The Nature of the Firm. Economica, 4(16), 386-405.

Coelli, T. J., and Battese, G. E. (1996). Identification of Factors which influence the Technical Inefficiency of Indian Farmers. Australian Journal of Agricultural Economics, 40(2), $103-$ 128.

Coxhead, I., Linh, V. H., and Tam, L. D. (2012). Global market shocks and poverty in Vietnam: The case of rice. Agricultural Economics (United Kingdom), 43(5), 575-592.

Da Silva, C. A. B. (2005). The growing role of contract farming in agri-food systems development : drivers, theory and practice. FAO Rome.

David, B., Spencer, H., (2012). Supermarket Procurement Practices in Developing Countries: Redefining the Roles of the Public and Private Sectors. International Journal of Sustainable Development, 5(8), 41-50.

Dehejia, R. H., and Wahba, S. (2002). Propensity Score-Matching Methods For Nonexperimental Causal Studies, 84(1), 151-161.

Demont, M., and Rutsaert, P. (2017). Restructuring the Vietnamese Rice Sector: Towards Increasing Sustainability. Sustainability, 9(3), 325.

Diep, T. T. (2013). Changes in the technical and scale efficiency of rice production activities in the Mekong delta, Vietnam. Agricultural and Food Economics, 1, 16.

Duy, N. N., and Flaaten, O. (2016). Profitability Effects and Fishery Subsidies: Average Treatment Effects Based on Propensity Scores. Marine Resource Economics, 31(4), 373402.

Duy, V. Q. (2012). The role of access to credit in rice production efficiency of rural households in the Mekong Delta, Vietnam. Centre for ASEAN Studies, (84), 1-16.

Eaton, C., and Shepherd, A. W. (2001). Contract Farming: Partnerships for Growth. Food and Agriculture Organization (FAO), 145(Rome).

Elepu, G., and Nalukenge, I. (2009). Contract Farming, Smallholders and Commercialization of 
Agriculture in Uganda: The Case of Sorghum, Sunflower, and Rice Contract Farming Schemes. Working Paper No. AfD-0907 Issued in July 2009, Ceter for(Agriculture for Development).

Feder, G., Just, R., and Zilber, D. (1985). Adoption of Agricultural Innovations in Developing Countries : A Survey. Economic Development and Cultural Change, 33(2), 255-298.

Fishbein, M., and Ajzen, I. (2011). Predicting and Changing Behavior: The Reasoned Action Approach. Psychology Press, Talor and Francis Group, New York.

Frédéric, T., and Dao, T., (2005). Community Biodiversity Management. (M. T. and E. O. Walter Simon de Boef, Abishkar Subedi, Nivaldo Peroni, Ed.). Taylor and Francis Group, New York.

Gatto, M., Wollni, M., Asnawi, R. and Qaim, M. (2017). Oil Palm Boom, Contract Farming, and Rural Economic Development: Village-Level Evidence from Indonesia. World Development. Pergamon, 95, 127-140.

Ghosh, M., and Whalley, J. (2004). Are price controls necessarily bad? The case of rice in Vietnam. Journal of Development Economics, 73(1), 215-232.

Gibson, J., and Kim, B. (2013). Do the urban poor face higher food prices? Evidence from Vietnam. Food Policy, 41, 193-203.

Giraud, G. (2013). The world market of fragrant rice, main issues and perspectives. International Food and Agribusiness Management Review, 16(2), 1-20.

Goletti, F., Minot, N., and Berry, P. (1997). Marketing constraints on rice exports from Vietnam. Washington, DC: International Food Policy Research Institute, June.

Greene, W. H. (2002). Econometric analysis (5th ed.). New York University.

Greiner, R. (2015). Motivations and attitudes influence farmers' willingness to participate in biodiversity conservation contracts. Agricultural Systems, 137, 154-165.

Grosh, B. (1994). Contract Farming in Africa: an Application of the New Institutional Economics. Journal of African Economies, 3(2), 232-261.

Gyau, A., Spiller, A., Simmons, P., Winters, P., Patrick, I., Singh, S., (2008). The impact of supply chain governance structures on the inter-firm relationship performance in agribusiness. Agricultural Economics, 54(4), 176-185.

Handschuch, C., Wollni, M., and Villalobos, P. (2013). Adoption of food safety and quality standards among Chilean raspberry producers - Do smallholders benefit? Food Policy, 40, 64-73.

Hanink, D. M., and Owusu, J. H. (2000). Vertical Coordination in the Agro-Food Industry and Contract Farming: A Comparative Study of Turkey and the USA. Department of Agricultural and Resource Economics University of Connecticut, 52(3), 363-383.

Hazell, P. B. R. (1985). Rice in the Global Economy. Journal of Agricultural Economics, 36(2), 145-159.

Heckman, J. (1979). Sample selection bias as a specification error. Econometrica, 47, 153-162.

Henson, S. and Reardon, T. (2005). Private agri-food standards: Implications for food policy and the agri-food system. Food Policy, 30(3), 241-253.

Hernández, R., Reardon, T., and Berdegué, J. (2007). Supermarkets, wholesalers, and tomato growers in Guatemala. Agricultural Economics, 36(3), 281-290.

Hoang, V.-N. (2013). Analysis of productive performance of crop production systems: An 
integrated analytical framework. Agricultural Systems, 116, 16-24.

Hoang, L. Van, and Yabe, M. (2012). Impact of Environmental Factors on Profit Efficiency of Rice Production: A Study in Vietnam's Red River Delta. Global Journal of Human Social Science (B), 6(1), 91-98.

Holzapfel, S., and Wollni, M. (2014). Is GlobalGAP certification of small-Scale farmers sustainable? Evidence from Thailand. Journal of Development Studies, 50(5), 731-747.

Hongdong, G., Robert, W. J., and Jianhua, Z. (2007). Contract Farming in China: Perspectives of Farm Households and Agribusiness Firms. Comparative Economic Studies, 49, 285-312.

Huber, M., Lechner, M., and Wunsch, C. (2013). The performance of estimators based on the propensity score. Journal of Econometrics, 175(1), 1-21.

Huh, W. T., Athanassoglou, S. and Lall, U. (2012). Contract farming with possible reneging in a developing country: Can it work?. IIMB Management Review, 24(4), 187-202.

Imbens, G. W., and Rubin, D. B. (2015). Causal Inference in Statistics, Social, and Biomedical Sciences: An Introduction.

Imbens, G. W. (2004). Nonparametric estimation of average treatment effects under exogeneity: a review. Review of Economics and Statistics, 86(1), 4-29.

Imbens, G. W., and Rubin, D. B. (2015). Causal Inference in Statistics, Social, and Biomedical Sciences: An Introduction.

IRRI. (2005). World Rice Statistic, International Rice Research Institute, Manila. Retrieved from www.irri.org/science/ricestat/ (accessed August 15, 2016).

Jaenicke, H., Anh, D. T., Nghiep, P. C., Jaenicke, H., Anh, D. T. and Nghiep, P. C. (2010). Harnessing local under used crops to improve household nutrition and income opportunities in Vietnam : case of Hoa vang sticky rice in Red river delta. Processding paper of 116th EAAE Seminar, October 27th -30th, 2010, Parma (Italy).

Jia, X., and Bijman, J. (2013). Contract farming: Synthetic themes for linking farmers to demanding markets. Contract Farming: for inclusive market access, FAO.

Kersting, S., and Wollni, M. (2012). New institutional arrangements and standard adoption: Evidence from small-scale fruit and vegetable farmers in Thailand. Food Policy, 37(4), $452-462$.

Key, N., and Runsten, D. (1999). Contract Farming, Smallholders, and Rural Development in Latin America: The Organization of Agroprocessing Firms and the Scale of Outgrower Production. World Development, 27(2), 381-401.

Khai, H. V., and Yabe, M. (2011). Technical Efficiency Analysis of Rice Production in Vietnam. Journal of International Society for Southeast Asian Agricultural Sciences (ISSAAS), 17(1), 135-146.

Kherallah, M., and Kirsten, J. F. (2002). The new institutional economics: Applications for agricultural policy research in developing countries. Agrekon, 41(2), 110-133.

Kleemann, L., Abdulai, A. and Buss, M. (2014). Certification and Access to Export Markets: Adoption and Return on Investment of Organic-Certified Pineapple Farming in Ghana. World Development, 64, 79-92.

Klein, B., Crawford, R. G. and Armen A, A. (1978). Vertical Integration , Appropriable Rents , and the Competitive Stable. The University of Chicago Press, 2(2), 297-326.

Khush, G. S. (1997). Origin, dispersal, cultivation and variation of rice. In Oryza: From Molecule to Plant (pp. 25-34). Dordrecht: Springer Netherlands. 
Kleemann, L., Abdulai, A., and Buss, M. (2014). Certification and Access to Export Markets: Adoption and Return on Investment of Organic-Certified Pineapple Farming in Ghana. World Development, 64, 79-92.

Klein, B., Crawford, R. G. ., and Armen A, A. (1978). Vertical Integration , Appropriable Rents , and the Competitive Stable. The University of Chicago Press, 21(2), 297-326.

Kolawole, O. (2006). Determinants of Profit Efficiency Among Small Scale Rice Farmers in Nigeria: A Profit Function Approach. Research Journal of Applied Sciences, 1(1), 116122.

Krugman, P. (1994). Defining and Measuring Productivity. OECD.Org.

Kubo, K. (2013). Rice Yield Gap between Myanmar and Vietnam : A Matter of Price Policy or Public Investment in Technology? Asian Journal of Agriculture and Development, 10(1).

Kulkarni, S. and Grethe, H. (1999). A comparative study of contract and non-contract farmers in India.

Kumbhakar, S.C., and Lovell, C. A. K. (2000). Stochastic frontier analysis. Cambridge, UK: Cam-Bridge Univ. Press.

Latruffe, L., Balcombe, K., Davidova, S., and Zawalinska, K. (2005). Technical and scale efficiency of crop and livestock farms in Poland: does specialization matter? Agricultural Economics, 32, 281-296.

Liese, B., Isvilanonda, S., and Tri, K. N. (2014). Economics of Southeast Asian Rice Production.

Linh, V. H. (2012). Efficiency of rice farming households in Vietnam. International Journal of Development Issues, 11, 60-73.

Little, R. J., and D. B. R. (2002). Statistical Analysis With Missing Data. Hoboken, NJ: WileyInterscience.

Loc, V., Khiem, L., Nguyen, T., (2010). High and low value fish chains in the Mekong Delta: challenges for livelihoods and governance. Environ Dev Sustain, 12, 889-908.

Loc, V., and Son, N. P. (2011). Vietnamese rice value chain analysis. The Economic Review, Cantho University. Vietnam, 96-108.

Lutz, C., Praagman, C., and Hai, L. T. D. (2006). Rice market integration in the Mekong River Delta: The transition to market rules in the domestic food market in Vietnam. Economics of Transition, 14(3), 517-546.

Macharia, M. A., Mshenga, P. M., Ngigi, M., Gido, O. E., and Kiprop, K. J. (2014). Effect of transaction costs on smallholder maize market participation: Case of Kwanza District, Trans Nzoia County, Kenya. International Journal of Development and Sustainability. 3(4), 715725 .

Maina, C. M., Lagat, J. K. and Mutai, B. K. (2015). Effect of transaction costs on choice of mango marketing channel: the case of small scale farmers in Makueni County, Kenya. IOSR Journal of Agriculture and Veterinary Science Ver. III, 8(4), 2319-2372.

Maertens, M., and Swinnen, J. F. M. (2009). Trade, Standards, and Poverty: Evidence from Senegal. World Development, 37(1), 161-178.

Maertens, M., and Vande Velde, K. (2017). Contract-farming in Staple Food Chains: The Case of Rice in Benin. World Development, 95, 73-87.

Magesa, M. M., Michael, K., and Ko, J. (2014). Access to Agricultural Market Information by Rural Farmers in Tanzania. International Journal of Information and Communication Technology Research, 4(7), 7-9. 
Markelova, H., Meinzen-Dick, R., Hellin, J., and Dohrn, S. (2009). Collective action for smallholder market access. Food Policy, 34(1), 1-7.

Marshall, G. (1998). A dictionary of sociology. Oxford University Press.

Mayen, C. D., Balagtas, J. V, and Alexander, C. E. (2010). Technology Adoption and Technical Efficiency: Organic and Conventional Dairy Farms in the United States. American Journal of Agricultural Economics, 92(1), 181-195.

Meeusen, W., and Broeck, J. Van Den. (1977). Economics Department of the University of Pennsylvania Institute of Social and Economic Research, Osaka University Efficiency Estimation of Production Functions, 18(2).

Minot, N., and Goletti, F. (1998). Export Liberalization and Household Welfare: The Case of Rice in Vietnam. American Journal of Agricultural Economics, 80(November), 738-749.

Minot, N., and Goletti, F. (2000). Rice Market Liberalization and poverty in Viet Nam. Research Report of the International Food Policy Research Institute, Library of Congress Cataloging-in-Publication Data.

Minot, N., and Roy, D. (2007). Impact of high-value agriculture and modern marketing channels on poverty: An analytical framework. International Food Policy Research Institute, 139.

Minot, N., and Sawyer, B. (2016). Innovation for inclusive value-chain development: Successes and challenges. (D. H. André Devaux, Maximo Torero, Jason Donovan, Ed.).

Minten, B., Murshid, K. A. S., and Reardon, T. (2013). Food Quality Changes and Implications: Evidence from the Rice Value Chain of Bangladesh. World Development, 42(1), 100-113.

Minten, B., Randrianarison, L., and Swinnen, J. F. M. (2009). Global Retail Chains and Poor Farmers: Evidence from Madagascar. World Development, 37(11), 1728-1741.

Miyata, S., Minot, N., and Hu, D. (2009). Impact of Contract Farming on Income: Linking Small Farmers, Packers, and Supermarkets in China. World Development, 37(11), 1781-1790.

Moustier, P., Tam, P. T. G., Anh, D. T., Binh, V. T., and Loc, N. T. T. (2010). The role of farmer organizations in supplying supermarkets with quality food in Vietnam. Food Policy, 35(1), 69-78.

Mwambi, M. M., Oduol, J., Mshenga, P., and Saidi, M. (2014). Does contract farming improve smallholder income? The case of avocado farmers in Kenya. Journal of Agribusiness in Developing and Emerging Economices, 6(1), 2-20.

Naziri, D., Aubert, M., Codron, J.-M., Loc, N. T. T., and Moustier, P. (2014). Estimating the Impact of Small-Scale Farmer Collective Action on Food Safety: The Case of Vegetables in Vietnam. The Journal of Development Studies, 50(5), 715-730.

Netemeyer, R., Ryn, M. Van, and Ajzen, I. (1991). The theory of planned behavior. Orgnizational Behavior and Human Decision Processes, 50, 179-211.

Ngoc, Q. P., and Anh, H. La. (2014). Viet Nam_Household welfare and Pricing of Rice: Does the Large-Scale Field Model matter for Viet Nam? Trade policies, household welfare and poverty alleviation. United Nations, 301-335.

Nielsen, C. P. (2003). Vietnam's Rice Policy: Recent Reforms and Future Opportunities. Asian Economic Journal, 17(1), 1-26.

Oliver Masakure, S. H. (2005). Why Do Small-Scale Producers Choose to Produce under Contract? Lessons from Nontraditional Vegetable Exports from Zimbabwe. World Development, 33(10), 1721-1733.

Otsuka, K., Nakano, Y., and Takahashi, K. (2016). Contract Farming in Developed and 
Developing Countries. Annual Review of Resource Economics, 8(1), 353-376.

Otter, V., Engler, a., and Theuvsen, L. (2014). The influence of the interplay of supply chain network relationships on farmers' performance in the Chilean NTAE sector. Journal on Chain and Network Science, 14(3), 149-169.

Oya, C. (2012). Contract Farming in Sub-Saharan Africa: A Survey of Approaches, Debates and Issues. Journal of Agrarian Change, 12(1), 1-33.

Pandey, S., and van Minh, D. (1998). A socio-economic analysis of rice production systems in the uplands of northern Vietnam. Agriculture, Ecosystems and Environment, 70(2-3), 249258.

Pingali, P. L., Khiem, N. T., Gerpacio, R. V, and Xuan, V. O. T. (1997). Prospects for sustaining Vietnam's reacquired rice exporter status. Food Policy, 22(4), 345-358.

Pohl, C., and Nielsen, C. P. (2002). Vietnam in the International Rice Market, (132).

Prabhu L . Pingali and Vo-Tong Xuan. (1992). Vietnam: Decollectivization and Rice Productivity Growth. Economic Development and Cultural Change, The University of Chicago Press, 40(4), 697-718.

Prowse, M. (2012). Contract Farming in Developing Countries - A Review Contract Farming in Developing Countries - A Review. Institute of Development Policy and Management, University of Antwerp.

Rahman, S., Wiboonpongse, A., and Sriboonchitta, S. (2009). Production efficiency of Jasmine rice producers in Northern and North-eastern Thailand. Journal of Agricultural Economics, 60(2), 419-435.

Ramaswami, B., Birthal, P. S., and Joshi, P. . (2005). Efficiency and distribution in contract farming: The case of Indian poultry growers Discussion Papers in Economics Efficiency and Distribution in Contract Farming: The Case of Indian Poultry Growers, 1-39.

Ramberg, B. J. (2011). ICC Guide to Incoterms 2010.

Rao, E. J. O., Brümmer, B., and Qaim, M. (2012). Farmer participation in supermarket channels, production technology, and efficiency: The case of vegetables in Kenya. American Journal of Agricultural Economics, 94(4), 891-912.

Rawlins, G. (1985). Measuring the Impact of IRDP II on the Technical Efficiency Level of Jamaican Peasant Farmers. Social and Economic Studies, 34(2).

Reardon, T., Barrett, C. B., Berdegué, J. A., and Swinnen, J. F. M. (2009). Agrifood Industry Transformation and Small Farmers in Developing Countries. World Development, 37(11), $1717-1727$.

Reardon, T., Chen, K. Z., Minten, B., Adriano, L., Dao, T. A., Wang, J., and Gupta, S. Das. (2014). The quiet revolution in Asia's rice value chains. Annals of the New York Academy of Sciences, 1331(1), 106-118.

Rosenbaum, P. R., and Rubin, D. B. (1983). The Central Role of the Propensity Score in Observational Studies for Causal Effects. Biometrika, 70(1), 41-55.

Ross, S. A. (1973). Theory of Agency: The Principal's Problem. American Economic Association The Economic, 63(2), 134-139.

Ryan, J. (2002). Assessing the impact of food policy research: rice trade policies in Viet Nam. Food Policy, 27, 1-29.

Saenger, C., Qaim, M., Torero, M., and Viceisza, A. (2013). Contract farming and smallholder incentives to produce high quality: Experimental evidence from the Vietnamese dairy 
sector. Agricultural Economics (United Kingdom), 44(3), 297-308.

Saenger, C., Torero, M., and Qaim, M. (2014). Impact of third-party contract enforcement in agricultural markets - A field experiment in Vietnam. American Journal of Agricultural Economics, 96(4).

Saigenji, Y. (2010). Contract farming and its impact on production efficiency and rural household income in the vietnamese tea sector. PhD Thesis, University of Hohenheim.

Saigenji, Y., and Zeller, M. (2009). Effect of contract farming on productivity and income of small holders: The case of tea production in north-western Vietnam. International Association of Agricultural Economists, Beijing China, August 16-22, 2009, 1-18.

Sanford, J. G., and Oliver, D. H. (1986). The Costs and Benefits of Ownership: A Theory of Vertical and Lateral Integration. Journal of Political Economy, 94(4), 691-719.

Sartorius, J. K. and K. (2013). Linking agribusiness and small-scale farmers in developing countries: Is there a new role for contract farming? Working Paper, University of Pretoria Pretoria, 0002 South Africa.

Scherer, F.M. 1980, Industrial Market Structure and Economic Performance, 2nd ed. Boston.

Schipmann, C., and Qaim, M. (2011). Supply chain differentiation, contract agriculture, and farmers' marketing preferences: The case of sweet pepper in Thailand. Food Policy, 36(5), 666-676.

Schulze, B., Spiller, A., and Theuvsen, L. (2007). A broader view on vertical coordination: lessons from German pork production. Journal on Chain and Network Science, 7(1), 3553.

Secer, A., Davran, K. M., and Emeksiz, F. (2006). Vertical Coordination : Contract Production Method To Solve Marketing Problems in the Rural Areas. Journal of European Central of Agriculture, 7(3), 533-536.

Shiferaw, B., Hellin, J., and Muricho, G. (2016). Markets Access and Agricultural Productivity Growth in Developing Countries: Challenges and Opportunities for Producer Organizations. Cooperatives, Economic Democratization and Rural Development, 103.

Simmons, P., Winters, P., and Patrick, I. (2005). An analysis of contract farming in East Java, Bali, and Lombok, Indonesia. Agricultural Economics, 33(3), 513-525.

Singh, S. (2000). Theory and Practice of Contract Farming: A Review. Journal of Social and Economic Development, 2(2), 228-246.

Smith, J. A., and Todd, P. E. (2005). Does matching overcome LaLonde's critique of nonexperimental estimators? Journal of Econometrics (Vol. 125).

Smith, W. (2013). Agriculture in the central Mekong Delta, (December), 1-13.

Soe, W. P. P., Moritaka, M., and Fukuda, S. (2015). An analysis of the factors influencing marketing channel choice by paddy rice farmers in Myanmar. Journal of the Faculty of Agriculture, Kyushu University, 60(2), 535-542.

Springer-Heinze, A. (2008). ValueLinks Manual. Gtz, (January), 243.

Sriboonchitta, S. (2008). Overview of Contract Farming in Thailand: Lessons Learned ADB Institute Discussion Paper No. 112.

Thawatchai, D. (2011). Composite Index of Market Access for the Export of Rice from Thailand. International Centre for Trade and Sustainable Development (ICTSD), (31).

Ton, G., Desiere, S., Vellema, W., Weituschat, S., and D 'haese, M. (2017). The Effectiveness of Contract Farming in Improving Smallholder Income and Food Security in Low- and 
Middle-Income Countries: A Mixed-Method Systematic Review. 3ie Systematic Review, (38).

Trifković, N. (2014). Certified standards and vertical coordination in aquaculture: The case of pangasius from Vietnam. Aquaculture, 433(0), 235-246.

Tuan, N. P. (2012). Contract farming and its impact on income and livelihood for small scale farmers: case study in Vietnam. Journal of Agribusiness and Rural Development, 4(26), 147-166.

Tzouvelekas, V., and Pantzios, C. J. (2001). Technical efficiency of alternative farming systems : the case of Greek organic and conventional olive-growing farms, 26, 549-569.

Ulimwengu, J., and Badiane, O. (2010). Vocational Training and Agricultural Productivity: Evidence from Rice Production in Vietnam. The Journal of Agricultural Education and Extension, 16(4), 399-411.

UNCTAD. (2009). World investment report, 1, 251-257.

USDA. (2015). Vietnam Grain and Feed annual. Foreign Agricultural Service. Retrieved from http://gain.fas.usda.gov/Recent GAIN Publications/Grain and Feed Update_Hanoi_Vietnam_9-4-2015.pdf

USDA (2016), "Rice: world market and trade", available at: https://apps.fas.usda.gov/psdonline/circulars/grain-rice.pdf, (accessed 12 December 2017).

Vanslembrouck, I., Van Huylenbroeck, G., and Verbeke, W. (2002). Determinants of the Willingness of Belgian Farmers to Participate in Agri-environmental Measures. Journal of Agricultural Economics, 53(3), 489-511.

Van de Ven, Wynand P. and van Praag, Bemnard M., (1981). The demand for deductibles in private health insurance: A probit model with sample selection. Journal of Economics, 17, $229-252$.

Vandeplas, A., Minten, B. and Swinnen, J. (2013). Multinationals vs. Cooperatives: The Income and Efficiency Effects of Supply Chain Governance in India. Journal of Agricultural Economics, 64(1), 217-244.

Verhofstadt, E. and Maertens, M. (2015). Can agricultural cooperatives reduce poverty? Heterogeneous impact of cooperative membership on farmers' welfare in Rwanda. Applied Economic Perspectives and Policy, 37(1), pp. 86-106.

VIETTRADE. (2008). Report on Vietnamese Rice sector, 1-56.

Vinh, T., and Dinh, P. (2014). Some Solutions for Developing Contract Integration in Production - Consumption of Rice in Dong Thap Province. Journal of the Vietnamese Science and Development, 12(6), 844-852.

Vo, H. T., and Nguyen, T. T. (2016). Cost Efficiency of Rice Production in Vietnam : An Application of Stochastic Translog Variable Cost Frontier. Asian Journal of Agricultural Extension, Economics and Sociology, 8(1), 1-10.

Wang, H. H., Wang, Y. B., and Delgado, M. S. (2014). The Transition to Modern Agriculture: Contract Farming in Developing Economies. American Journal of Agricultural Economics, 96(5), 1257-1271.

Wang, H., Moustier, P., and Loc, N. T. T. (2014). Economic impact of direct marketing and contracts: The case of safe vegetable chains in northern Vietnam. Food Policy, 47(0), 1323.

Warning, M., and Key, N. (2002). The Social Performance and Distributional Consequences of 
Contract Farming: An Equilibrium Analysis of the Arachide de Bouche Program in Senegal. World Development, 30(2), 255-263.

Weatherspoon, D. D., and Reardon, T. (2003). The Rise of Supermarkets in Africa: Implications for Agrifood Systems and the Rural Poor. Development Policy Review, 21(3), 333-355.

WB (2005). Food safety and agricultural health standards: challenges and opportunities for developing country exports, p. 142. Available at: http://siteresources.worldbank.org/INTRANETTRADE/Resources/Topics/Standards/standar ds_challenges_synthesisreport.pdf, (accessed 12 December 2007).

WB (2016). Rural population (percent of total population) Data, Available at: http://data.worldbank.org/indicator/SP.RUR.TOTL.ZS (accessed 12 December 2017).

Will, M. (2013), Contract farming handbook: A practical guide for linking small-scale producers and buyers through business model innovation, GIZ, Federal Ministry for Economic Cooperation and Development, Germany.

Williamson, O. E. (1975). Markets and hierarchies: Analysis and antitrust implications. NewYork: Free Press.

Williamson, O. e. (1979). Transaction-Cost Economics: The Governance of Contractual Relations. The Journal of Law and Economics, The Booth School of Business, University of Chicago, 22(2), 233-261.

Williamson, O. E. (1991). Comparative Economic Organization: The Analysis of Discrete Structureal Alternatives. Administrative Science Quarterly, Vol. 36, No. 2, pp. 269-296.

Woldie, Getachew Abebe (2010). Optimal Farmer Choice of Marketing Channels in the Ethiopian Banana Market. Journal of Agricultural \& Food Industrial Organization: 8(1) 7.

Wollni, M., and Andersson, C. (2014). Spatial patterns of organic agriculture adoption: Evidence from Honduras. Ecological Economics, 97, 120-128.

Wollni, M., and Brümmer, B. (2012). Productive efficiency of specialty and conventional coffee farmers in Costa Rica: Accounting for technological heterogeneity and self-selection. Food Policy, 37(1), 67-76.

Wollni, M., and Zeller, M. (2007). Do farmers benefit from participating in specialty markets and cooperatives? The case of coffee marketing in Costa Rica. Agricultural Economics, $37(2-3), 243-248$.

Wooldridge, J. (2009). Estimating Average Treatment Effects: Unconfoundedness.

Wooldridge, J. M. (2002). Econometric analysis of cross section and panel data, 2nd ed. MIT, MIT Cambridge, Mass, London.

Wooldridge, J. M. (2007). Inverse probability weighted estimation for general missing data problems. Journal of Econometrics, 141(2), 1281-1301.

Wynand, P. M. M. V. D. V., and Bernard, M. . V. P. (1981). The demand for deductibles in private health insurance: A probit model with sample selection. Journal of Econometrics, 17, 229-252.

Ya'kub, A., Perdanan, W., Yanny, I., Mi, Y., Kim, K., (2012). Revisiting Vietnam Rice Farming: Moving Towards Industrialization. La Via Campesina 2012.

Young, K. B., Wailes, E., Cramer, G., and Khiem, N. T. (2002). Vietnam's Rice Economy: Developments and Prospects. Arkansas Agricultural Experiment Station, (Research Report 968), 1-32. 
Zulfiqar, F., Datta, A., Thapa, G. B, (2017), Determinants and resource use efficiency of "better cotton": An innovative cleaner production alternative, Journal of Cleaner Production, $166,1372-1380$. 


\section{Appendices}

Appendix 1: Paddy yield (tons per hectare) in Southeast Asia 2005-2015

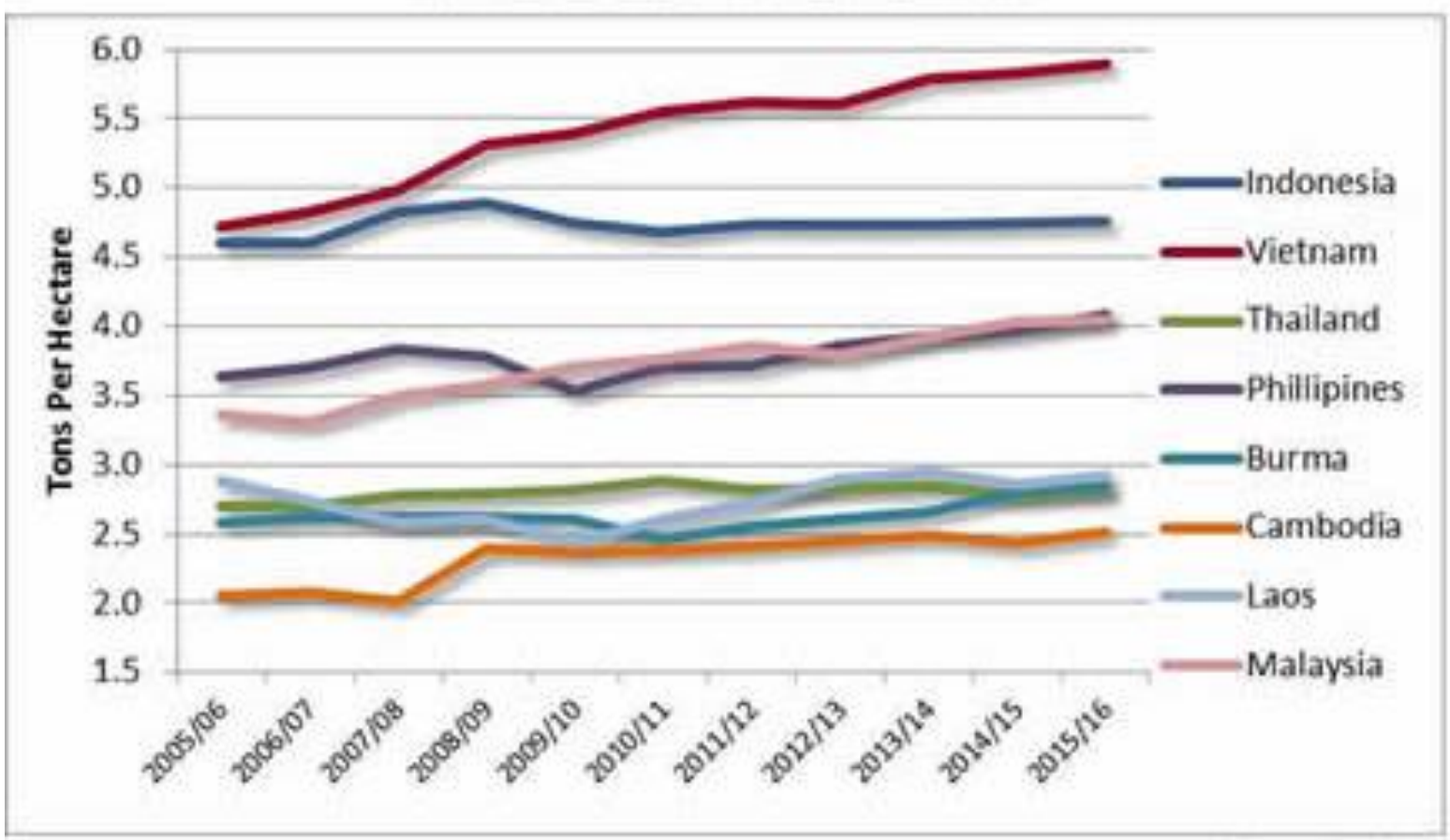

Source: USDA (2015)

Appendix 2: Vietnam exports of rice by grade 2013-2016

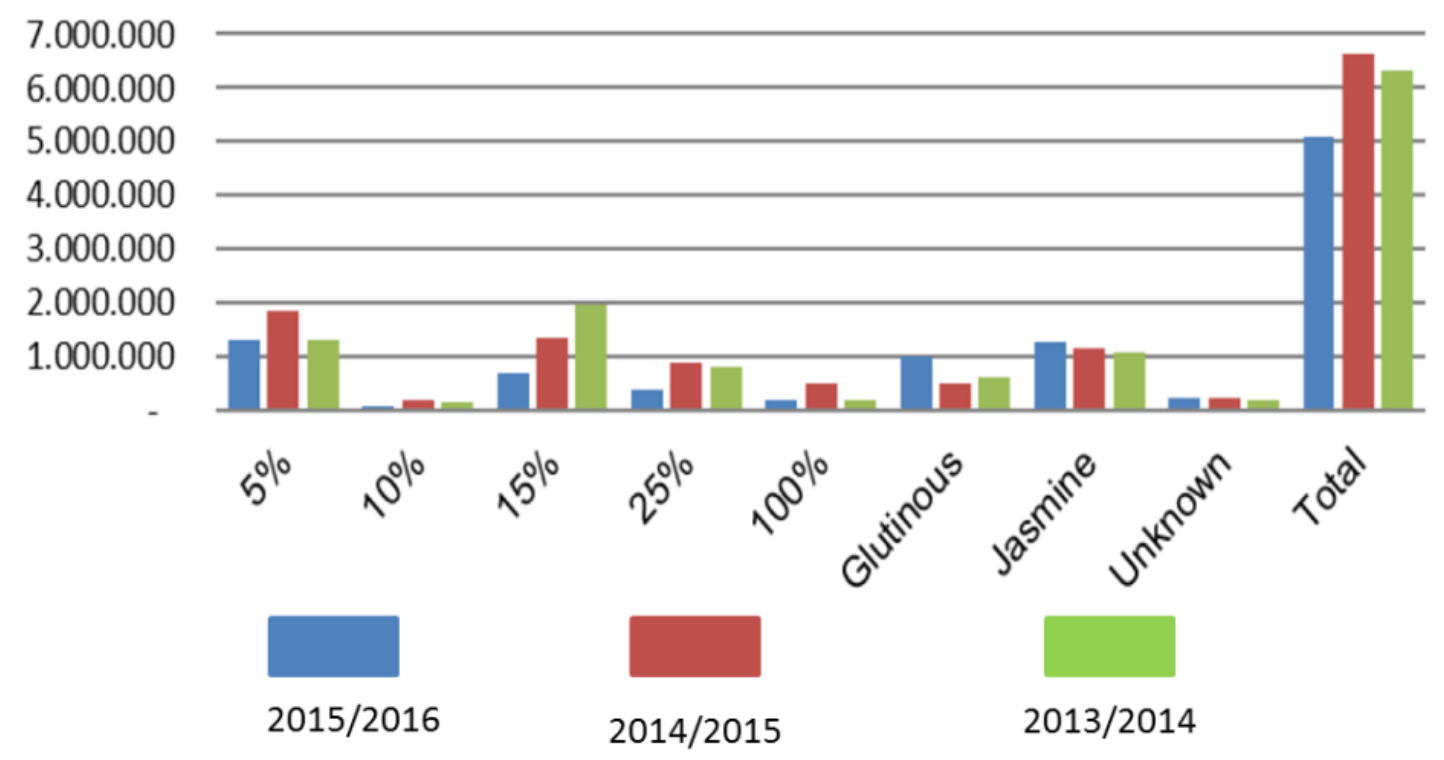

Source: USDA (2017) 
Appendix 3. Technical efficiency distribution with selection bias controlling

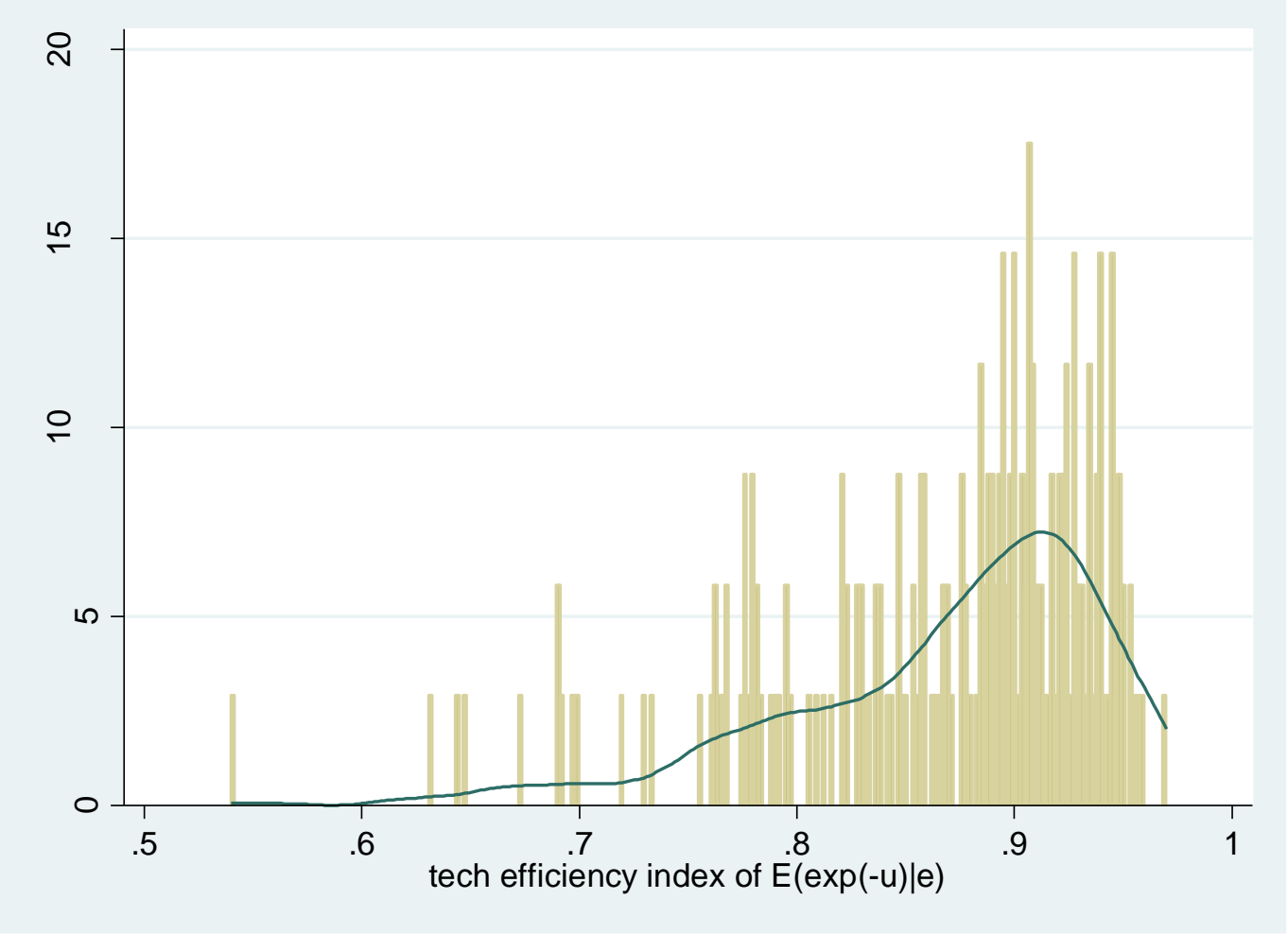

Sources: authors'onwed calculations

Appendix 4: Household questionnaire 2016 


\section{Georg-August-Universität \\ Göttingen}

\section{HOUSEHOLD SURVEY 11.2015- 3.2016}

\section{CONTRACT FARMING FOR EXPORT-ORIENTED RICE SECTOR IN THE MEKONG RIVER DELTA OF VIETNAM}

\section{Introductory statement}

We are PhD-students from Georg-August- University of Goettingen in Germany, who are interested to know about all activities relate to rice production at household level. You have been randomly selected to participate in this interview which contains questions connected with farmer characteristics, contract farming activities, membership in farmer associations (FAs) and the determinants on farmer performance. Thank you very much for your information.

We assure that all information provided by you during this interview will be kept confidential and only be used for research purposes. It will take almost 2 hours to complete this questionnaire. If you volunteer yourself for this interview, may we start? For further inquiries, comments and/or suggestions about this survey, please contact Ms. Le Ngoc Huong; Cell phone: 0165.9357969 or Email: hlengoc@gwdg.de

Enumerator name: (ENUNAME)

Supervisor's name:

Date of data collection: (CODATE)

Module contents

Module 1: Survey information

Module 2: Farmer characteristics

Module 3: Tenure and farm production

Module 4: Contract farming production

Module 5: The perception of contract farming scheme

Module 6: Trust and Commitment

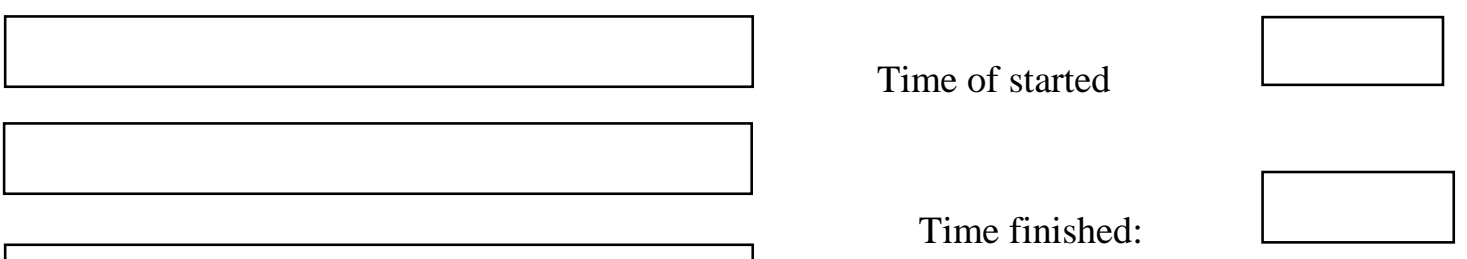

Page 1

Module 7: Non-contract participant information

Page 9

Page 1-2

Module 8: Shocks

Page 9

Module 9: Household asset

Page10

Page 6-7

Module 10: Non- farm income/off-farm income

Page 11

Module11: Farmer Association and Willingness to pay 


\section{MODULE 1. SURVEY INFORMATION}

1.1. Province (PROV)(1- Can Tho; 2- An Giang; 3:-Kien Giang)

\section{SURINFOR}

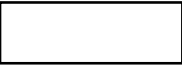

1.3. Commune (COMM) 1- Vong The; 2- Tay Phu;3- Thanh An; 4- My Phuoc; 4- My Hiep Son; 6-Vong Dong; 7- Thanh Thang; 8- Thanh Loi; 9- other)

1.4 Village (VILLAG)

1.5. Do you participate in rice contract farming in 2015? (CONTRICE) ([1] Yes [0] No)

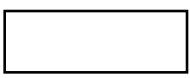

1.5.1. Have you ever dropped out from CF? (DROPOUT)

1.6. Name of head of HHs (HENAME):

1.8 Name of respondent (RNAME):

1.10. Telephone number (PHONE)

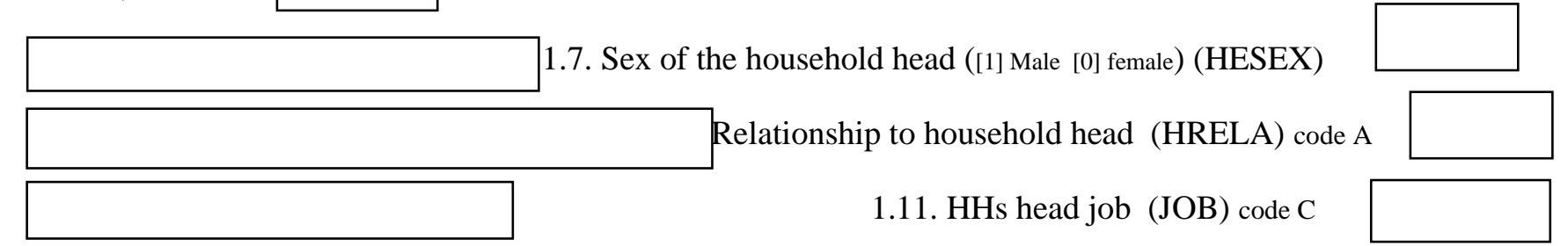

1.12. Distance to central market (DISTANCE) $(\mathrm{km})$

1.13. Which year did your household start farming in this village? (RICEEXPER)*

Code A: [1] Head; [2] Wife/Husband; [3] Son/Daughter; [4] Son/Daughter in law; [5] Father/Mother; [6] Father/Mother in law; [7] Sister/Brother; [8] Grandchild; [9] Other relatives; [10] No answer; [99] Not applicable.

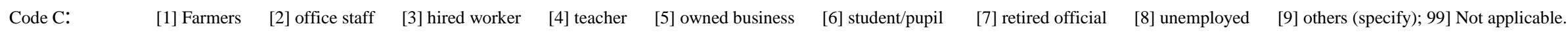

Note: - Ref. Period from 1st December 2014 to 30 November 2015; - Unit: 1 cong = $1000 \mathrm{~m} 2$; - VND: the currency of Vietnam; $1 E U R=25.000$ VND (date: 12, Nov, 2015)

- Focused on rice for export production, read out loud and explain the code if necessary!

(*)As an independent household

Code A: [1] Head; [2] Wife/Husband; [3] Son/Daughter; [4] Son/Daughter in law; [5] Father/Mother; [6] Father/Mother in law; [7] Sister/Brother; [8] Grandchild; [9] Other relatives; [10] No answer; [99] Not applicable. 


\section{MODULE 2. DEMOGRAPHICS OF THE HOUSEHOLD}

2.1 Name of major farmer (FULLNAME):

2.3 Age (AGE):

2.5 Marriage satus (MARIED) code B:

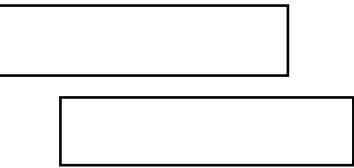

2.7 Do you participate in any farmer associations? (ORGHHMB) ([1] Yes [0] No)

2.8 Number of hh member (NUMEM):

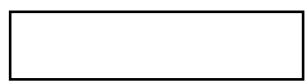

(DEPMEM):

2.10 Number of dependent member

Code B:

[1]Single [2] Married

[3] Others
DEMOS

\subsection{Gender (GEN) ([1] Male [0] female)):}

2.4 Number of schooling years (EDULEVEL):

2.6 Relationship to HH head (RELATION) code A:

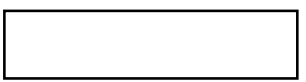

2.9 Number of agricultural member (AGMEM):

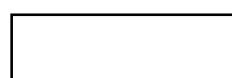

MODULE3. TENURE AND FARM PRODUCTION

3.1. Total farm size? (TOAREA)

3.2. Total rice farming size (AGAREA)

3.3. Hired land size (CULTAREA)

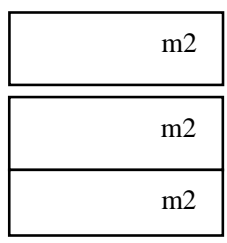

Hired price: (PHIRE):

Please specify the land characteristics.

\begin{tabular}{|l|l|l|l|l|}
\hline \multicolumn{1}{|c|}{ Slot of rice farming land } & 1 & 2 & 3 & \multicolumn{1}{|c|}{5} \\
\hline $\mathrm{m} 2)$ & & & & \\
\hline quality (Code $\mathrm{M})$ & & & & \\
\hline nce from hh place to farming land $(\mathrm{km})$ & & & & \\
\hline
\end{tabular}

Code M: [1] low quality, [2] Normal quality ,[3] high quality, [4] other (specify) 


\subsection{Rice production}

ALLRICE

Please list all plots that produced rice during the last 12 months (december 12. 2014 - November.2015), starting with the plot planted export-oriented rice varieties:

\begin{tabular}{|c|c|c|c|c|c|c|c|c|}
\hline 1 & 2 & 3 & 4 & 5 & 6 & 7 & 8 & 9 \\
\hline Season & $\begin{array}{c}\text { Land } \\
\text { (code } \\
\text { part 3.3) }\end{array}$ & $\begin{array}{l}\text { What was the } \\
\text { variety planted in } \\
\text { the plot each } \\
\text { season? } \\
\text { Code E }\end{array}$ & $\begin{array}{c}\text { Seed sources } \\
\text { [1] } \\
\text { company/contractors } \\
\text { [2] self-service } \\
\text { [3] agency }\end{array}$ & $\begin{array}{c}\text { Total of } \\
\text { quantity of } \\
\text { crop } \\
\text { harvested } \\
(\mathrm{kg})\end{array}$ & $\begin{array}{c}\text { Rice for } \\
\text { home } \\
\text { consumptio } \\
\mathrm{n} \\
\\
(\mathrm{kg})\end{array}$ & $\begin{array}{c}\text { Do you sell? } \\
\text { [1] Có } \\
{[0] \text { Không }}\end{array}$ & $\begin{array}{c}\text { Quantity } \\
\text { (kg) }\end{array}$ & $\begin{array}{c}\text { Price } \\
\text { 1000VND }\end{array}$ \\
\hline RICESEA & & NAMEVAR & PADSOURCE & PROMAIN & HOCONSU & SOLD & QSOLD & PRICESOLD \\
\hline \multirow{3}{*}{ 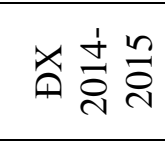 } & 1 & & & & & & & \\
\hline & 2 & & & & & & & \\
\hline & 3 & & & & & & & \\
\hline \multirow{3}{*}{ 至 } & 1 & & & & & & & \\
\hline & 2 & & & & & & & \\
\hline & 3 & & & & & & & \\
\hline \multirow{2}{*}{ సై } & 1 & & & & & & & \\
\hline & 2 & & & & & & & \\
\hline
\end{tabular}

\begin{tabular}{|c|c|c|c|c|c|c|c|c|c|c|c|c|c|c|c|c|c|c|c|}
\hline 1 & 2 & 9 & 10 & 11 & 12 & 13 & \multicolumn{3}{|c|}{14} & 15 & 16 & 17 & 18 & 19 & 20 & 21 & 22 & 23 & 24 \\
\hline \multirow{3}{*}{$\begin{array}{c}\text { Seaso } \\
\text { ns }\end{array}$} & \multirow{4}{*}{$\begin{array}{c}\text { Land } \\
\text { code } \\
\text { part } 3.3\end{array}$} & \multicolumn{5}{|c|}{ Seed, landing preparation } & \multicolumn{13}{|c|}{ Fertilizers } \\
\hline & & \multirow{2}{*}{$\begin{array}{c}\text { Quant } \\
\text { ity } \\
(\mathrm{kg})\end{array}$} & \multirow{2}{*}{$\begin{array}{c}\text { Sourc } \\
\text { e } \\
\text { Code G }\end{array}$} & \multirow{2}{*}{$\begin{array}{c}\text { Price } \\
\text { kg } \\
\text { (1000 } \\
\text { VND) }\end{array}$} & \multirow{2}{*}{$\begin{array}{l}\text { Manure } \\
\text { [1] Có } \\
\text { [0] Không }\end{array}$} & \multirow{2}{*}{$\begin{array}{l}\text { If yes, } \\
\text { please } \\
\text { specify } \\
\text { Code } \mathrm{H}\end{array}$} & \multicolumn{3}{|c|}{ Animal output fertilizer } & \multirow{2}{*}{$\begin{array}{c}\text { Ure- } \\
\text { URE } \\
\text { Kg }\end{array}$} & \multirow{2}{*}{$\begin{array}{c}\text { Pri } \\
\text { ce } \\
1000 \\
\text { VN } \\
\text { D }\end{array}$} & \multirow{2}{*}{$\begin{array}{l}\mathrm{N} \\
\mathrm{Kg}\end{array}$} & \multirow{2}{*}{$\begin{array}{c}\text { price } \\
1000 \\
\text { VND }\end{array}$} & \multirow{2}{*}{$\begin{array}{c}\text { Kali } \\
\text { Kg }\end{array}$} & \multirow{2}{*}{$\begin{array}{c}\text { price } \\
1000 \\
\text { VND }\end{array}$} & \multirow{2}{*}{$\begin{array}{c}\text { DAP } \\
\mathrm{Kg}\end{array}$} & \multirow{2}{*}{$\begin{array}{c}\text { pric } \\
\text { e } \\
1000 \\
\text { VND }\end{array}$} & \multirow{2}{*}{$\begin{array}{l}\mathrm{NP} \\
\mathrm{K} \\
\mathrm{Kg}\end{array}$} & \multirow{2}{*}{$\begin{array}{l}\text { Giá } \\
1000 \\
\text { VND }\end{array}$} \\
\hline & & & & & & & $\begin{array}{c}\text { Số } \\
\text { lượng }\end{array}$ & $\begin{array}{c}\text { Đơn } \\
\text { vị } \\
{[1] \text { bao }} \\
\text { tải } \\
{[2] \mathrm{kg}}\end{array}$ & $\begin{array}{l}\text { Giá } \\
\text { (1000 } \\
\text { VND) }\end{array}$ & & & & & & & & & & \\
\hline $\begin{array}{c}\text { RICES } \\
\text { EA }\end{array}$ & & $\begin{array}{c}\mathrm{Q} \\
\text { SEED }\end{array}$ & $\begin{array}{c}\mathrm{S} \\
\text { SEED }\end{array}$ & $\begin{array}{c}\mathrm{P} \\
\text { SEED }\end{array}$ & BUFER & KUFER & $\begin{array}{c}\text { Q } \\
\text { MAN }\end{array}$ & $\begin{array}{c}\text { U } \\
\text { MAN }\end{array}$ & $\begin{array}{c}\mathrm{P} \\
\text { MAN }\end{array}$ & $\begin{array}{c}\mathrm{Q} \\
\mathrm{N} 2\end{array}$ & $\begin{array}{c}\mathrm{P} \\
\mathrm{N} 2\end{array}$ & $\begin{array}{c}\mathrm{Q} \\
\mathrm{P} 2 \mathrm{O} 5\end{array}$ & $\begin{array}{c}\mathrm{P} \\
\mathrm{P} 2 \mathrm{O} 5\end{array}$ & $\begin{array}{c}\mathrm{Q} \\
\text { KALI }\end{array}$ & $\begin{array}{c}\mathrm{P} \\
\text { KALI }\end{array}$ & $\begin{array}{c}\text { Q } \\
\text { DAP }\end{array}$ & $\begin{array}{c}\mathrm{P} \\
\text { DAP }\end{array}$ & $\begin{array}{c}\mathrm{Q} \\
\mathrm{NP} \\
\mathrm{K}\end{array}$ & $\begin{array}{c}\mathrm{P} \\
\mathrm{NPK}\end{array}$ \\
\hline
\end{tabular}




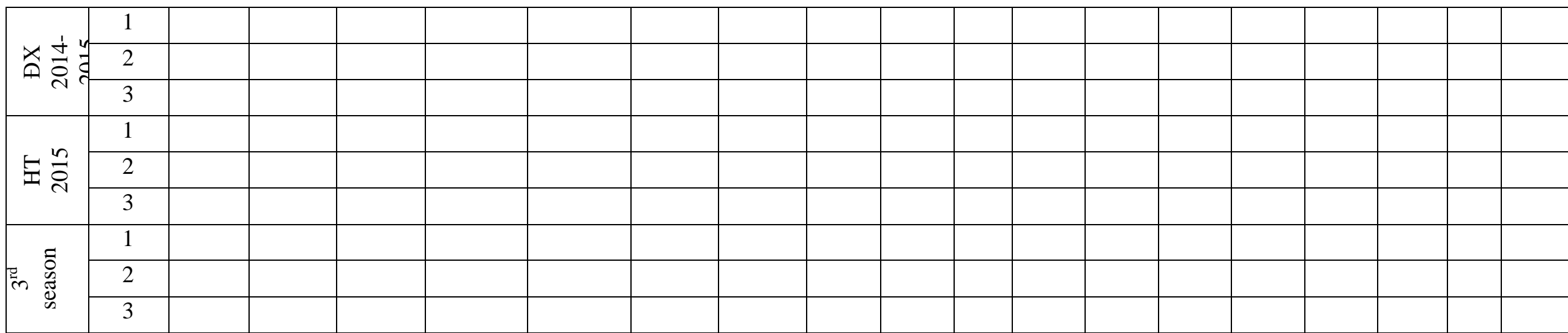

\begin{abstract}
[2] FAs;
\end{abstract}
[3] seed supplier; [4] Neighbor;

[5] relatives;

[6] gilf;

[7] other (specify); [10] no answer

[99] not applicable;

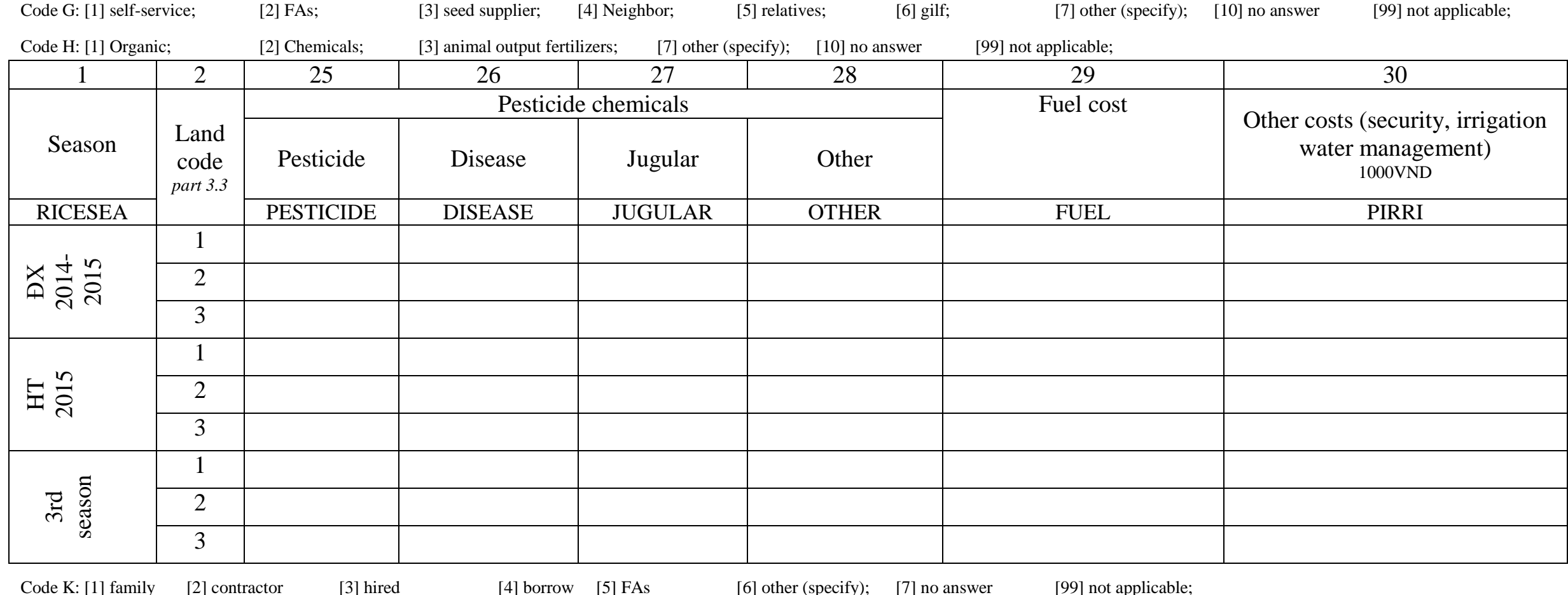




\begin{tabular}{|c|c|c|c|c|c|c|c|c|c|c|c|c|c|c|c|c|c|c|c|}
\hline \multicolumn{20}{|c|}{ 31. Human cost } \\
\hline \multirow[b]{2}{*}{ 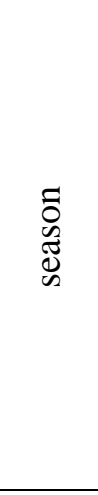 } & \multirow[b]{2}{*}{$\begin{array}{c}\text { Land } \\
\text { code } \\
\text { part } \\
3.3\end{array}$} & \multicolumn{3}{|c|}{$\begin{array}{l}\text { Land preparation } \\
\text { (LAND) }\end{array}$} & \multicolumn{3}{|c|}{$\begin{array}{l}\text { Seed distribution } \\
\text { (GROW) }\end{array}$} & \multicolumn{3}{|c|}{$\begin{array}{c}\text { Fertilizer } \\
\text { (FERTILIZE) }\end{array}$} & \multicolumn{3}{|c|}{$\begin{array}{c}\text { Chemical spray } \\
\text { (SPRAY) }\end{array}$} & \multicolumn{3}{|c|}{$\begin{array}{l}\text { Water plump } \\
\text { (PLUMP) }\end{array}$} & \multicolumn{3}{|c|}{$\begin{array}{l}\text { Harvesting cost } \\
\text { (HARVEST) }\end{array}$} \\
\hline & & $\begin{array}{c}\text { Fami } \\
\text { ly } \\
\text { labor } \\
\text { days }\end{array}$ & $\begin{array}{l}\text { Hire } \\
\text { d } \\
\text { labor } \\
\text { days }\end{array}$ & $\begin{array}{c}\text { Pric } \\
\text { e for } \\
\text { hire } \\
\text { d } \\
\text { labo } \\
\text { r/da } \\
\text { y } \\
1000 \\
\text { VND }\end{array}$ & $\begin{array}{c}\text { Fam } \\
\text { ily } \\
\text { labo } \\
\text { r } \\
\text { days }\end{array}$ & $\begin{array}{c}\text { Hire } \\
\mathrm{d} \\
\text { labo } \\
\text { rdays }\end{array}$ & $\begin{array}{c}\text { Pric } \\
\text { e for } \\
\text { hire } \\
\text { d } \\
\text { labo } \\
\text { r/da } \\
\text { y } \\
1000 \\
\text { VND }\end{array}$ & $\begin{array}{c}\text { Fam } \\
\text { ily } \\
\text { labo } \\
\text { r } \\
\text { days }\end{array}$ & $\begin{array}{c}\text { Hire } \\
\mathrm{d} \\
\text { labo } \\
\text { rdays }\end{array}$ & $\begin{array}{c}\text { Pric } \\
\text { e for } \\
\text { hire } \\
\text { d } \\
\text { labo } \\
\text { r/da } \\
\text { y } \\
1000 \\
\text { VND }\end{array}$ & $\begin{array}{c}\text { Fam } \\
\text { ily } \\
\text { labo } \\
\text { r } \\
\text { days }\end{array}$ & $\begin{array}{c}\text { Hired } \\
\text { labord } \\
\text { ays }\end{array}$ & $\begin{array}{c}\text { Pric } \\
\text { e for } \\
\text { hire } \\
\text { d } \\
\text { labo } \\
\text { r/da } \\
\text { y } \\
1000 \\
\text { VND }\end{array}$ & $\begin{array}{c}\text { Family } \\
\text { labor } \\
\text { days }\end{array}$ & $\begin{array}{l}\text { Hired } \\
\text { labord } \\
\text { ays }\end{array}$ & $\begin{array}{l}\text { Pric } \\
\text { e for } \\
\text { hire } \\
\text { d } \\
\text { labo } \\
\text { r/da } \\
\text { y } \\
1000 \\
\text { VND }\end{array}$ & $\begin{array}{c}\text { Famil } \\
\text { y } \\
\text { labor } \\
\text { days }\end{array}$ & $\begin{array}{l}\text { Hired } \\
\text { labord } \\
\text { ays }\end{array}$ & $\begin{array}{l}\text { Price } \\
\text { for } \\
\text { hired } \\
\text { labor } \\
\text { /day } \\
1000 \\
\text { VND }\end{array}$ \\
\hline \multirow{3}{*}{ 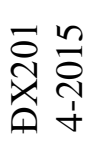 } & 1 & & & & & & & & & & & & & & & & & & \\
\hline & 2 & & & & & & & & & & & & & & & & & & \\
\hline & 3 & & & & & & & & & & & & & & & & & & \\
\hline \multirow{3}{*}{ 至 } & 1 & & & & & & & & & & & & & & & & & & \\
\hline & 2 & & & & & & & & & & & & & & & & & & \\
\hline & 3 & & & & & & & & & & & & & & & & & & \\
\hline \multirow{3}{*}{ 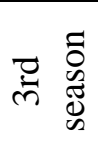 } & 1 & & & & & & & & & & & & & & & & & & \\
\hline & 2 & & & & & & & & & & & & & & & & & & \\
\hline & 3 & & & & & & & & & & & & & & & & & & \\
\hline
\end{tabular}

3.5 Production and revenue details for the other crops and livestock grown during the last 12 months [tháng 12/2014 - tháng 11/2015]

OTHERCROPS

Apart from rice production, did you plant any other kind of crops during the past 12 months?[1] Yes, [2] No, go to 3.7

\begin{tabular}{|c|c|c|c|c|c|c|c|c|c|c|}
\hline 1 & 2 & 3 & 4 & 5 & 6 & 7 & 8 & 9 & 10 & 11 \\
\hline \multirow{2}{*}{$\begin{array}{l}\text { ID crop } \\
\text { Code L }\end{array}$} & \multirow{2}{*}{$\begin{array}{c}\text { Crop area? } \\
\text { unit: } \mathrm{m}^{2}\end{array}$} & \multirow[t]{2}{*}{ quantity $(\mathrm{kg})$} & \multirow{2}{*}{$\begin{array}{c}\text { Did you } \\
\text { sell the } \\
\text { product? } \\
\text { [1] Yes } \\
\text { [2] No }\end{array}$} & \multirow{2}{*}{$\begin{array}{l}\text { Selling } \\
\text { quantity } \\
(\mathrm{kg})\end{array}$} & \multirow{2}{*}{$\begin{array}{c}\text { Average selling } \\
\text { price } \\
1000 \mathrm{VND} / \mathrm{kg}\end{array}$} & \multicolumn{4}{|c|}{ Average production cost (1000VND) } & Total cost \\
\hline & & & & & & seeds & fertilizers & chemicals & others & $(1000 \mathrm{VND})$ \\
\hline
\end{tabular}




\begin{tabular}{|c|c|c|c|c|c|c|c|c|c|c|}
\hline IDCROP & ACROP & QCROP & SELLOT & CROSOLD & CROAPRICE & CQUAN1 & CPRIC1 & CQUAN2 & CPRIC2 & CROTOT \\
\hline & & & & & & & & \\
\hline & & & & & & & & & & \\
\hline
\end{tabular}

\subsection{Livestock and aquaculture}

LIVESTOCKAQUA

Did you have any livestock and aquaculture production within 12 months? ?[1] Yes,[2] No, go to part 4

\begin{tabular}{|c|c|c|c|c|c|c|c|c|c|c|c|c|}
\hline \multirow{4}{*}{ 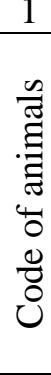 } & \multirow{3}{*}{\multicolumn{2}{|c|}{$\begin{array}{c}\text { Did you have such } \\
\text { livestock? }\end{array}$}} & 3 & 4 & 5 & & 6 & & & 7 & & 8 \\
\hline & & & \multicolumn{2}{|c|}{ Total number } & \multirow{2}{*}{$\begin{array}{c}\text { Did you } \\
\text { sell? } \\
{[1] \text { Yes }} \\
\text { [0] No }\end{array}$} & \multicolumn{2}{|c|}{ Selling quantity } & \multicolumn{4}{|c|}{ Total cost(1000 VND) } & \multirow{2}{*}{$\begin{array}{c}\text { Total } \\
\text { cost } \\
1000 \mathrm{VND}\end{array}$} \\
\hline & & & quantity & & & quantity & Price per unit & seeds & foods & vaccination & others & \\
\hline & ANIMAL & $\begin{array}{l}\text { [1] yes } \\
\text { [0] No, go } \\
\text { ahead }\end{array}$ & TOTLIVE & ULIVE & SLIVE & QLIVE & PLIVE & CLIVE1 & CLIVE2 & CLIVE3 & CLIVE4 & TCOST \\
\hline 1 & $\begin{array}{l}\text { Pork (for } \\
\text { meat) }\end{array}$ & & & & & & & & & & & \\
\hline 2 & $\begin{array}{l}\text { Pork (for } \\
\text { plant) }\end{array}$ & & & & & & & & & & & \\
\hline 3 & Fish & & & & & & & & & & & \\
\hline 4 & Shrimp & & & & & & & & & & & \\
\hline 5 & Chicken & & & & & & & & & & & \\
\hline 6 & Beef & & & & & & & & & & & \\
\hline 7 & Duck & & & & & & & & & & & \\
\hline 8 & Others (-----) & & & & & & & & & & & \\
\hline
\end{tabular}


3.7 Where do you sale your product? [1] Company through contract; [2] Middlemen/processor; [3] Local market

3. 8 Do you have information about the rice price over the world market before selling? [1] Yes; [2] No

3.9 Do you have information about last year selling price? [1] Yes; [2] No

*DO YOU HAVE CONTRACT NOW? [1] Yes; continue ; [2] No, move to Module 7

\section{MODULE4. CONTRACT FARMING PRODUCTION}

\section{CFRICE}

4.1 When did you start signing the contract for rice production? (CYEAR)

4.2 Who gave you the decisive information that motivated you to sign the contract? (CSOUR)

[1] Contractors [2] Neighbor; [3] FAs; [4] Village officials; [5] Researcher; [7] Trader; [8] Other (specify); [9] No answer; [99] Not applicable

4.3 Did you stop signing contract in between?

[1] Yes ; [2] No, go to 4.4

4.3.1 In which years did you stop signing the contract? [years] (YCSTOP)

4.3.2 Could you tell the reasons why did you stop signing the contract? (list the most important aspects)

[1] Inconvenient [2] Low income [3] Non-flexible [4] Take time [5] No idea [6] others (specify)

4.4 Who decide to sign the contract in your household? (Code A) (WHOSC) Gender :[1] Male ; [2] Female

Code A: [1] Head; [2] Wife/Husband; [3] Son/Daughter; [4] Son/Daughter in law; [5] Father/Mother; [6] Father/Mother in law; [7] Sister/Brother; [8] Grandchild; [9] Other relatives; [10] No answer; [99] Not applicable.

4.5 Did you receive the technical supports from contractor? (EXTENT)

How many times does expert visit your farm per season? (TECHCROP) (Number of times)

4.6 Did you get money right after selling the products to contractor? (PAYMENT) [1] Yes; [2] No, move to Module 5 How long did you wait for getting the money? (Number of days) (NUWDATE)

4.7 Do you receive the information about inputs (rice seeds) every crop and contract terms and conditions?

4. 8 Do you have information about the rice price over the world market before signing the contract?

[1] Yes; [2] No

4.9 Do you have information about the rice price of former contract offered by the company?

[1] Yes; [2] No

[1] Yes; [2] No

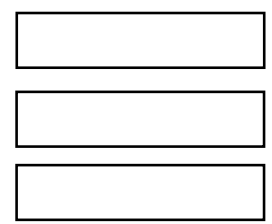




\section{MODULE 5. THE PERCEPTION OF CONTRACT}

PERCEPT Do you negotiate the terms and conditions in the contract with contractor before signi

5.2 What type of contract are you signing? (CTYPE)(1) Group ; (2) Individual

5.3 What kind of contract have you signed? (KINDC)

(1) Production (2) Marketing (3) Resource (4) Other (specify....................)

5.4 What kind of price is specified in the contract? (KINDP)

(1) Fixed price; (2) Floating price; (3) Floor price; (4) Flexible price; (5) Other (specify)

5.5 Have you ever breached the contract? (CTBREAK) [1] Yes, [2] No, go to 5.7

What happened when you breached the contract? (BREKRE)

[1] The company quit the contract for the next season, [2] You paid the penalty, [3] There was nothing happen , [4] No answer , [5] Other (Specify.............)

5.6 What is the main reason for breaching the contract? (REABREAK)

[1] Market price is higher than contract price, [2] the storage and transportation fees from the company are so high , [3] No answer, [4] Other,

specify.............................................

5.7 Why did your household choose to sign the contract farming to produce export-oriented rice? (mark " $\mathrm{x}$ " for selection)

\begin{tabular}{|c|c|c|c|c|c|}
\hline \multirow{3}{*}{$\begin{array}{l}\text { To what extent do you agree with the statement about the reason for contract farming } \\
\text { participation? }\end{array}$} & \multicolumn{5}{|c|}{ Answer } \\
\hline & 1 & 2 & 3 & 4 & 5 \\
\hline & $\begin{array}{l}\text { Strongly } \\
\text { Disagree }\end{array}$ & Disagree & Neutral & Agree & $\begin{array}{l}\text { Strongly } \\
\text { Agee }\end{array}$ \\
\hline \multicolumn{6}{|l|}{ Improve household income (IMPROVE) } \\
\hline \multicolumn{6}{|l|}{ 1. Contact farming helps us to sell the product with a higher price than without contract } \\
\hline \multicolumn{6}{|l|}{ 2. Contact farming helps us to save production costs due to priority in receiving credit } \\
\hline \multicolumn{6}{|l|}{ 3. Contact farming helps us to save production costs due to low seeds price } \\
\hline \multicolumn{6}{|l|}{ 4. Contract farming helps to improve technical skills in export-oriented rice production } \\
\hline \multicolumn{6}{|l|}{ 5. We can specify our benefit before producing rice due to advanced price in contract } \\
\hline \multicolumn{6}{|l|}{$\begin{array}{l}\text { 6. We always get a higher selling price (mentioned in the contract) than market price at the } \\
\text { harvesting time. }\end{array}$} \\
\hline 7. We find it easy to sell the product to the market & & & & & \\
\hline
\end{tabular}


8. Contact farming helps us to reduce the risk referring to market price fluctuations

9. Contact farming helps us to access market easier through convenient transportation

10. Contact farming helps us to have an easier processing procedure

Export rice contract farming and its impacts on social aspect and environment of region (SOCIAL)

1. Contract farming contributes to have a modern farming system

2. Producing rice at larger scale is better than small scale

3. We can produce rice which is safe to environment through reducing amount of fertilizer

4. We can produce rice which is safe to environment through reducing amount of pesticide.

It is suitable to regional development strategies (REGIONAL)

1. The Contractor help to improve the infrastructure of the region

2. Contract Farming improve the living standard of the village

\section{MODULE 6.TRUST AND COMMITMENT}

\section{TRUSTNCOM}

6.1. Trust with contractor

Do you agree with these statements below?

(TRUST)

1. Company always treats you fairly regarding input supply price

2. You sign the contract base on the reputation of the company in the market.

3. The contractor always keeps their promise and fulfils the obligation.

4. We can reduce some uncertain damages to our production process (whether, social

effectiveness...).

5 . We think that company gives you a degree of freedom

6.2 Relationship commitment

Do you agree with these statements below?

(COMIT)

1. We have never faced up with any confusion during contract time

2.The conflicts never happen

\begin{tabular}{|c|c|c|c|c|}
\hline \multicolumn{5}{|c|}{ Answer } \\
\hline 1 & 2 & 3 & 4 & 5 \\
\hline $\begin{array}{c}\text { Strongly } \\
\text { Disagree }\end{array}$ & Disagree & Neutral & Agree & $\begin{array}{c}\text { Strongly } \\
\text { agree }\end{array}$ \\
\hline & & & & \\
\hline & & & & \\
\hline & & & & \\
\hline
\end{tabular}

\begin{tabular}{|c|c|c|c|c|}
\hline \multicolumn{5}{|c|}{ Answer } \\
\hline 1 & 2 & 3 & 4 & 5 \\
\hline $\begin{array}{l}\text { Strongly } \\
\text { Disagree }\end{array}$ & Disagree & Neutral & Agree & $\begin{array}{c}\text { Strongly } \\
\text { agree }\end{array}$ \\
\hline & & & & \\
\hline & & & & \\
\hline
\end{tabular}


3. The disagreement has never happened

4. We have good communicating relation

5. We are willing to continue maintaining the long term relationship with contractor in future

\begin{tabular}{|l|l|l|l|l|}
\hline & & & & \\
\hline & & & & \\
\hline & & & & \\
\hline
\end{tabular}

6.3 Risk perspectives

\begin{tabular}{|c|c|c|c|c|c|}
\hline \multirow{3}{*}{$\begin{array}{l}\text { Do you agree with these statements below? } \\
\text { (RISKPERS) }\end{array}$} & \multicolumn{5}{|c|}{ Answer } \\
\hline & 1 & 2 & 3 & 4 & 5 \\
\hline & $\begin{array}{l}\text { Strongly } \\
\text { Disagree }\end{array}$ & Disagree & Neutral & Agree & $\begin{array}{l}\text { Strongly } \\
\text { agree }\end{array}$ \\
\hline 2.We share the risk of production & & & & & \\
\hline 3.We share the risk of uncertainty with the company & & & & & \\
\hline 4.We understand about market risk of contractor in rice export value chains & & & & & \\
\hline
\end{tabular}

MODULE7. NON-CONTRACT SMALLHOLDERS (mark " $\mathrm{x}$ " for selection)

7.1 Have you ever heard about contract farming? [1] Yes; [2] No, move to Module 8

NONCFRICE

7.2 Feedback from non-contract farming participants

To what extent do you agree with these statements below?

(FEDNONCF)

1.Joining the contract for export rice producing reduces the freedom in making decision

2. Contract farming is really complicated issue

3.We are afraid of taking risks joining into the contract because of price and production cost

4. We got the opportunity to become contract farmers in the past but we refused

5.We have the intention to participate into contract farming in the near future 


\section{MODULE 8: SHOCKS}

\section{SHOCK}

8.1. Experienced shocks faced after contract arrangement that impacted on household income the last 12 months?

\begin{tabular}{|c|c|c|c|c|c|c|c|}
\hline SHOCKS & $\begin{array}{l}\text { Was it } \\
\text { happen? } \\
\text { [1] Yes } \\
\text { [2] No, go to } \\
\text { the next } \\
\text { shock }\end{array}$ & $\begin{array}{l}\text { How many } \\
\text { times does } \\
\text { shock } \\
\text { happen per } \\
\text { year? }\end{array}$ & $\begin{array}{l}\text { How was the } \\
\text { household } \\
\text { affected by } \\
\text { [shock]? } \\
\text { (Code G) }\end{array}$ & SHOCKS & $\begin{array}{c}\text { Was } \\
\text { it } \\
\text { happe } \\
\text { n? } \\
\text { [1] Yes } \\
\text { [2] No, } \\
\text { go to } \\
\text { the next } \\
\text { shock }\end{array}$ & $\begin{array}{l}\text { How many } \\
\text { times shock } \\
\text { happen per } \\
\text { year? } \\
\text { Code AC }\end{array}$ & $\begin{array}{l}\text { How was the } \\
\text { household } \\
\text { affected by } \\
\text { [shock]? } \\
\text { (CodeAD) }\end{array}$ \\
\hline 1. Too much rain & & & & 6. Strong decrease in outputs price & & & \\
\hline 2. The higher temperature & & & & 7. Contract cancelation & & & \\
\hline 3. Flooding & & & & 8. Low quality product refusal & & & \\
\hline $\begin{array}{l}\text { 4. Insect disease for rice } \\
\text { production }\end{array}$ & & & & 9. Strong increase in inputs price & & & \\
\hline 5. Loss of job in non-agriculture & & & & 10. Others & & & \\
\hline
\end{tabular}

Code AC: [1] Never; [2] 1-3 time; [3] 4-6 time; [4] more than 6; Code AD:[1] extreme seriously; [2] seriously; [3] slightly [4] not at all;

8.2. Recovery from these shocks (*Note: Please ask the respondent to answer these items below)

REBORN

\begin{tabular}{|l|l|l|l|}
\hline \multicolumn{1}{|c|}{ Items } & $\begin{array}{c}\text { What did you do to recover } \\
\text { from these shocks?[1] Yes; [2] No }\end{array}$ & \multicolumn{1}{c|}{$\begin{array}{c}\text { What did you do to recover from } \\
\text { these shocks? [1] Yes; [2] No }\end{array}$} \\
\hline $\begin{array}{l}\text { 1.Diversification of agricultural } \\
\text { varieties }\end{array}$ & & $\begin{array}{l}\text { 6. Borrowed finance from } \\
\text { relatives/friends/neighbors }\end{array}$ \\
\hline 2. Reduction of production inputs & & 7. Borrowed from bank/financial funds & 8. Supported from government \\
\hline 3. Migration for another job & & 9. Help from contractor \\
\hline 4. Sold livestock (pig, cow) & & 10. Help from relatives/friends/neighbors & \\
\hline 5. Sold crop products (maize, rice) & & \\
\hline
\end{tabular}




\section{MODULE 9: HOUSEHOLD ASSETS}

HHASSET

9.1. Please list the machinery that household own to use for rice production

\begin{tabular}{|l|l|c|c|c|}
\hline STT & \multicolumn{1}{|c|}{ Type of asset } & Quantity & Purchasing price & Source code K \\
\hline NUM & \multicolumn{1}{|c|}{ TYPEASS } & MACHQA & COSTASS & WHENASS \\
\hline 1 & Combine harvesting machine & & & \\
\hline 2 & Threshing machine & & & \\
\hline 3 & Land processing machine & & & \\
\hline 4 & Water plump & & & \\
\hline 5 & Knapsack sprayer & & & \\
\hline 6 & Dryer & & & \\
\hline 7 & Others & & & \\
\hline
\end{tabular}

Code $\mathrm{K}:[1]$ family,

9.2 Household credit accessibility :

9.2.1 Do you borrow money from any credit organizer? (CREDIT)? ([1] Yes [0] No, move to part 10)

9.2.2 Where do you often borrow money? (WHELOAN): Code G

(specify) [9] no answer, [99] Not applicable

9.2.3 What the aim of your loan (LOANPUR) ?

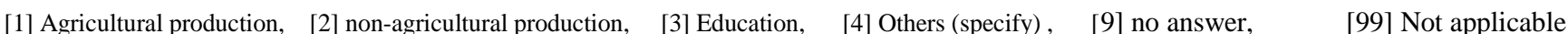

9.2.4 How much money you have to borrow per season? (LOANPER)

9.2.5 How much is interest rate?: (INTERA)

MODULE 10.NON-FARM INCOME (Non-farm activities are all activities not related to agricultural production on your own farm).

10.1. Have any of household members been engaged in non-farm activities during the past 12 months? [1] Yes

(if one member is engaged in more than one activity, use more than one row) 


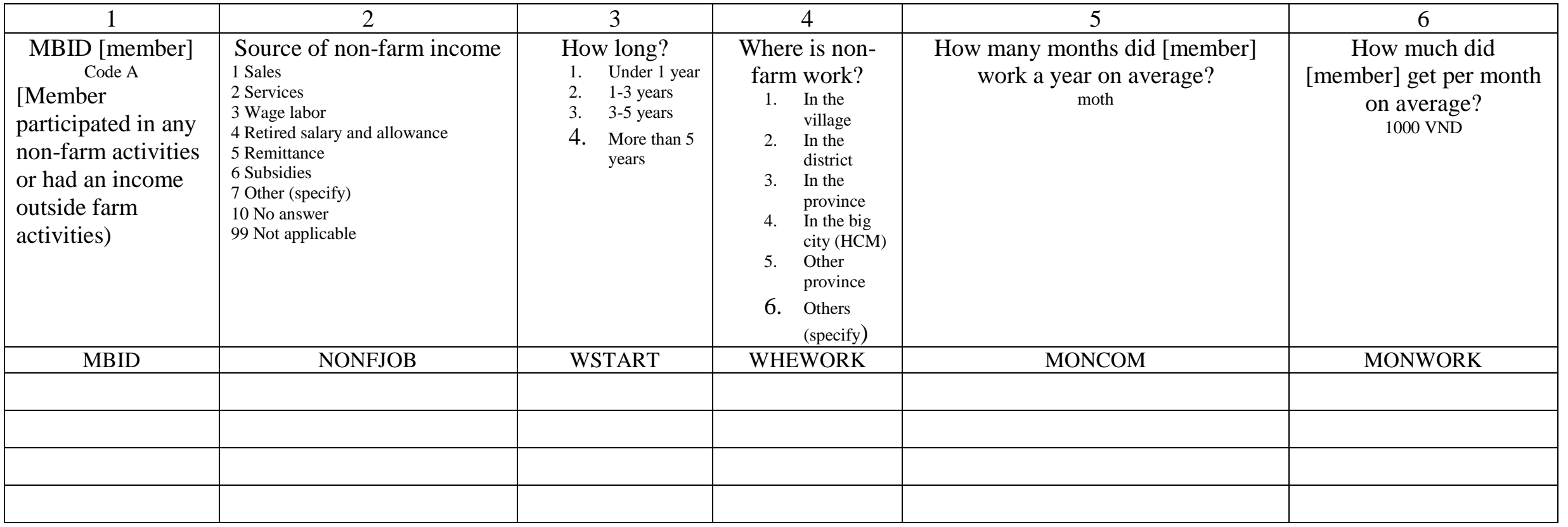

Code A: [1] Head; [2] Wife/Husband; [3] Son/Daughter; [4] Son/Daughter in law; [5] Father/Mother; [6] Father/Mother in law; [7] Sister/Brother; [8] Grandchild; [9] Other relatives; [10] No answer; [99] Not applicable 


\section{MODULE 11: COOPERATIVES AND THE WILLINGNESS TO PAY FOR COOPERATIVE PARTICIPATION}

WTP

The purpose of this section is to determine the level of acceptance by farmers who are contracting partners with the enterprise in two cases: (i) the willingness to participate in group contract under the management of cooperative between traditional farmer association, the contractors and rice farmers and (ii) the willingness to pay for participating in cooperatives.

11.1 Currently, the company is piloting to sign and conduct contract farming scheme through cooperatives with the aim to improve the quality of existing contract farming arrangement. The cooperatives will manage most of the current work that the company is carrying out directly with each household such as representatives for seed, fertilizer, pesticides at the original cost and then redistribute to the member the benefit after harvesting season as the shareholder. In addition, during the cultivation, the company's technical staff will support the cooperative in terms of quantity of spraying materials and techniques and pest control to control the drug residues. By the time of harvesting, the cooperative representative negotiates on price, form of payment, ensuring the best price for TV. Are households willing to participate in this form of link or not?

Please make your choice: [1] Agree; [2] Disagree

11.2 If you have to pay a fee to participate in this form of cooperatives in the following cases: membership fee per participant when joining the cooperatives is 2.000.000VND per household per year, if profits, then dividends will be shared.

- Please make your choice: [1] Agree; [2] Disagree

- Please tell us about the above rates: 1] Too low [2] Low [3] Medium [4] High [5] Too high

- I do not know or have no idea

If you find that the fee is too high, please provide a number that if you go down then you will be ready to join the cooperatives:

If you find that the fee is too low, please provide a number that if you go there will be willing to join the cooperatives: VND

Please provide the reason why you are not willing to pay for the fee....

Thank you so much for attending this interview! 


\section{List of Publications and Presentations}

\section{Working Papers}

- The role of market information access for contract farming participation of smallholder farmers in developing and emerging economies (with T. Ludwig, V. Otter);

- Do smallholders in emerging economies benefit from contract farming? Empirical evidence from the Vietnamese export rice sector with T. Ludwig, V. Otter);

- Contract farming effects on technical efficiency of export-oriented rice production in Vietnam (with C. Beber, T. Ludwig, V. Otter).

\section{$\underline{\text { Conference contributions - Oral presentations }}$}

- $30^{\text {th }}$ ICAE 2018, July $27^{\text {th }}$ - August $2^{\text {nd }} 2018$, Vancouver, Canada, the International Association of Agricultural Economists (IAAE):

https://cslide.ctimeetingtech.com/icae2018/attendee/confcal/session/list?q=Huongand $\underline{\mathrm{c}=\mathrm{aandr}=\mathrm{st} \sim 2 \_1}$

- $7^{\text {th }}$ EAAE PhD workshop 2017, Nov. 8-10, 2017, the Escola Superior d'Agricultura de Barcelona (ESAB), Politechnic University of Catalonia, Spain.

- IFAMA world conference 2017, Jul. 18 - 22, 2017, Miami, Florida, the USA; http://www.ifama.org/resources/Pictures/Logos/2017-Symposium.pdf.

- Tropentag 2016, Conference on International Research on Food Security, Natural Resource Management and Rural Development, Sep. 19 - 21, 2016, Vienna, Austria; http://www.tropentag.de/abstract.php?code=dR3EGhnt. In: Book of Abstracts of the Tropentag 2016: Solidarity in a competing world-fair use of resources, Freyer, B. and E. Tielkes (Eds.) 1. Aufl.- Göttingen: Cuvillier, 2016. (ISBN. 978-3-7369-9341-9).

- The Student Southeast Asian Conference, Nov. 4-6. 2016, Asia Africa Institute, Hamburg, organized by the University of Hamburg, Germany; http://www.southeastasiaconference.com/en/abstracts. 


\section{Curriculum Vitae N. H. Le}

Personal data

\section{Name:}

Address:

Tel:

Email:

Date of Birth

Marital status:

Education

\section{University of Goettingen}

Dr.

PhD Degree in Agricultural Economics

Dissertation: Contract Farming in Vietnam: Empirical Research on Marketing Determinants, Farm Performance and Technical Efficiency of the Export-oriented Rice Sector in the Mekong River Delta

Grade: 1.3/ Magna cum laude/ sehr gut/ very good

Supervisor: Prof. Ludwig Theuvsen; Prof. Dr Achim Spiller

University of Giessen

Giessen, Germany

Pre-Phd.

Master courses and German language

\section{Foreign Trade University}

MSc.

Masters' degree in World Economics and International Economic Relations

Thesis: Garment and textile processing in Vietnam, a research on firm performance and WTO entry challenges

Grade: good

Supervisor: Prof. Dr. Le Ngoc Son

\section{Foreign Trade University}

Bachelor

Bachelor's degree in International Trade

Grade: good

Research interests

- Agricultural economics and policy

- Emerging and Developing Economics

- Agricultural Supply Chain Management

Related research experience

Doctoral researcher

Ho Chi Minh City, Vietnam

2001-2005

University of Göttingen, Department of Agricultural Economics and Rural Development

- Initiated collaboration with Nha Trang University, Vietnam to conduct doctoral research

- Conducted data collection with 300 household in the Mekong River Delta, Vietnam.

- Evaluated the effectiveness of contract farming in developing rice value chain

- Investigated the farm performance (income and technical efficiency) and contract farming participating determinants

- Applied propensity score matching methods to mitigate unobserved heterogeneity and endogeneity problems in the data set 
- Established external research network, coordinated to the PrimeFish project (European Union's Horizon 2020 Research and Innovation Program under grant agreement No.635761)

- Supervised master students for block seminar and master thesis and other doctoral research (internal seminars, doctoral seminars)

\section{Lecturer}

Nha Trang University, Vietnam; Faculty of Economics

2014-2011

- Lectured in International Business Relations, Risk Management, International Business Management for undergraduate and master program

- Coordinated the governmental and NGOs project for business management and human resources

- Extension services assisted for smallholders in seafood value chain activities

- Supervised bachelor students in conducting field interviews to investigate cooperative performance in providing livelihood assets

\section{Lecturer}

Foreign Trade University, Vietnam

2011-2005

Faculty of International Business Management

- Lecturer in International Business Transaction

- Supervised bachelor students in conducting bachelor thesis and field work activities

Recognitions and awards

The International Association of Agricultural Economists (IAAE)

2018

Conference grant

ICAE 2018, Vancouver, Canada

The Fiat Panis Foundation

Conference grant

IFAMA 2017, Miami- Florida- USA

Fiat Panis Foundation

Fieldwork grants

Data collection for PhD thesis in Mekong River Delta, Vietnam

The Vietnamese association of young enterprises

Scholarship for young leadership and academic researcher

Reward of 22nd SEAGames

Volunteer Main Media Center of Ho Chi Minh City in Vietnam

Working papers

[1] N. Huong Le, T. Ludwig and V. Otter. The role of market information access for contract farming participation of smallholder farmers in developing and emerging economies. Submitted to the Journal of Small Business and Enterprise Development in 10.2018, under revision process.

[2] N. Huong Le, T. Ludwig and V. Otter. Do smallholders in emerging economies benefit from contract farming? Empirical evidence from the Vietnamese export rice sector.

[3] N. Huong Le, C. Beber, T. Ludwig and V. Otter. Contract farming effects on technical efficiency of export-oriented rice production in Vietnam. Submitted to the Agricultural Economics in 10.2018, under revision process. 
Conference presentations

[1] N. Huong Le, C. Beber, T. Ludwig and V. Otter. Contract farming effects on technical efficiency of export-oriented rice production in Vietnam. 30 ${ }^{\text {th }}$ ICAE 2018, Vancouver, Canada, by the International Association of Agricultural Economists (IAAE).

[2] N. Huong Le, T. Ludwig and V. Otter. The determinants for contract farming participation of smallholder farmers in developing and emerging economies IFAMA world conference 2017, Miami, Florida, the USA;

[3] N. Huong Le, T. Ludwig and V. Otter. Contract farming for rice production in Vietnam. Tropentag 2016, Conference on International Research on Food Security, Natural Resource Management and Rural Development, Sep. 19 - 21, 2016, Vienna, Austria;

[4] N. Huong Le, Aye Moe San. Contract farming for rice sector: an comparative research from Vietnam and Myanmar. The Student Southeast Asian Conference, Nov. 4-6. 2016, Asia Africa Institute, Hamburg, organized by the University of Hamburg, Germany.

Language

Vietnamese: Native

English: Fluent

German: Immediate (B1)

Computer skills

Statistic and computational software: SPSS, STATA, Excel.

Office Software: MS Office

Leadership activities

University of Goettingen

President of the Vietnamese community in Goettingen

Organizing team of the first ASEAN student festival

Foreign Trade University

President of the youth union

Main Media Center of 22nd SEA-Games

Volunteer

References

Prof. Dr Ludwig Theuvsen

(Ph.D thesis supervisor)

University of Goettingen, Germany.

Email: theuvsen@uni-goettingen.de.

Dr. Le Kim Long

(Vice dean)

Department of Economics

Nha Trang University, Vietnam

Email: lekimlong@ntu.edu.vn.
Goettingen,

Germany

2016/09-2015/09

HCMC, Vietnam

2008/10-2006/10

HCMC, Vietnam

2004/3-2004/02
Dr. Verena Otter

(Paper co-author)

University of Goettingen, Germany

Email: verena.otter@agr.uni-goettingen.de

Prof. Dr. Nguyen Thi Thu Ha

(Vice chairman)

Department of International Business

Administration

Foreign Trade University, Vietnam.

Email: hantt@ftu.edu.vn. 